\title{
WestVirginiaUniversity
}

THE RESEARCH REPOSITORY @ WVU

Graduate Theses, Dissertations, and Problem Reports

2001

\section{Computational modeling of hydrogen embrittlement of iron aluminides}

Roxana Cisloiu

West Virginia University

Follow this and additional works at: https://researchrepository.wvu.edu/etd

\section{Recommended Citation}

Cisloiu, Roxana, "Computational modeling of hydrogen embrittlement of iron aluminides" (2001). Graduate Theses, Dissertations, and Problem Reports. 1108.

https://researchrepository.wvu.edu/etd/1108

This Thesis is protected by copyright and/or related rights. It has been brought to you by the The Research Repository @ WVU with permission from the rights-holder(s). You are free to use this Thesis in any way that is permitted by the copyright and related rights legislation that applies to your use. For other uses you must obtain permission from the rights-holder(s) directly, unless additional rights are indicated by a Creative Commons license in the record and/ or on the work itself. This Thesis has been accepted for inclusion in WVU Graduate Theses, Dissertations, and Problem Reports collection by an authorized administrator of The Research Repository @ WVU. For more information, please contact researchrepository@mail.wvu.edu. 
COMPUTATIONAL MODELING OF HYDROGEN EMBRITTLEMENT OF IRON ALUMINIDES

\author{
by \\ Roxana Cisloiu \\ Thesis submitted to the College of Engineering and Mineral Resources \\ at West Virginia University \\ in partial fulfillment of the requirements \\ for the degree of \\ Master of Science \\ in \\ Mechanical Engineering
}

\author{
Approved by \\ Dr. Bruce S. Kang, Committee Chairperson \\ Dr. Victor Mucino \\ Dr. Kenneth Means
}

Department of Mechanical and Aerospace Engineering

Morgantown, West Virginia

2001

Keywords: hydrogen embrittlement, finite element simulation, iron aluminides, diffusion, crack growth 


\section{Abstract \\ Computational Modeling of Hydrogen Embrittlement of Iron Aluminides}

\section{Roxana Cisloiu}

Comparative fracture tests of two $\mathrm{Fe}-28 \% \mathrm{Al}$ iron aluminides revealed that alloys with $\mathrm{B}$, $\mathrm{Zr}$, and $\mathrm{C}$ addition (FA189) are extrinsically more susceptible to environmental embrittlement than the base ternary alloy (FA186) under constant tensile loading condition. This may due to the effect of smaller grain sizes caused by alloy addition. To further investigate the grain boundary size effect as related to the susceptibility of hydrogen embrittlement, comparative finite element modeling simulations of intergranular fracture of two iron aluminides (FA186 and FA189) were carried out . The computational simulations involved sequentially coupled stress and hydrogen diffusion analyses to determine crack-tip stress state and the extent of hydrogen diffusion at the crack tip region. Principal strain failure criteria is adopted to simulate intergranular fracture. Good qualitative agreement between the modeling and experimental results is observed. The results further confirm our assessment that grain boundary morphology is important in controlling environmental embrittlement of iron aluminides. 


\section{ACKNOWLEDGEMENTS}

The author would like to express his gratitude to Dr. Bruce S. Kang, the author's

research advisor, whose valuable guidance and assistance made possible the completion of this thesis. His support and numerous academic suggestions are greatly appreciated.

Special appreciation is also extended to Dr. Victor Mucino and Dr. Ken Means, for carefully reading the whole thesis and making helpful comments. 


\section{TABLE OF CONTENTS}

TITLE PAGE

ABSTRACT

ACKNOWLEDGEMENTS

TABLE OF CONTENTS

iii

iv

LIST OF FIGURES

LIST OF TABLES

Chapter 1: Introduction and Research Objectives

1.1 Iron aluminides and environmental embrittlement

1.2 Motivation for computational analysis related to the experimental program

1.3 Research objectives

Chapter 2: Review of Related Work

2.1 Investigations on hydrogen embrittlement of iron aluminides

2.2 Mechanisms of hydrogen embrittlement

2.3 Numerical simulations of environmentally assisted fracture

Chapter 3: Summary of the Experimental Program Relevant to the Computational 17 Analysis

$\begin{array}{lll}3.1 & \text { Test materials and specimen } & 17\end{array}$

3.2 Fractography and microstructure examinations 18

$\begin{array}{lll}3.3 & \text { Test results } & 20\end{array}$

Chapter 4: Finite Element Analysis Model 25

$\begin{array}{lll}\text { 4.1 Stress analysis model } & 25\end{array}$

4.1.1 Submodeling technique in ABAQUS 25

4.1.2 Global model 27

$\begin{array}{lll}4.1 .3 \text { Submodels } & 28\end{array}$

$\begin{array}{ll}\text { 4.1.4 Micromechanics } & 31\end{array}$

4.2 Stress-assisted hydrogen diffusion model 34

4.2.1 Hydrogen in iron 34

4.2.2 The role of hydrostatic stress in hydrogen embrittlement 34

4.2.3 Governing equations used for the hydrogen diffusion model 36

4.2.4 Material properties related to the hydrogen diffusion model 39

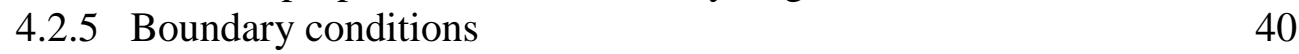

4.3 Steps of simulating intergranular fracture due to hydrogen 41 embrittlement

Chapter 5: Results and Discussions $\quad 48$

Chapter 6: Conclusions and Recommendations $\quad 68$

$\begin{array}{ll}6.1 \text { Conclusions } & 68\end{array}$

$\begin{array}{ll}6.2 \text { Recommendations } & 69\end{array}$

$\begin{array}{ll}\text { References } & 71\end{array}$

$\begin{array}{ll}\text { Appendix A } & 76\end{array}$

$\begin{array}{ll}\text { Appendix B } & 83\end{array}$ 


\section{LIST OF FIGURES}

Fig. 3.1 Single-Edge-Notched Specimen (geometry and dimensions) 17

Fig. 3.2 Representative fractographies for FA-186 and FA-189 in air 19

Fig. 3.3 Microstructure of FA-186 and FA-189 19

Fig. 3.4 Schematic representation of transgranular and intergranular fracture formation for FA-186 and FA-189 20

Fig. 3.5 Sequence of maximum principal strain distributions ahead of the crack 22 tip with crack growth. FA-186, room temp, air, $\mathrm{K}_{\mathrm{I}}=36.9 \mathrm{MPa} \sqrt{\mathrm{m}}$

Fig. 3.6 Sequence of maximum principal strain distributions ahead of the crack tip 23 with crack growth. FA-189, room temp, air, $\mathrm{K}_{\mathrm{I}}=17.36 \mathrm{MPa} \sqrt{\mathrm{m}}$

Fig. 4.1 Global Model 27

Fig. 4.2 Unit cell 28

Fig. 4.3 Grain and grain boundary elements $\quad 29$

Fig. 4.4 Submodel and grain size of FA-186 30

Fig. 4.5 Submodel and grain size of FA-189 30

Fig. 4.6 Superposed contour plots of global model and submodel of FA-186: 33

(a) principal strain ; (b) principal stress

Fig. 4.7 Superposed contour plots of global model and submodel of FA-189: 33

(a) principal strain ; (b) principal stress

Fig. 4.8 Boundary conditions for hydrogen diffusion model 41

Fig. 4.9 Schematic intergranular crack growth simulation 44

Fig. 4.10 Submodel and corresponding adjusted global model 47

Fig. 5.1 Maximum principal strain distribution and intergranular crack growth of 54

FA-186 in vacuum, $\mathrm{K}_{\mathrm{I}}=17.36 \mathrm{MPa} \sqrt{\mathrm{m}}$, failure strain of $4 \%$.

Fig. 5.2 Maximum principal strain distribution and intergranular crack growth of

FA-186 in vacuum, $\mathrm{K}_{\mathrm{I}}=17.36 \mathrm{MPa} \sqrt{\mathrm{m}}$, failure strain of $6 \%$.

Fig. 5.3 Maximum principal strain distribution and intergranular crack growth of 56

FA-186 in vacuum, $\mathrm{K}_{\mathrm{I}}=36.9 \mathrm{MPa} \sqrt{\mathrm{m}}$, failure strain of $4 \%$.

Fig. 5.4 Maximum principal strain distribution and intergranular crack growth of 57

FA-186 in vacuum, $\mathrm{K}_{\mathrm{I}}=36.9 \mathrm{MPa} \sqrt{\mathrm{m}}$, failure strain of $6 \%$.

Fig. 5.5 Sequence of hydrogen diffusion zones, maximum principal strain

distribution and intergranular crack growth of FA-186 in air

$\mathrm{K}_{\mathrm{I}}=17.36 \mathrm{MPa} \sqrt{\mathrm{m}}$

Fig. 5.6 Sequence of hydrogen diffusion zones, maximum principal strain

and intergranular crack growth of FA-186 in air, $\mathrm{K}_{\mathrm{I}}=36.9 \mathrm{MPa} \sqrt{\mathrm{m}}$, failure of strain of $4 \%$.

Fig. 5.7 Sequence of hydrogen diffusion zones, maximum principal strain distribution and intergranular crack growth of FA-186 in air, $\mathrm{K}_{\mathrm{I}}=17.36 \mathrm{MPa} \sqrt{\mathrm{m}}$, failure strain of $6 \%$.

Fig. 5.8 Maximum principal strain distribution and intergranular crack growth of 62 FA-189 in vacuum, $\mathrm{K}_{\mathrm{I}}=17.36 \mathrm{MPa} \sqrt{\mathrm{m}}$, failure strain of $6 \%$.

Fig. 5.9 Maximum principal strain distribution and intergranular crack growth of 63 FA-189 in vacuum, $\mathrm{K}_{\mathrm{I}}=17.36 \mathrm{MPa} \sqrt{\mathrm{m}}$, failure strain of $4 \%$. 
Fig. 5.10 Maximum principal strain distribution and intergranular crack growth of 64 FA-189 in vacuum, $\mathrm{K}_{\mathrm{I}}=36.9 \mathrm{MPa} \sqrt{\mathrm{m}}$, failure strain of $6 \%$.

Fig. 5.11 Sequence of hydrogen diffusion zones, maximum principal strain distribution and intergranular crack growth of FA-189 in air, $\mathrm{K}_{\mathrm{I}}=17.36 \mathrm{MPa} \sqrt{\mathrm{m}}$, failure strain of $6 \%$.

Fig. 5.12 Sequence of hydrogen diffusion zones, maximum principal strain 67 distribution and intergranular crack growth of FA-189 in air, $\mathrm{K}_{\mathrm{I}}=17.36 \mathrm{MPa} \sqrt{\mathrm{m}}$, failure strain of $4 \%$. 


\section{LIST OF TABLES}

Table 1. Chemical Composition of Iron Aluminides (at.\%) 2

Table 2. Test matrix for specimens studied, FA-186 and FA-189 20

Table 3. Failure mode of the specimens studied 20

Table 4. Material properties $\quad 32$

Table 5. Reduction of Young's Modulus 43

Table 6. Finite element simulation matrix 48 


\section{CHAPTER 1}

\section{INTRODUCTION AND RESEARCH OBJECTIVES}

\subsection{Iron Aluminides and Environmental Embrittlement}

Iron and aluminum form several stable intermetallic alloys, including alloys with ordered bcc structures $-\mathrm{B}_{2}-\mathrm{FeAl}$ and $\mathrm{DO}_{3}-\mathrm{Fe}_{3} \mathrm{Al}$. These intermetallic compounds thus have a characteristic lattice which is generally more complicated than the lattices for pure metals or solid solutions and their characteristic properties are very different from those of any constituent element. These materials have received favorable attention for advanced aerospace applications either at ambient or intermediate temperatures because of their superior characteristics as compared to stainless steel and iron-based superalloys.

Iron aluminides posses many advantages that make them attractive for hightemperature structural applications such as: heat exchangers, piping for chemical process industries, furnace heating elements, and automotive exhaust systems and valves. One of these attractive properties is represented by the fact that in oxidizing environments, they form, due to their high content of aluminum, thin films of aluminide oxides that are compact and protective. They also have low densities, relatively high melting points, good high-temperature strength properties and low material cost ${ }^{[1]}$.

A major disadvantage in their development was the fact that iron aluminides, like other ordered intermetallics, exhibit low fracture toughness and ductility at room

temperature due to environmental effects ${ }^{[2,3,4]}$. Also, poor fracture resistance and limited fabricability restrict the use of aluminides as engineering materials in most cases. 
For the past ten years, significant efforts have been made to understand brittle fracture and poor ductility in these aluminides. It was found that both intrinsic and extrinsic factors govern brittle fracture in the aluminides. One of these factors, an extrinsic one, is their susceptibility to hydrogen embrittlement at room temperature because of exposure to moisture.

It is widely recognized that these intermetallic compounds can be severely embrittled by moist air or hydrogen environment but moisture-induced embrittlement seems to be the most severe case for the iron aluminides.

It is interesting to note that other intermetallics that do not contain a reactive element such as aluminum are not sensitive to moisture at all. It is obvious therefore, that the role of aluminum in the iron aluminides is to react with water vapor, reaction whose result is the atomic hydrogen, which is responsible for the embrittlement of these alloys $^{[47]}$. Hydrogen-induced environmental embrittlement of many intermetallic alloys has been examined in several papers ${ }^{[8,9,11,12,18]}$.

\subsection{Motivation for Computational Analysis Related to Experimental Program}

Comparative crack growth tests of three iron aluminides (FA-186, FA-187 and FA189 as shown in Table 1) subjected to tensile loading in air, oxygen or water environment were conducted at $\mathrm{WVU}^{[48,49]}$.

Table1. Chemical composition of Iron Aluminides (at. \%)

\begin{tabular}{|c|c|c|c|c|c|c|}
\hline Alloy & $\mathrm{Fe}$ & $\mathrm{Al}$ & $\mathrm{Cr}$ & $\mathrm{Zr}$ & C & B \\
\hline FA-186 & balance & 28 & 5 & & & \\
\hline FA-187 & balance & 28 & $\overline{5}$ & 0.5 & 0.05 & \\
\hline FA-189 & balance & 28 & 2 & 0.5 & 0.05 & 0.005 \\
\hline
\end{tabular}


Moiré interferometry was applied to obtain full-field crack tip displacements, from which crack extension, crack growth rate, crack-tip strain fields, and stress intensity factors were evaluated ${ }^{[10]}$.

The experimental results, have shown that, among the three alloys, the ternary alloy FA-186 has the best fracture resistance, highest fracture toughness and least sensitivity to hydrogen embrittlement.

These results were quite surprising because the purpose of adding small amount of boron to FA-189 was to improve the grain boundary cohesive strength such that the loss of cohesive strength at the interfaces (intergranular fracture) can be minimized. Micro-alloying with B and/or $\mathrm{Zr}$ results in much smaller grain size which implies that FA-189 should have, intrinsically, higher fracture toughness than that of FA-186. However, as indicated by experimental results, FA-189 is more susceptible to environmental embrittlement than FA-186 under low strain loading condition. Thus, to further investigate the effect of grain boundary morphology (e.g. size effect) as related to the susceptibility to hydrogen embrittlement, comparative finite element simulations of intergranular fracture of two iron aluminides, FA-186 and FA-189, subjected to stressassisted hydrogen embrittlement are conducted in this research.

The objective of the numerical analyses is to correlate with the experimental results as well as to further validate the assertion that grain boundary morphology plays an important role on the extrinsic fracture behavior of iron aluminides in the presence of hydrogen embrittlement.

It should be noted that the quasi-statically computational modeling analysis presented is qualitative in nature. No attempt has been made in this analysis to include 
the study of hydrogen transport kinetics such as incubation time period, kinetics of degradation, and the critical hydrogen concentration build-up before fracture.

\subsection{Research Objectives}

This study was carried out to accomplish the following goals:

(1) To carry out comparative finite element simulations of hydrogen-assisted fracture behavior of two iron aluminides (FA-189 and FA-186).

(2) Develop a finite element simulation model that can sequentially couple stress and hydrogen diffusion analyses to simulate the intergranular fracture of iron aluminides.

(3) Correlate the finite element results with the experimental results. 


\section{CHAPTER 2}

\section{REVIEW OF RELATED WORK}

\subsection{Investigation of Hydrogen Embrittlement on Iron Aluminides}

For more than 40 years, metallurgists tried to find a substitute for stainless steel because this one was prone to corrosion. They looked to iron aluminides as strong and corrosion resistant alloys. But, unfortunately iron aluminides have their own characteristic feature: they break too easily at room temperature. Finally, in 1990, two ORNL materials scientists, Liu and McKamey found why these alloys kept breaking. They discovered that the aluminides are intrinsically quite ductile and their brittle nature is caused by hydrogen released when aluminum atoms in the aluminides react with water vapor. Material scientists found that intermetallic compounds can be severely embrittled by gaseous environments, including moist air, oxygen, or hydrogen.

It was found that a relatively small hydrogen concentration is enough to induce

environmental embrittlement. McKamey, C.G. ${ }^{[5]}$ studied the embrittlement effect from a vacuum of $10^{-4} \mathrm{~Pa}$ to a water vapor partial pressure of $1330 \mathrm{~Pa}$, and showed that a water vapor level as low as $133 \mathrm{~Pa}$ ( 1 torr) can cause significant embrittlement.

Hydrogen embrittlement has been observed in many compounds, primary at room temperature, but in some cases (e.g. titanium aluminides), at elevated temperatures as well. The occurrence of moisture-induced cracking or hydrogen embrittlement in several aluminides such as $\mathrm{TiAl}, \mathrm{Ti}_{3} \mathrm{Al}, \mathrm{Fe}_{3} \mathrm{Al}$, and $\mathrm{Ni}_{3} \mathrm{Al}$, has limited potential structural 
applications of these materials, because it was not found yet a satisfactory solution for using them in aggressive environments ${ }^{[17]}$.

The environmental reaction involves aluminum reacting with water vapor, such that atomic hydrogen is released and drawn via dislocation motion ahead of the crack tip.

In spite of the restrictions on the use of intermetallics in hydrogen environments, there are few published work on the topic of embrittlement of these materials. Several investigators have reported environmentally - induced cracking in iron aluminides ${ }^{[2-9]}$. In 1989, Liu et al. demonstrated first that moisture has been involved in the embrittlement of both $\mathrm{Fe}_{3} \mathrm{Al}^{[3]}$ and $\mathrm{FeAl}^{[4]}$. For example, they measured the ductility and tensile strength of $\mathrm{Fe}_{3} \mathrm{Al}$ and they found that both of them are severely reduced in the presence of moist environment, compared to vacuum or oxygen. Either hydrogen was released from water vapor or cathodically precharged ${ }^{[12]}$ it was considered to be the embrittling agent for both alloys ${ }^{[3,4,11]}$.

The effect of composition and microstructure of iron aluminides was studied by C.T.Liu et al ${ }^{[47]}$. If the composition is within the range of stability of iron aluminides, embrittlement by hydrogen or by moisture will not depend on aluminum content. Their tests showed that fracture invariably will occur in air at elongation of about $5 \%$ or less, while vacuum and oxygen provided elongation between 15-20\% ${ }^{[12-14]}$. The influence of adding chromium also has been studied. Initially it was reported that for alloys with $28 \% \mathrm{Al}$, an addition of chromium between 2 and $6 \%$ provided an improvement in room temperature ductility but recent work on more complex alloys showed a different result. For example, alloy FA-122 (28\% Al, 5\% Cr, small quantities of boron and zirconium) ${ }^{[47]}$ showed a high ductility, about $13 \%$ elongation, in vacuum 
condition, but its ductility in air and hydrogen environment was still very low, at 3\% level. This value has to be compared to $6 \%$ elongation for binary Fe-23.5 at. \% $\mathrm{Al}$ and $5 \%$ for binary $\mathrm{Fe}-25$ at. $\% \mathrm{Al}$. For this alloy the fracture mode was mixed in air, hydrogen and vacuum. Further fatigue crack growth studies indicated no benefit of chromium on crack growth of $\mathrm{Fe}-28$ at. \% $\mathrm{Al}$ alloys. Even though, Klein O. et al. showed that the addition of $\mathrm{Cr}$ will make the intermetallics be less susceptible to environmental embrittlement, the role of chromium in this phenomena is not clear yet for many of the researchers. However, a clear effect of chromium is on the fracture mode; when chromium is present the fracture mode is a mixed one while in binary alloys the transgranular cleavage predominates. Another observation was that the positive effect of chromium was noted when the surface condition was very good which implies that it depends on the presence of oxide films.

C.T.Liu et al. ${ }^{[4]}$ were the first to report that moisture environments have a deleterious effect on the ductility of binary $\mathrm{Fe}_{3} \mathrm{Al}$ tested under monotonic loading. They reported that alloys containing 28 at. \% $\mathrm{Al}$, tested in the $\mathrm{B} 2$ condition, displayed only 4.1\% elongation in air compared to $12.0 \%$ in oxygen and $12.8 \%$ in vacuum. An identical pattern of behavior was revealed when testing an alloy annealed to produce $\mathrm{DO}_{3}$ order, except that slightly lower ductility was obtained in the same conditions of environment. These observations together with the fact that the fracture mode was transgranular cleavage for all the specimens lead to the conclusion that the type of order didn't affect too much the fracture behavior. Although Liu et al. ${ }^{[4]}$ suggested that the embrittling agent was hydrogen released from water vapor in contact with aluminum, no direct evidence for hydrogen embrittlement was reported. Later, Shea et al. ${ }^{[12]}$, Kasul, Heldt ${ }^{[15]}$ 
and Zhang et al. ${ }^{[16]}$, have confirmed the advantageous effect of oxygen or vacuum on ductility. The most severe embrittlement was observed when hydrogen was charged simultaneously with tensile testing.

Another element whose content could possibly have a influence on environmental embrittlement is aluminum. Liu et al. ${ }^{[3]}$ have shown clearly that Fe-36.5 at. \% $\mathrm{Al}$ is severely embrittled either in moist air or in water. Tensile elongation is only 2 $\%$ in air or water, compared to $17.6 \%$ in dry oxygen. They concluded that when the aluminum content is greater than $38 \%$ the susceptibility to environment is reduced and they advanced the possibility that at these aluminum levels the grain boundaries of $\mathrm{FeAl}$ alloys might be intrinsically brittle which indicates that at high aluminum levels we cannot state that there is or there is not an environmental embrittlement.

Recently, W.C.Luu and J.K.Wu ${ }^{[21]}$ performed tensile tests of six iron aluminides in air, vacuum and hydrogen precharged. They concluded that for $\mathrm{Fe}-18 \mathrm{Al}-5 \mathrm{Cr}$ and $\mathrm{Fe}-$ $28 \mathrm{Al}-5 \mathrm{Cr}$ the diffusion path is limited along grain boundaries, subgrain boundaries and precipitates on matrix. Their tensile tests conducted in air have shown that Fe-28Al, Fe$28 \mathrm{Al}-5 \mathrm{Cr}$ and $\mathrm{Fe}-40 \mathrm{Al}$ exhibited most degradation in elongation and strength; Fe-28Al and $\mathrm{Fe}-28 \mathrm{Al}-5 \mathrm{Cr}$ specimens tested in air both show transgranular cleavage fracture while Fe-40Al shows intergranular fracture. They concluded that moisture induced hydrogen embrittlement is one of the most possible embrittlement mechanisms of the brittleness in intermetallics explained by segregation of moisture induced hydrogen atoms at the crack tip, lowering the bonding strength of grain boundaries, and causing transgranular cleavage or intergranular fracture. Thus, the susceptibility of iron aluminides (with 
greater or equal than 28 at.\% $\mathrm{Al}$ ) to moisture is much stronger than to hydrogen environment.

Liu $^{[20]}$ studied also the influence of boron on environmental embrittlement. He found that when boron was added to Fe-40Al to strengthen grain boundaries, the ductility increased in air from $1.2 \%$ to $4.3 \%$, with a further increase to $16.5 \%$ in oxygen. This positive effect on strengthening grain boundaries due to boron addition is noted only when the aluminum content is below 46 at. $\%$.

Microstructure studies revealed that ductility is improved when $\mathrm{F}_{3} \mathrm{Al}$ is recrystallized or partly recrystallized. Although the reason for this effect is not known yet, it has been suggested that the mobility of dislocations might increase in this case compared to the unrecrystallized material ${ }^{[50]}$. There have been no systematic studies of grain size effects on ductility of wrought alloys in aggressive environments. For powder metallurgy alloys (PM), varying grain size of PM Fe-25 at. \% Al from 12 to about $200 \mu \mathrm{m}$ caused a small but steady decrease in ductility in each environment ${ }^{[17]}$.

Recent research indicated ${ }^{[7]}$, that the presence of surface passive films can reduce hydrogen embrittlement. Passivity-inducing elements such as $\mathrm{Ti}, \mathrm{Zr}, \mathrm{V}, \mathrm{Nb}, \mathrm{Ta}$, $\mathrm{Cr}$, Mo, W, Si and Ni have been micro-alloyed with $\mathrm{Fe}_{3} \mathrm{Al}$ and it was found that all the alloy additions, except $\mathrm{V}$, enhanced the passivity of the base intermetallic.

\subsection{Mechanisms of Hydrogen Embrittlement}

The mechanism of hydrogen embrittlement is still not clear, despite many years of intensive investigation. Over the years a number of theories have been developed, and 
several mechanisms have been proposed to explain the effect of hydrogen on materials behavior and these have been reviewed in a number of papers ${ }^{[22-24]}$. The overall opinion is that there is not just one mechanism, which can be applied to all combinations of metals and environments.

The chemical reaction responsible for the liberation of hydrogen in the presence of a reactive metal is suggested to be ${ }^{[8,9]}$

$$
x M+y H_{2} \rightarrow M_{x} O_{y}+2 y H
$$

In the case of aluminides, the reaction can be simplified to:

$$
2 \mathrm{Al}+3 \mathrm{H}_{2} \mathrm{O} \rightarrow \mathrm{Al}_{2} \mathrm{O}_{3}+6 \mathrm{H}
$$

Although oxide films are known to be protective, the $\mathrm{Al}_{2} \mathrm{O}_{3}$ film is porous and, therefore, non-protective. Thus, atomic hydrogen can interact easily with the intermetallic compound.

Birnbaum ${ }^{[23]}$ classified the hydrogen embrittlement mechanisms as follows:

(i) hydrogen related phase change mechanism;

(ii) hydrogen enhanced local plasticity (HELP)mechanism, and

(iii) hydrogen effects on the cohesive energy.

There are also some other mechanisms proposed to particular systems including the pressure theory which states that hydrogen atoms can recombine at internal voids or fissures resulting in a high pressure of hydrogen gaseous molecules which is sufficient to increase the internal cavity thus causing progressive failure ${ }^{[25]}$. Petch and Stables proposed another mechanism suggesting that hydrogen atoms reduce the energy required to create a new surface, which therefore, explains the crack advance. 
(i) Hydrogen-related phase change theory. Birnbaum describes this mechanism as the stress-induced formation of hydrides and subsequent brittle failure of these phases. The fracture proceeds by the formation of hydrides in the stress concentrated regions at the crack tip, cracking of the hydrides followed by a crack arrest when this one reaches the matrix surface and a cyclic repetition of the above processes, resulting in a discontinuous crack growth. The hydrides are brittle phases because of restricted dislocation mobility, and cracking of the hydrides is a brittle cleavage mode.

(ii) Hydrogen-enhanced local plasticity. The term hydrogen embrittlement commonly refers to the loss of macroscopic ductility and the brittle appearance of failed surfaces. Beachem ${ }^{[26]}$ reported first the existence of a highly localized deformation process, while the macroscopic deformation is still small, proposing the idea that at a microscopic level the effect of hydrogen atoms was to intensify the local plasticity. His statement was based on observations of dimpled surfaces using high-resolution microscopy. The process has been given the name of hydrogen-enhanced local plasticity by Birnbaum ${ }^{[23]}$ and the mechanism of highly localized failure involves shear processes. Lynch $^{[27]}$ and Birnbaum ${ }^{[23]}$ developed this concept from the original work of Beachem. The difference in their approaches is the emphasis that Lynch gives to the effect of surface adsorbed hydrogen while Birnbaum considers that the effect is due to hydrogen within the material as well as at the surface. Based on examinations of the fracture surfaces and in-situ environmental-cell transmission electron microscopy (TEM), Birnbaum claims that HELP is a practicable mechanism for a large number of metals and alloys including nickel-base, iron-base and aluminum-base alloys. He claims that this mechanism is applicable to both transgranular and intergranular fracture. 
Birnbaum's describes the cracking process starting from localization of hydrogen atoms at the crack tip, with effect in reducing the flow stress, continued by a localization of shear leading to fracture by different plastic-failure processes, although the exact mechanism by which shear localization causes fracture is not known.

(iii) Hydrogen effects on the cohesive energy. The basic idea of the decohesion model for hydrogen embrittlement is that diffused hydrogen atoms at high local concentrations in the lattice such as grain boundaries or interphase boundaries reduce the local maximum cohesive force ${ }^{[24]}$. When the local tensile stress is sufficiently high to equal the maximum local cohesive force decreased by hydrogen a crack will appear.

The decohesion model states that the cohesive force is lowered by hydrogen but does not attempt to provide an explanation for that effect. Evidence of decohesion in intermetallics is largely based upon the brittle appearance of fracture surfaces . The brittle appearance of hydrogen-induced and moisture-induced cracks in $\mathrm{Fe}_{3} \mathrm{Al}$ alloys also suggests decohesion as the likely mechanism. However, direct experimental measurements of cohesive strength are lacking and thus, the theoretical finding cannot be verified.

\subsection{Numerical Simulations of Environmentally Assisted Fracture}

Numerical simulations of environmentally assisted fracture are relatively rare. An explanation for this would be the fact that models of environmentally assisted cracking have to account for the above-described mechanisms of hydrogen embrittlement. A reliable model should take into consideration more complex factors such as the absorption of hydrogen atoms, transport and localization of hydrogen atoms 
in the metal under conditions of localized stress and strain ${ }^{[25]}$. All of these factors have to be considered in predicting the response of a material to a particular environmental and mechanical condition. Localization of hydrogen atoms can occur at so-called "trap sites" such as dislocations, grain boundaries, interfaces between different phases, voids or cracks within the material in which hydrogen atoms can diffuse and recombine. Localization can also occur through the effect of stress on the chemical potential of hydrogen atoms. The chemical potential is a measure of how much the energy of a system changes if we add or remove a number of particles of a species while keeping the number of the other particles constant.

From a modeling point of view, to simulate mobile dislocations is very difficult, because models of crack-tip hydrogen distribution usually do not include grain boundaries and interfaces which would act as obstacles to hydrogen transport. For these reasons, analysis of hydrogen atom distribution has been largely qualitative and solutions have been usually one dimensional, with boundary conditions specifying a known constant concentration. The primary distinction between the different models has been in the way of how hydrostatic stress was defined, with earlier models ${ }^{[28]}$ using the elastic solutions for hydrostatic stress given by

$$
\sigma_{k k}=\frac{2(1+v)}{3(2 \pi r)^{1 / 2}} K_{I} \cos \left(\frac{\theta}{2}\right)
$$

where $K_{I}$ is the stress intensity factor, $r$ and $\theta$ are radial coordinates. This indicates that there is a singularity at the crack tip though in some numerical simulations this is hard to achieve, depending on the meshing possibilities. 
Other approaches have included plasticity at the crack tip. Thus, Unger and Aifantis ${ }^{[29]}$ assumed that $\sigma_{k k}$ was a constant within the plastic zone given by

$$
\sigma_{k k}=\frac{2}{3}(1+v) \sigma_{y}
$$

where $\sigma_{\mathrm{y}}$ is the yield strength, and used the elastic solution outside the plastic zone.

They also considered an alternative stress distribution in the plastic zone at the tip based on the slip-line field theory,

$$
\sigma_{k k}=\sigma_{y}[0.5+\ln (1+x / \rho)]
$$

where $\rho$ is the crack tip radius. This analysis was one-dimensional in character.

Kitagawa and Kojima ${ }^{[30]}$ evaluated the distribution of hydrogen atoms at a crack tip based on elastic-perfectly plastic material with simplified boundary conditions but with trapping also included. The number of traps was assumed to depend on the hydrostatic stress rather than on the strain.

Mao and $\mathrm{Li}^{[31]}$ measured (using secondary ion mass spectroscopy) and modeled by finite element analysis the hydrogen distribution around a crack tip subject to stress corrosion for pipeline steels. They carried out a finite element modeling, for an elasticplastic material, using the finite element code $A B A Q U S^{T M}$ to calculate the stress distribution around the crack tip based on the loading and specimen geometry in the experimental study. They assumed also a steady state diffusion of hydrogen and they concluded that hydrogen concentration at the crack tip increases with the applied stress intensity factor.

Sofronis and McMeeking ${ }^{[32]}$ have used the most rigorous analysis based on elastic-plastic theory for a blunted crack tip and allowed for trapping. The boundary conditions that they used are based on the assumption of a known constant 
concentration. They assumed that the trap sites were dislocations. The work of Sofronis and McMeeking represents the most important trial to describe the detailed distribution of hydrogen atoms at the crack tip and they are the only researchers who have so far carried out coupled diffusion elastic-plastic stress finite element analyses including the effect of hydrostatic stress and trapping. They predicted high local concentrations at the crack tip, around 80 times higher than the initial one, and they concluded that this high number is due primarily to the high dislocation density and trapping.

Toribio et al. (1995) ${ }^{[33]}$ also carried out coupled finite element analyses on notched bars but without the trapping of hydrogen.

More recently, Lufrano and Sofronis (1996) and Lufrano et al. (1996) studied the mechanisms associated with hydrogen embritllement at a stationary crack tip including the effects of stress-enhanced diffusion.

Later, A.Krom, Koers and Bakker ${ }^{[34]}$ have modified the original hydrogen transport model of Sofronis and McMeeking taking into account a factor depending on the strain rate trying to provide a correct hydrogen balance.

The modeling of crack tip hydrogen distribution is becoming more rigorous but further investigation on the effect of different boundary conditions, trapping parameters, the effect of $\mathrm{K}$, time and $\sigma_{\mathrm{y}}$ is required. In addition the effect of cyclic stress has not been studied yet.

Quantitative modeling of hydrogen cracking is a very complex problem because it has to account for the generation of hydrogen atoms and their absorption, their transport and distribution in the lattice and trap sites, the role of microstructure, material 
composition and mechanical properties. Due to all these problems progress in this direction has not been rapid. 


\section{CHAPTER 3}

\section{SUMMARY OF THE EXPERIMENTAL PROGRAM RELEVANT TO THE COMPUTATIONAL ANALYSIS}

\subsection{Test Materials and Specimen ${ }^{[48,49]}$}

The specimen modeled in this research was a single-edge-notched (SEN) with the following geometry and dimensions:

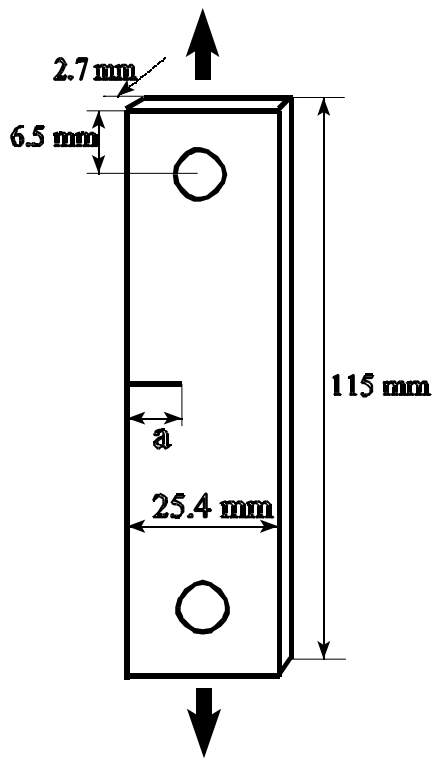

$$
\mathbf{a}=10 \mathrm{~mm}
$$

Fig. 3.1 Single-Edge-Notched Specimen[48,49]

The alloys used for these specimens were fabricated at Oak Ridge National Laboratory (ORNL) by vacuum induction melting and casting into graphite molds. The ingots were then hot forged (two passes, $25 \%$ per pass) at $1000^{\circ} \mathrm{C}$ followed by hot rolled at $800^{\circ} \mathrm{C}$ for seven passes to produce finished plate thickness of $6.35 \mathrm{~mm}$. The finished plates were either heat treated at $900^{\circ} \mathrm{C}$ for one hour then air quenched to produce partially ordered B2 structure or heat treated at $900^{\circ} \mathrm{C}$ for one hour followed by $500^{\circ} \mathrm{C}$ 
for 72 hours then air quenched to produce $\mathrm{DO}_{3}$ structure. Table 1 shows the composition of FA-186 and FA-189.

SEN specimens were machined from the plates and the initial notch was cut by Electron-Discharge Machining (EDM) with $0.1 \mathrm{~mm}$ diameter cutting wire. Some specimens were fatigue precracked.

Table 1. Chemical Composition of Iron Aluminides (at \%)

\begin{tabular}{||c||c||c||c||c||c||c||}
\hline Alloy & $\mathrm{Fe}$ & $\mathrm{Al}$ & $\mathrm{Cr}$ & $\mathrm{Zr}$ & $\mathrm{C}$ & $\mathrm{B}$ \\
\hline \hline FA-186 & balance & 28 & 5 & & & \\
\hline \hline FA-187 & balance & 28 & 5 & 0.5 & 0.05 & \\
\hline \hline FA-189 & balance & 28 & 2 & 0.5 & 0.05 & 0.005 \\
\hline
\end{tabular}

\subsection{Fractography and Microstructure Examinations}

A total of sixteen comparative crack growth tests were carried out under various

environments ${ }^{[48,49]}$. These tests were followed by fractographic analyses of the broken specimens using a scanning electron microscope (SEM) to evaluate the fracture path and to identify the fracture modes. Fractographies and microstructure examinations are very important in comparing the finite element results related to fracture paths and fracture modes with the experimental ones.

Figure 3.2 shows representative SEM fractographies of FA-186 and FA-189 tested in air in a region close to the crack tip, Figure 3.3 shows typical microstructure of FA-186 and FA-189 in $\mathrm{B} 2$ and $\mathrm{DO}_{3}$ condition and the grain sizes are estimated to be $193 \mu \mathrm{m}$ and $75 \mu \mathrm{m}$, respectively. Figure 3.4 shows a schematic representation of fracture modes for both of alloys at the crack growth initiation stage. 
FA-186

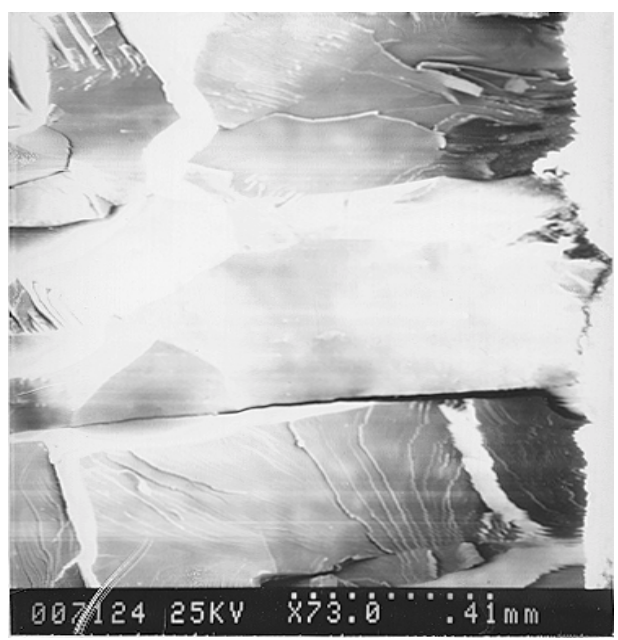

FA-189

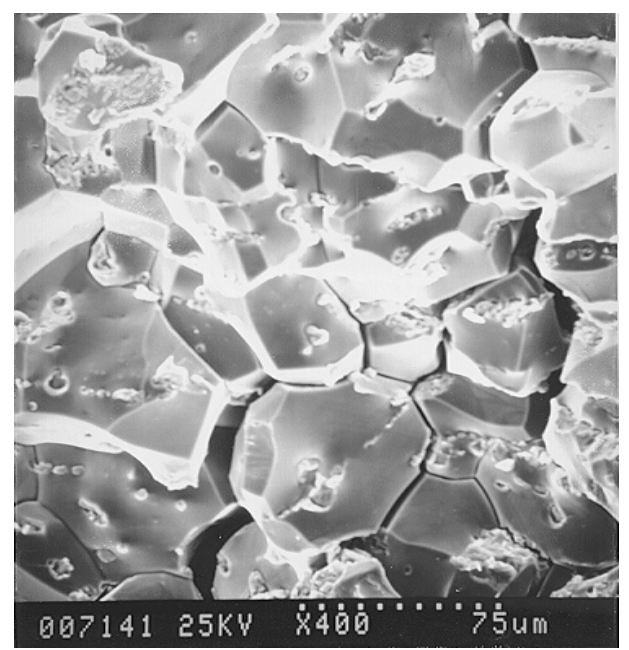

Fig. 3.2 Representative fractographies for FA-186 and FA-189 in Air

FA -186

(grain size $=0.193 \mathbf{m m}$ )
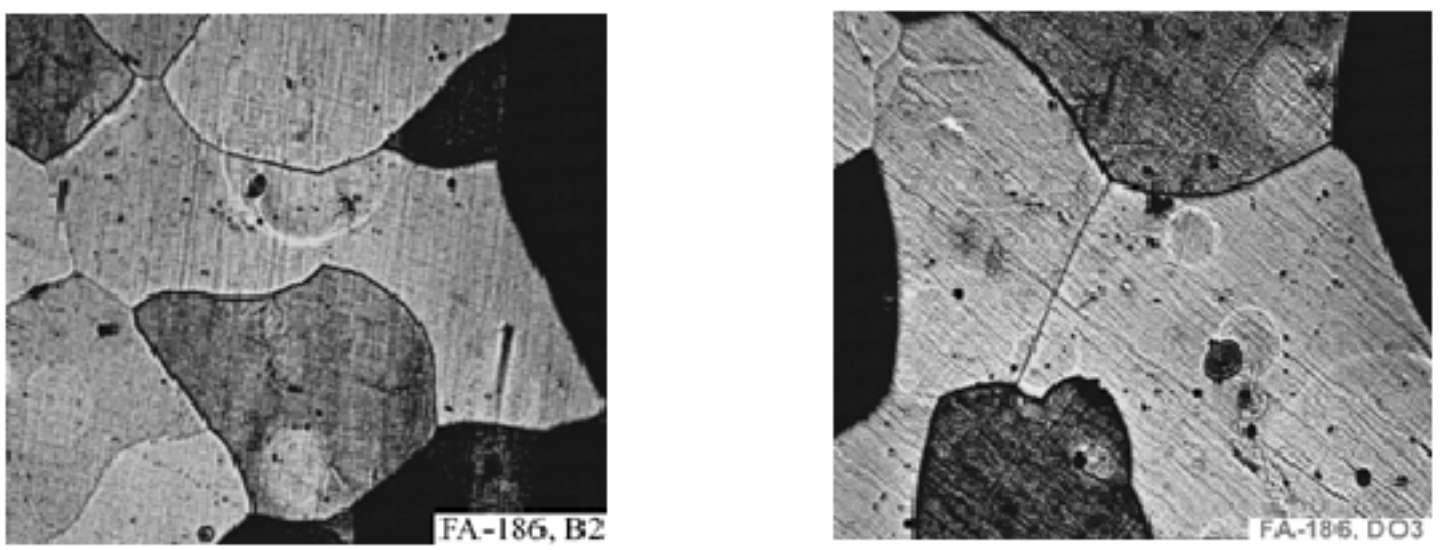

FA -189

(grain size $=0.075 \mathbf{m m})$
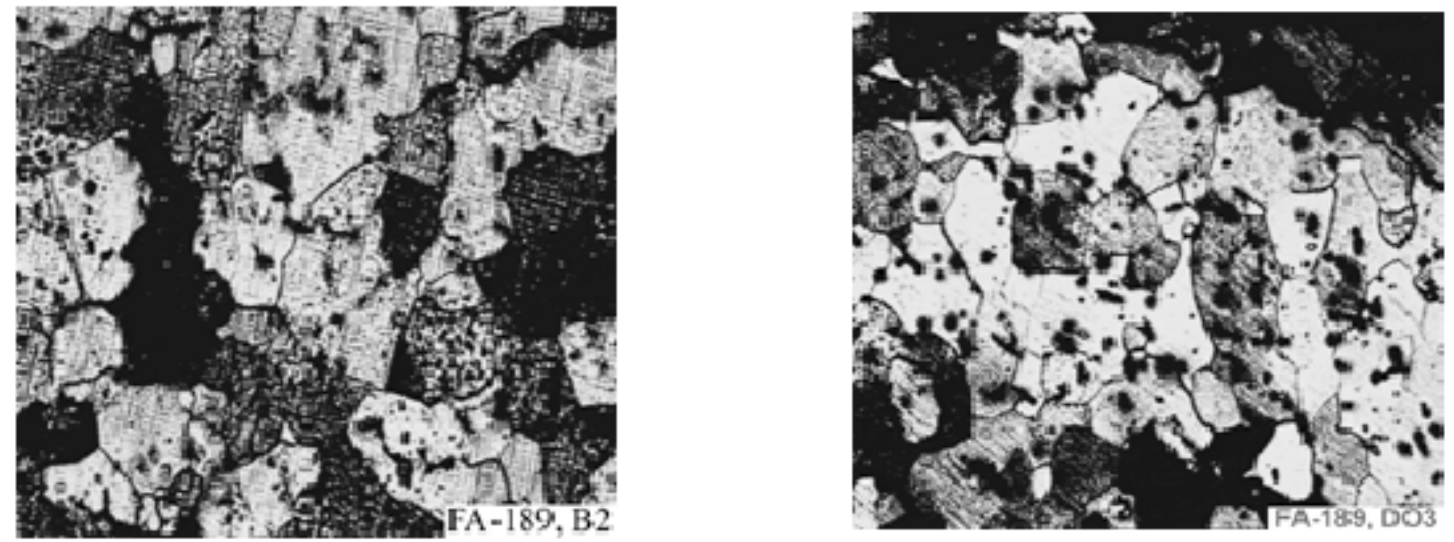

Fig 3.3 Microstructure of FA-186 and FA-189 


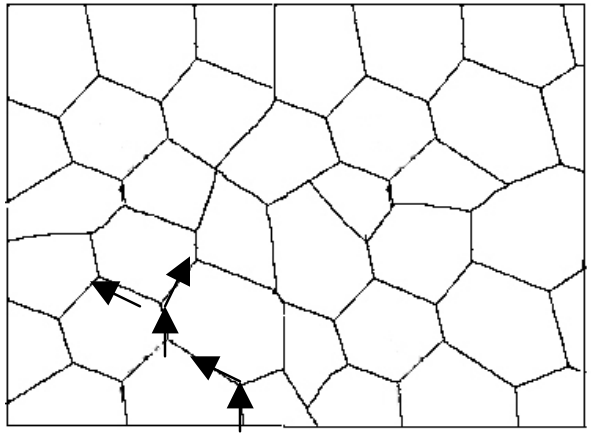

(a) Fracture mode of FA-189

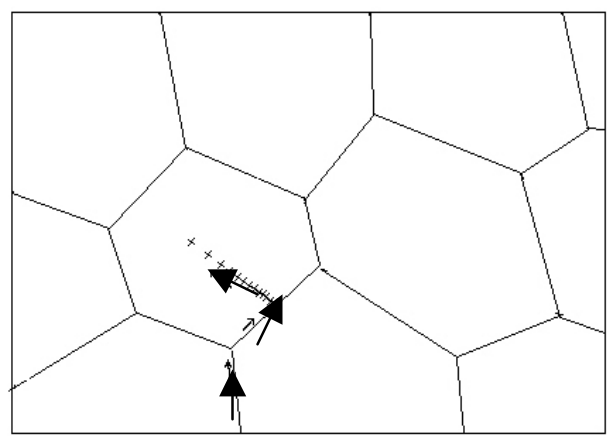

(b) Fracture mode of FA-186

Fig. 3.4 Schematic representation of transgranular \& intergranular fracture formation for

\section{FA-186 and FA-189}

\subsection{Test Results}

Tables 2 and 3 show the test matrix and the failure mode relevant to the computational modeling.

\begin{tabular}{|c|c|c|c|c|c|c|}
\hline $\begin{array}{c}\text { Iron } \\
\text { aluminide }\end{array}$ & Specimen & $\begin{array}{l}\text { Structure } \\
\text { Condition }\end{array}$ & Initial Crack & Environment & $\begin{array}{c}\text { Initial K } \\
M P a \sqrt{m}\end{array}$ & Lasting Time \\
\hline FA-186 & $86-1$ & $\mathrm{~B} 2$ & FP & Air & 36.9 & $7 \mathrm{~min}$ \\
\cline { 2 - 7 } & $86-10$ & $\mathrm{DO}_{3}$ & EDM & Air & 25 & $\begin{array}{c}94 \mathrm{~min}^{\mathrm{c}} \\
1 \mathrm{~min}\end{array}$ \\
\hline FA-189 & $89-2$ & $\mathrm{~B} 2$ & EDM & Air & 17.36 & $7 \mathrm{~min}$ \\
& $89-7$ & $\mathrm{DO}_{3}$ & EDM & Air & 17.36 & $3 \mathrm{~min}$ \\
\hline
\end{tabular}

Table 2. Test matrix for the specimens studied

\begin{tabular}{|c|c|c|c|}
\hline Alloy & Specimen & Environment & Initial fracture mode \\
\hline & $86-1$ & Air & mixed \\
\hline & $86-5$ & Dry Oxygen & mixed \\
\hline FA-186 & $86-10$ & Air & mixed \\
\hline & $86-9$ & Dry Oxygen & mixed \\
\hline & $86-w 1$ & Water & intergranular \\
\hline & $87-1$ & Air & intergranular \\
\hline & $87-5$ & Dry Oxygen & intergranular \\
\hline & $87-8$ & Air & intergranular \\
\hline & $87-w 1$ & water & intergranular \\
\hline & $87-7$ & Dry Oxygen & intergranular \\
\hline & $89-2$ & Air & intergranular \\
\hline & $89-1$ & Dry Oxygen & intergranular \\
\hline & $89-7$ & Air & intergranular \\
\hline & $89-6$ & Dry Oxygen & intergranular \\
\hline
\end{tabular}

Table 3. Failure mode of the specimens studied 
From these experimental results it can be concluded that specimens of the ternary alloy FA-186 tested in air showed some small amount of crack growth compared to specimens of FA-189, which showed substantial faster and longer crack growth. Also, for FA-189 initial crack growth always started with intergranular mode and the fracture path is along the grain boundaries. For FA-186 tested in air, it was observed rougher cleavage facets (i.e. more tilt and twist boundaries) which shows an initial intergranular failure changed quickly to a transgranular failure. For this alloy multiple cracks were formed as soon as the main crack started to grow regardless of the test environment. All these results are correlated with the maximum principal distribution ahead of crack-tip obtained after digital image processing of the original moiré fringe pattern as shown in the sequences. For FA-189 neither multiple cracks nor an expanding damage zone was observed. However, in FA-189, clear single crack growth was observed before its failure.

Generally, specimens tested in partially ordered B2 condition lasted a little longer than those in $\mathrm{DO}_{3}$ condition, regardless of the type of alloys.

No direct evidence has been obtained to associate the effect of $\mathrm{Zr}$ and $\mathrm{C}$ with the ductility but interesting observations can be made about the presence of boron ${ }^{[1]}$.

Figures 3.5 and 3.6 show the maximum principal strain distribution with crack growth, after digital image processing of the original moiré fringe pattern and representative moiré fringe patterns of FA-186 and FA-189 tested in air can be seen in Appendix A. 

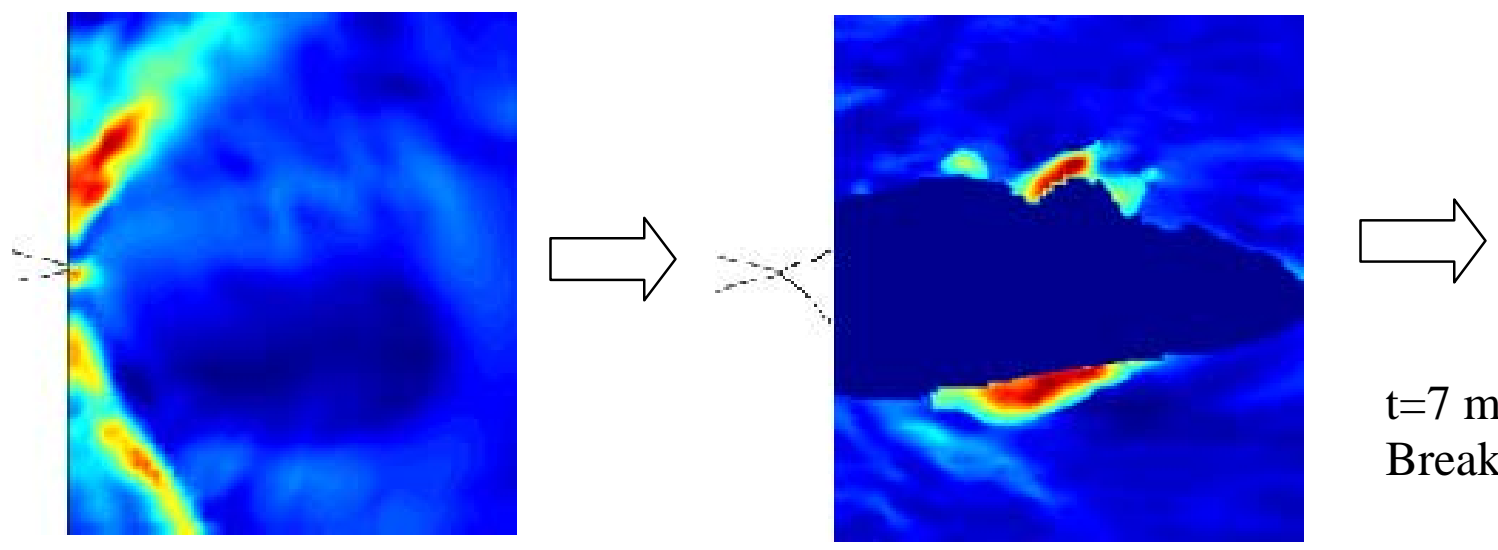

$\mathrm{t}=0 \mathrm{~min}$

$\mathrm{t}=5 \mathrm{~min}$

Fig. 3.5 Sequence of maximum principal strain distributions ahead of crack tip with crack growth. FA-186 SENT specimen, room temp, air. Initial applied $\mathrm{K}_{\mathrm{I}}=36.9 \mathrm{MPa} \sqrt{\mathrm{m}}$ 

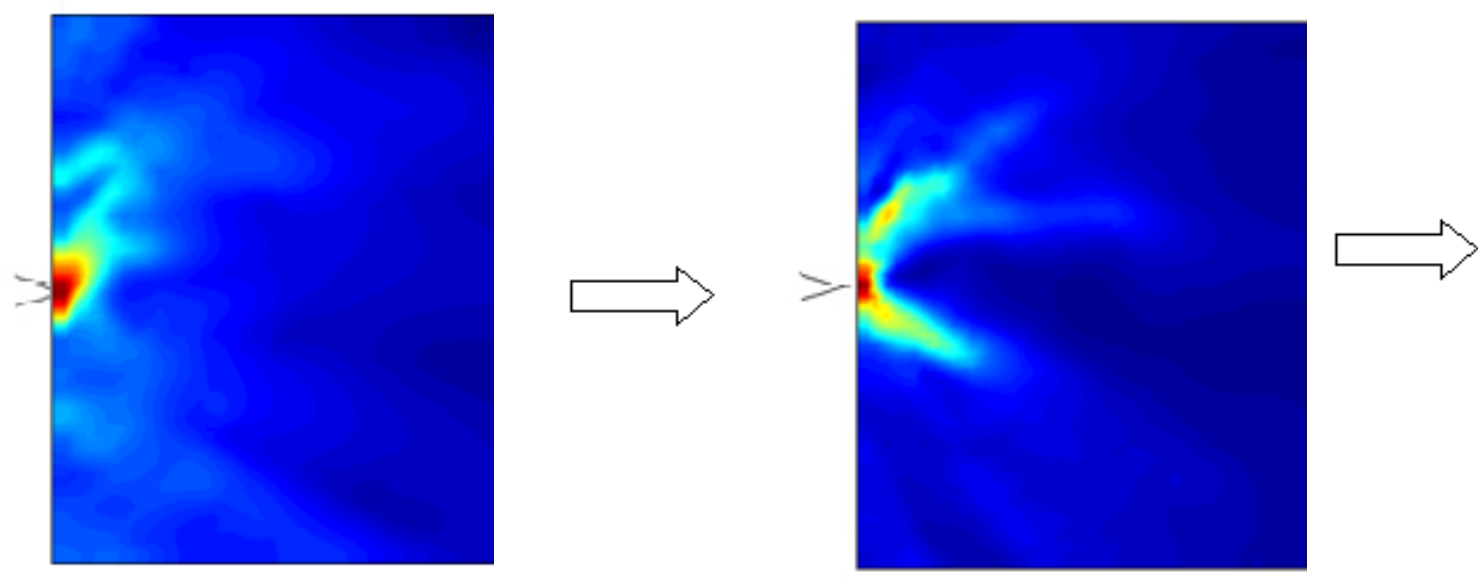

$\mathrm{t}=0 \mathrm{~min}$

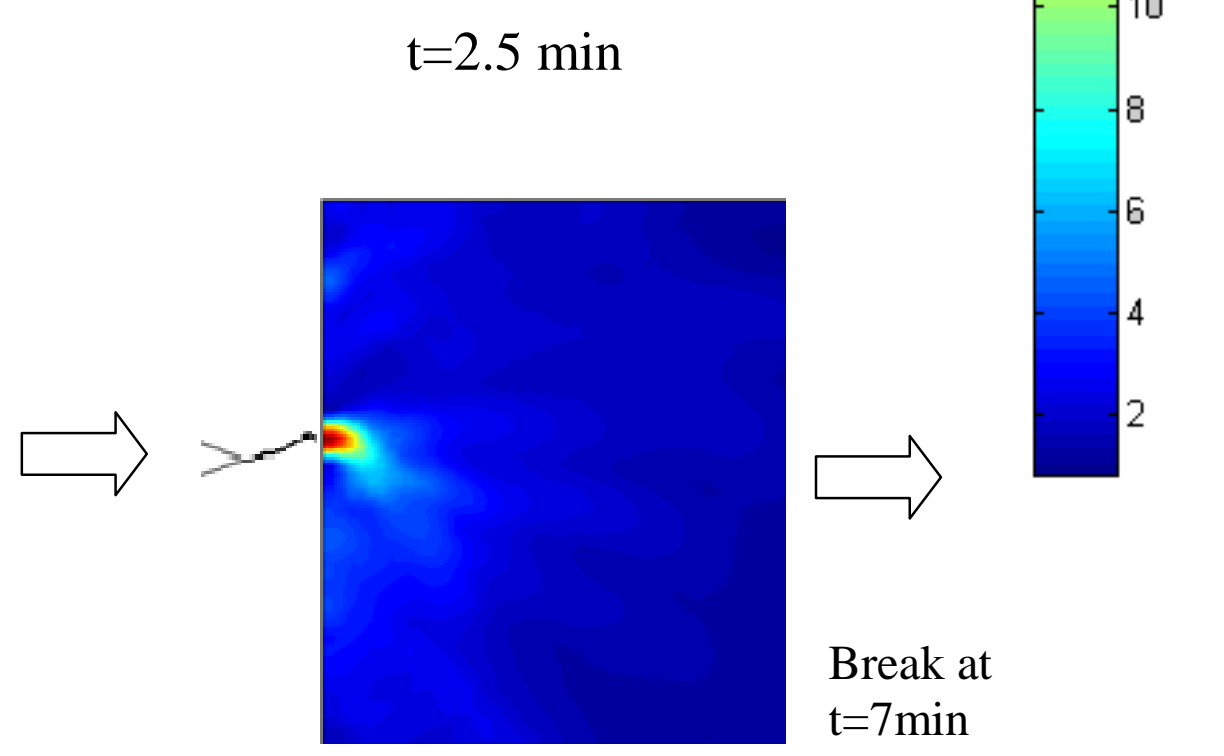

$\mathrm{t}=3.5 \mathrm{~min}$

$\mathrm{t}=4.5 \mathrm{~min}$

Fig. 3.6 Sequence of maximum principal strain distributions ahead of crack tip with crack growth. FA-189 SENT specimen, room temp, air. Initial applied $\mathrm{K}_{\mathrm{I}}=17.36 \mathrm{MPa} \sqrt{\mathrm{m}}$ 
Overall, the test results indicate that between the two alloys, the ternary alloy FA-186 has the best fracture resistance, highest fracture toughness and least sensitivity to hydrogen embrittlement. This result was quite surprising since the purpose of microalloying addition to the ternary alloy $(0.5 \% \mathrm{Zr}, 0.05 \% \mathrm{C}$ and $0.005 \% \mathrm{~B}) \mathrm{FA}-189$ is to enhance its resistance to hydrogen embrittlement.

Since hydrogen embrittlement is a diffusion-controlled process, and past studies have indicated that low strain rate loading can promote hydrogen embrittlement, the addition of $\mathrm{Zr}, \mathrm{C}$ and $\mathrm{B}$ to FA-189 may provide stronger grain boundary bonding for better fatigue resistance than the base ternary alloy FA-186. But under constant static loading condition and with smaller grain size (see Figure 3.3), at the crack-tip region, initial intergranular micro-cracks may assist the diffusion of atomic hydrogen along the grain boundaries, creating high hydrogen concentration areas and subsequently causing an accelerated dislocation motion at cleavage plans which results in a brittle fracture.

As a conclusion of the experimental results, FA-189 is extrinsically more brittle than FA-186, i.e. is most susceptible to hydrogen embrittlement, and this phenomenon, which will be further investigated using the finite element analysis, may be related to the grain boundary size effect. 


\section{CHAPTER 4}

\section{FINITE ELEMENT ANALYSIS MODEL}

\subsection{Stress Analysis Model}

All the numerical analysis and modeling of the failure of polycrystalline materials under mechanical loading and/or various environments that have been done so far can be classified into two categories. The first one is based on the continuum damage mechanics over macroscopic length scales and the second one involves micromechanics including microstructures such as inclusions and grain boundaries. These modeling techniques are mostly based on finite element analysis within their respective length scale.

In this research, a finite element model coupled with a hydrogen diffusion model is developed to simulate the intergranular crack growth due to hydrogen embrittlement. The macroscopic and microscopic finite element models were generated using the finite element software I-DEAS ${ }^{\mathrm{TM}}$. The hydrogen diffusion model and the computational modeling analyses were carried out using the commercial general-purpose finite element code $A B A Q U S{ }^{\mathrm{TM}}$ and visualized with $\mathrm{ABAQUS} \mathrm{CAE}^{\mathrm{TM}}$.

Typically, for each finite element stress analysis, the CPU time is $15 \mathrm{~min}$. and, for each finite element hydrogen diffusion calculation, the CPU time is around $30 \mathrm{~min}$.

\subsubsection{Submodeling Technique in ABAQUS}

The link between the macroscopic and microscopic scale is realized using the

submodeling technique in ABAQUS ${ }^{\mathrm{TM}}$. The concept of submodeling ${ }^{[35]}$ is to study a local part of a model based on the calculated results from a global model. 
The basic procedure is:

- Obtain a global solution using a coarse mesh.

- At the interface between the global model and local model, interpolate the nodal results of the global model to the boundary of a locally refined mesh.

- Obtain a detailed solution in the local area of interest.

A motivation for using a submodel for the area ahead of the crack-tip, where the response to the loading is deemed crucial, is that submodeling reduce analysis costs while providing detailed and more accurate near-tip stress and strain fields by using a refined mesh.

Other advantages of using submodeling are:

1) Element types may be different in the submodel compared to the global model.

- Second-order elements used in the local model and first-order elements used in the global model or vice versa.

- Solid elements may be used in the local model and shell elements used in the global, but not vice versa.

2) Materials may be different in the submodel compared with the global model.

- Locally microstructural representation and homogeneous, isotropic material representation for the global model (this research)

- Metal plasticity used in the local model and metal elasticity in the global model.

3) Procedures may be different in the submodel compared with the global model.

4) The submodeling implementation accommodates linear and nonlinear analysis. Independent analyses are performed on the global model and on the submodel and the only link is the transfer of values for the driven variables, in our case, the displacements. 


\subsubsection{Global Model}

Due to the symmetry of loading, only half of the specimen size was modeled and analyzed. Specimen geometry, nodes and elements were generated using the commercial software I-DEAS $^{\mathrm{TM}}$ and then exported to ABAQUS ${ }^{\mathrm{TM}}$ where the boundary conditions, loads and requirements for the submodel analysis are added.

The global model consists of 1744 four-node linear plane stress elements with a refined mesh in the region around the crack-tip.

The load applied is a uniform distributed load and the simulations were carried out for two values of stress intensity factor:

- $\quad \mathrm{K}_{\mathrm{I}}=17.34 \mathrm{MPa} \sqrt{\mathrm{m}}$ and the corresponding applied stress $\sigma=42.47 \mathrm{MPa}$

- $\mathrm{K}_{\mathrm{I}}=36.9 \mathrm{MPa} \sqrt{\mathrm{m}}$ and the corresponding applied stress $\sigma=90.4 \mathrm{MPa}$

Boundary conditions:

- $\quad$ The crack surface is traction free.

- $\quad$ The symmetry line is free of shear traction and displacements in the $y$ direction.

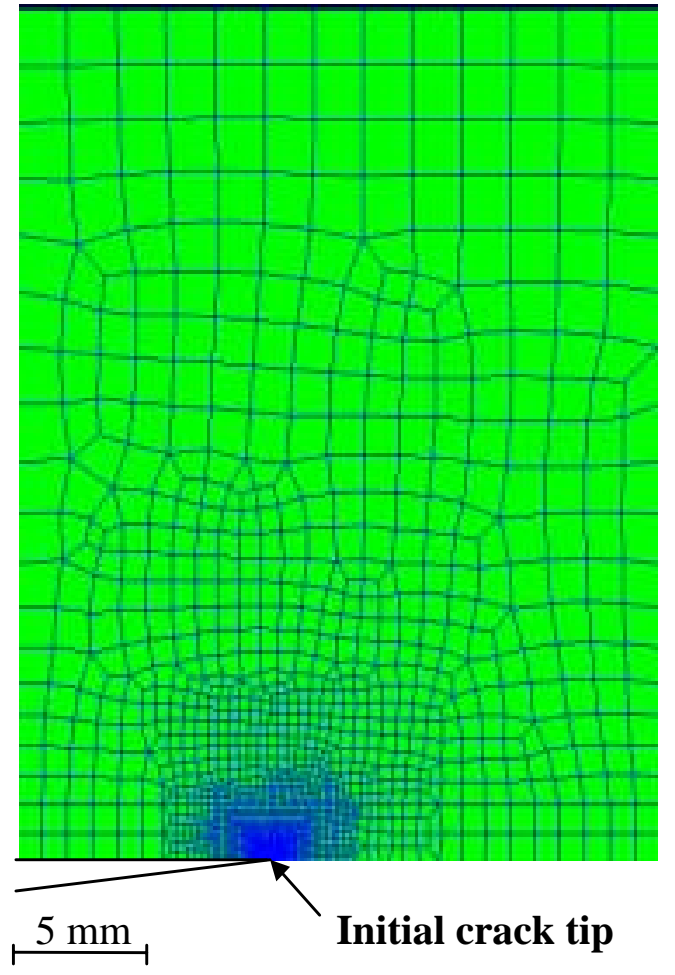

Fig. 4.1 Global Model 


\subsubsection{Submodels}

Near the crack tip region, two submodels are designed to represent qualitatively the grain size of FA-186 and FA-189, respectively. A multi-grain crack-tip cell is used in the local finite element mesh composed of a periodic array of regular hexagonal grains obtained by copying and reflecting a unit cell generated using the I-DEAS ${ }^{\mathrm{TM}}$ software as shown in Figure 4.2. The total numbers of grains for FA-186 is 48 and for FA-189 is 127. An initial intergranular crack is assumed to exist for both submodels starting from the left side of the model up to the node whose coordinate corresponds to the crack-tip coordinate. The stress analyses are carried out based on the interfacial boundary displacements which are obtained from the global FEA and then interpolated onto the boundary of the submodel.

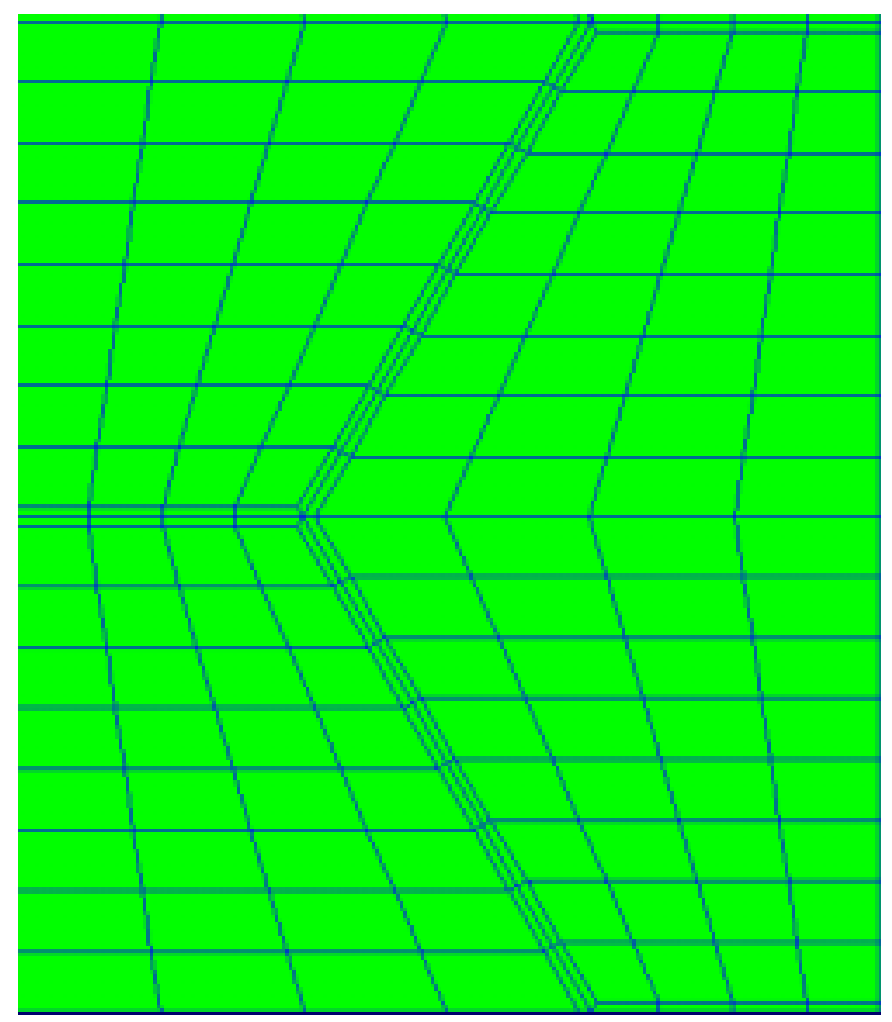

Fig.4.2 Unit Cell 
Each grain is composed of 108 quadrilateral plane stress elements and each grain boundary is simulated by 48 quadrilateral plane stress elements as shown in Figure 4.3

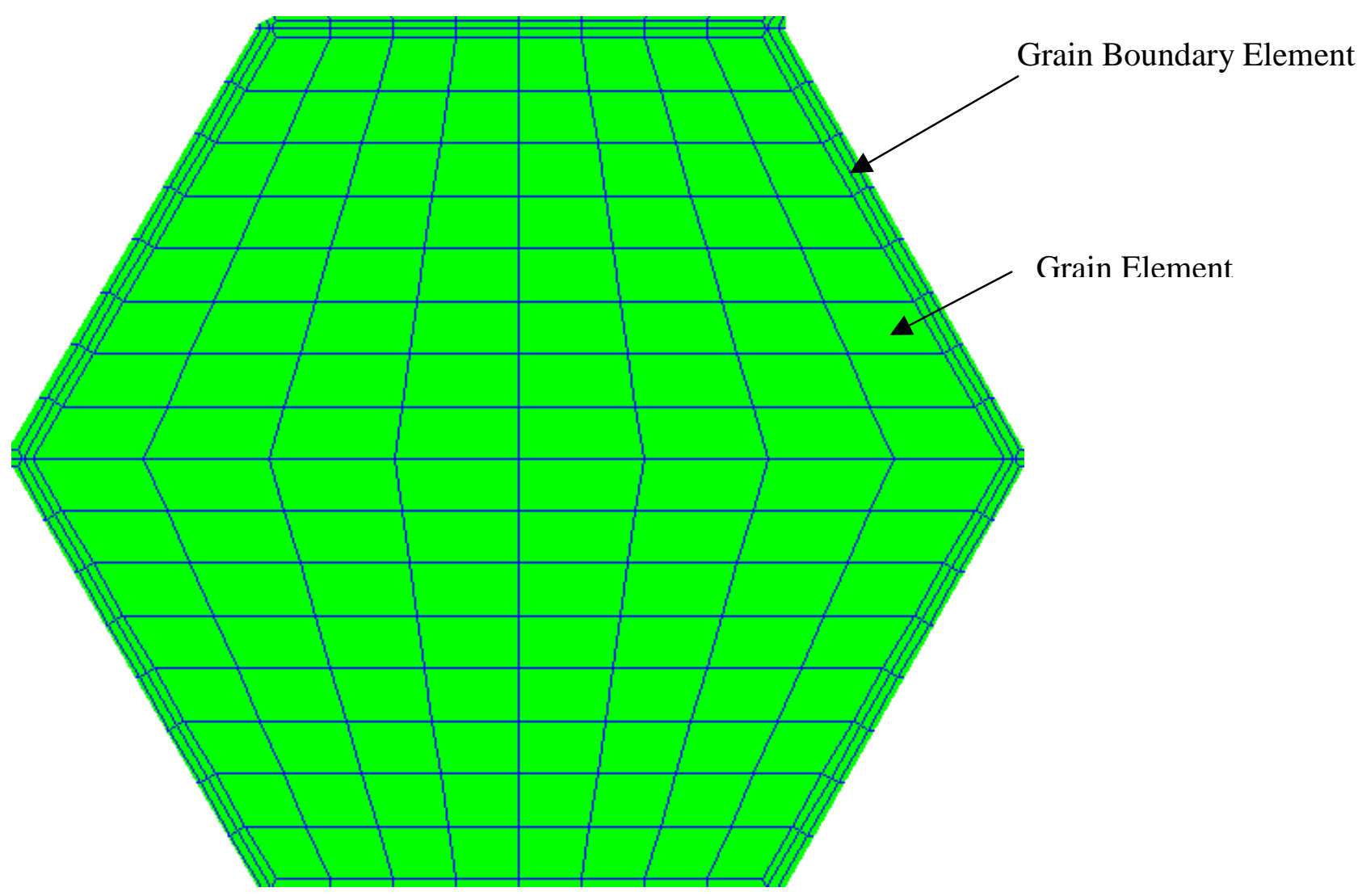

Fig. 4.3 Grain and grain boundary elements

The hexagon used in the submodel for FA-186 represents the typical grain size of $193 \mu \mathrm{m}$ and the submodel contains a total of 8,448 elements as shown in Figure 4. The hexagon used in the submodel of FA-189 represents the typical grain size of $75 \mu \mathrm{m}$ and the submodel contains a total of 22,528 elements as shown in Figure 4.5. The grain boundary is also properly represented in the submodels with assumed grain boundary thickness of $1.5 \mu \mathrm{m}$. 


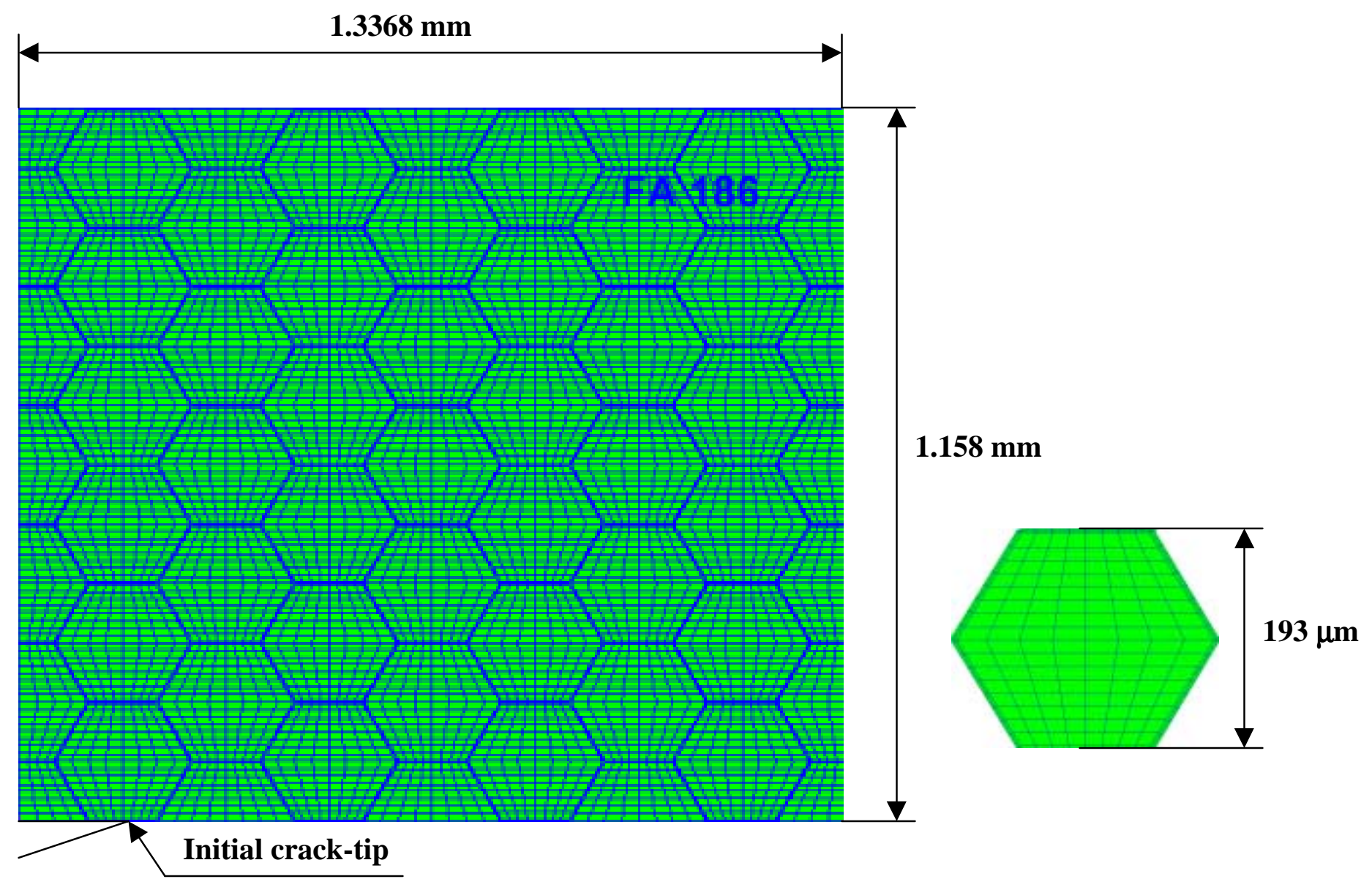

Fig. 4.4 Submodel and grain of FA-186

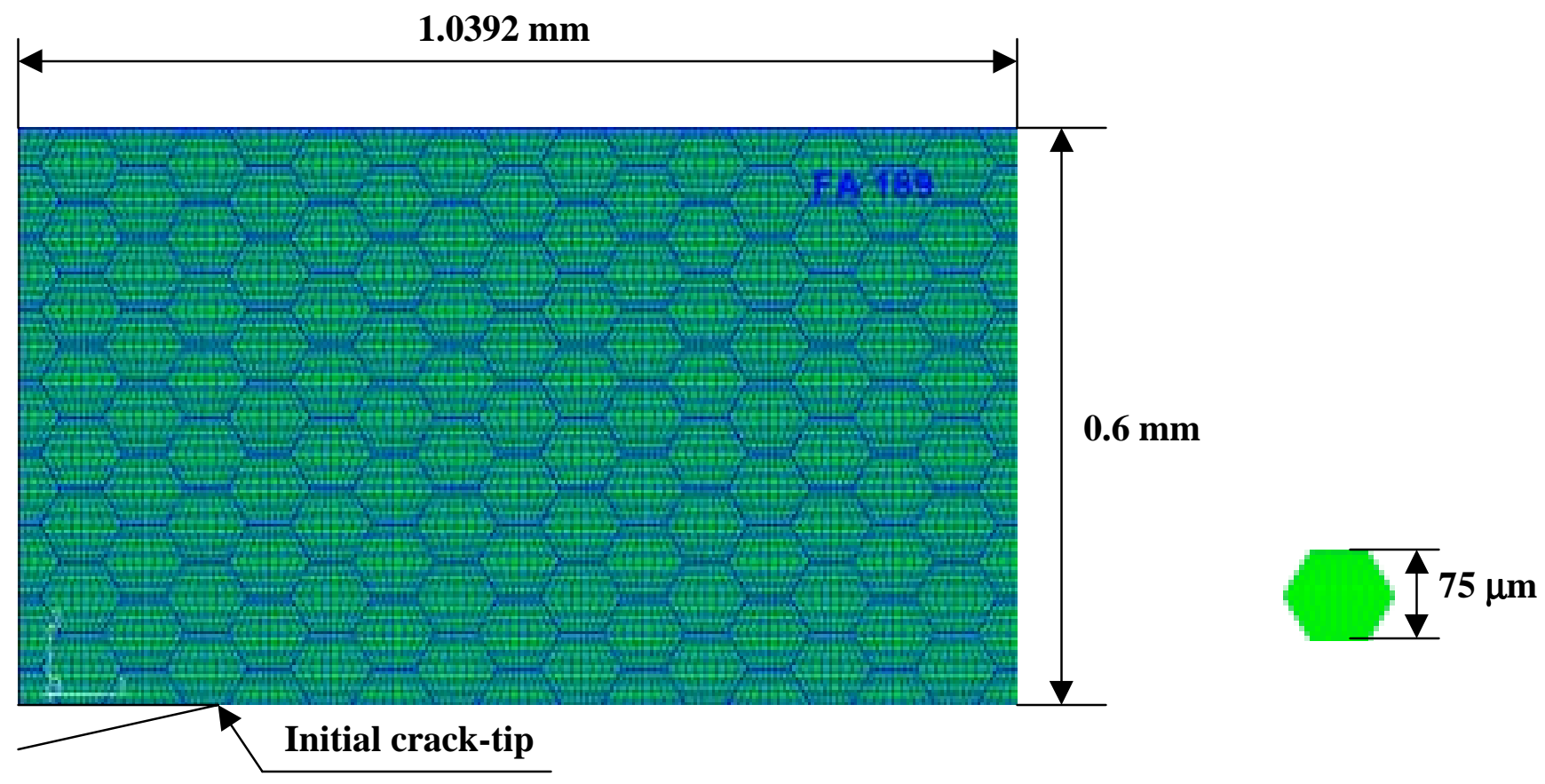

Fig. 4.5 Submodel and grain of FA-189 


\subsubsection{Micromechanics}

\section{Mechanical properties of the materials}

Young's Modulus: $\quad \mathrm{E}=1.41 \mathrm{e}+5 \mathrm{MPa}$

Poisson's Ratio: $\quad v=0.29$

The first assumption made in modeling the grains and grain boundaries was that the grain boundary is weaker than the matrix and, thus it's Young's modulus must be smaller than that of the matrix.

The second assumption made in order to carry the comparative analyses of FA186 and FA-189 is based on the fact that the addition of small amount of boron in FA189 was to improve the bonding strength of grain boundaries. Accordingly, it was considered that the Young's modulus value of the FA-189 grain boundary is larger than that of FA-186 grain boundary. Thus,

$$
\begin{aligned}
& \mathrm{E}_{\mathrm{GB}(\mathrm{FA}-186)}=40 \% \mathrm{E}_{\text {matrix }}=40 \% * 1.41 \mathrm{E}+5=0.564 \mathrm{E}+5 \mathrm{MPa} \\
& \mathrm{E}_{\mathrm{GB}(\mathrm{FA}-189)}=70 \% \mathrm{E}_{\text {matrix }}=70 \% * 1.41 \mathrm{E}+5=0.987 \mathrm{E}+5 \mathrm{MPa}
\end{aligned}
$$

The third basic assumption was needed to be able to replace the heterogeneous material in the submodels (with two different Young's modulus values for matrix and grain boundaries) by a homogenization procedure based on rule of mixture (ROM) to satisfy compatibility of displacements of submodel and global model.

$\mathrm{E}$ submodel $=\mathrm{E}$ matrix $\mathrm{V}$ matrix $+\mathrm{E}_{\mathrm{GB}} \mathrm{V}_{\mathrm{GB}}$, where:

E submodel represents the equivalent value of the overall effective Young's modulus of the submodel and it should have the same value as the Young's modulus of the global model . 
E matrix represents the Young's modulus value of the matrix or grains

$\mathrm{E}_{\mathrm{GB}}$ represents the Young's modulus value of the grain boundaries

$\mathrm{V}$ matrix represents the volume fraction of the matrix in the submodel

$\mathrm{V}_{\mathrm{GB}}$ represents the volume fraction of the grain boundaries in the submodel

The ROM formula can be written in terms of area fractions because the thickness

is considered the same, that is the thickness of the specimen $t=2.7 \mathrm{~mm}$

$$
\text { E submodel }=\mathrm{E} \text { matrix A matrix }+\mathrm{E}_{\mathrm{GB}} \mathrm{A}_{\mathrm{GB}} \text {, where: }
$$

A matrix (Area of grain elements / Total Area) is the area fraction of grains

$\mathrm{A}_{\mathrm{GB}}$ (Area of grain boundaries / Total Area ) is the area fraction of grain boundaries

The results obtained for the E matrix for FA-186 and respectively for FA-189 are presented in Table 4.

\begin{tabular}{|c|c|c|c|c|c|c|}
\hline Alloy & $\begin{array}{c}\text { Total Area of } \\
\text { Submodel }\end{array}$ & $\begin{array}{c}\text { Area of Grain } \\
\text { Boundaries } \\
\left(\mathrm{mm}^{2}\right)\end{array}$ & $\begin{array}{c}\text { Area Fraction } \\
\left(\mathrm{mm}^{2}\right)\end{array}$ & $\begin{array}{c}\mathrm{E}_{\mathrm{GB}} \\
(\mathrm{MPa})\end{array}$ & $\begin{array}{c}\mathrm{E}_{\text {Global }} \\
(\mathrm{MPa})\end{array}$ & $\begin{array}{c}\mathrm{E}_{\text {matrix }} \text { new } \\
(\mathrm{MPa})\end{array}$ \\
\hline FA-186 & 1.5054 & 0.064 & $4.25 \%$ & $0.564 \mathrm{E}+5$ & $1.41 \mathrm{E}+5$ & $1.447 \mathrm{E}+5$ \\
\hline FA-189 & 0.62352 & 0.05 & $8 \%$ & $0.987 \mathrm{E}+5$ & $1.41 \mathrm{E}+5$ & $1.443 \mathrm{E}+5$ \\
\hline
\end{tabular}

Table 4. Material properties

Figures 4.6 and 4.7 show the superposed contour plots of principal strains and stresses of the global model and the submodel. Also, displacement values of boundary nodes of global and local models, at different stages of analyses, are tabulated in the Appendix B. 


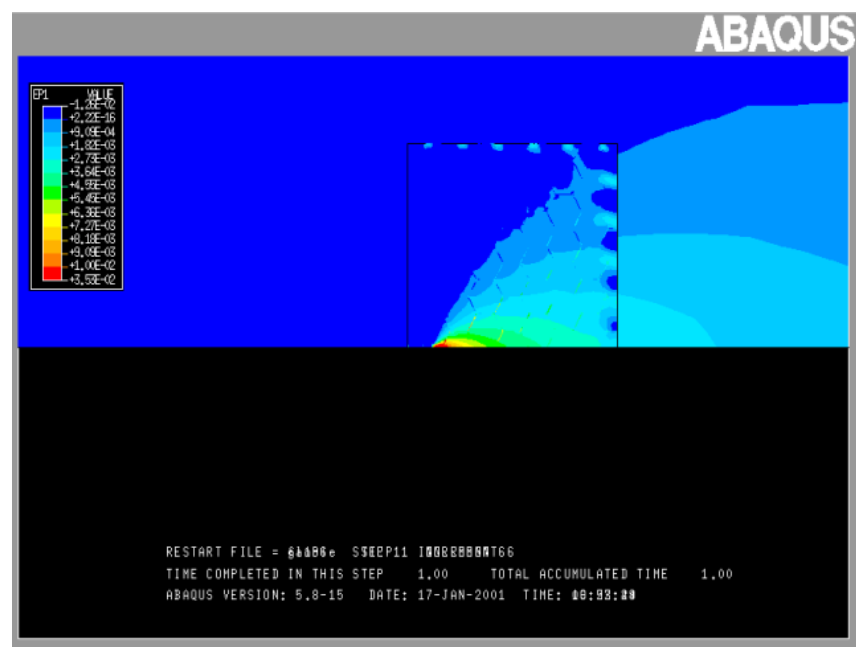

(a)

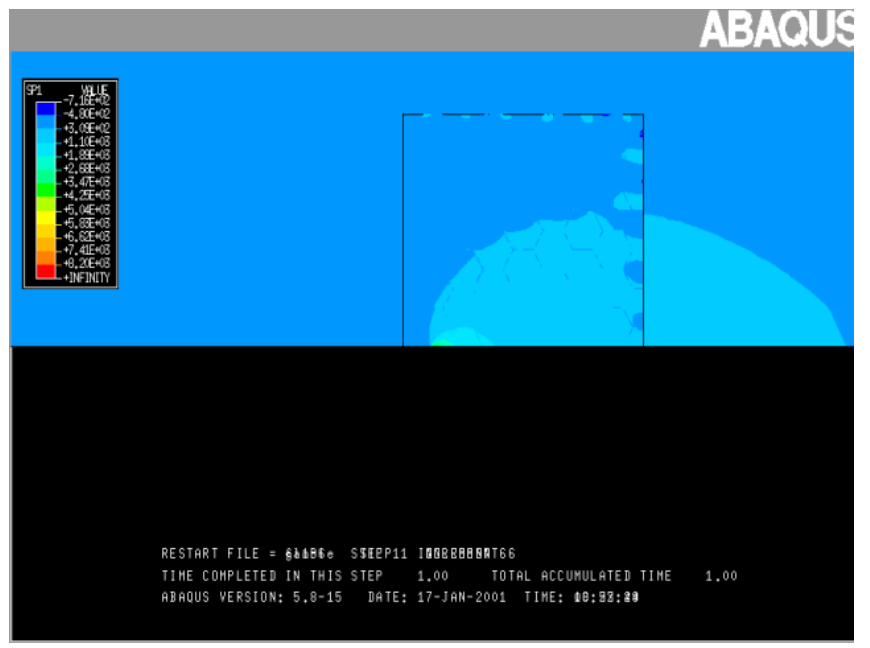

(b)

Fig. 4.6 Superposed contour plots of global model and submodel of FA-186:

(a) principal strain

(b) principal stress

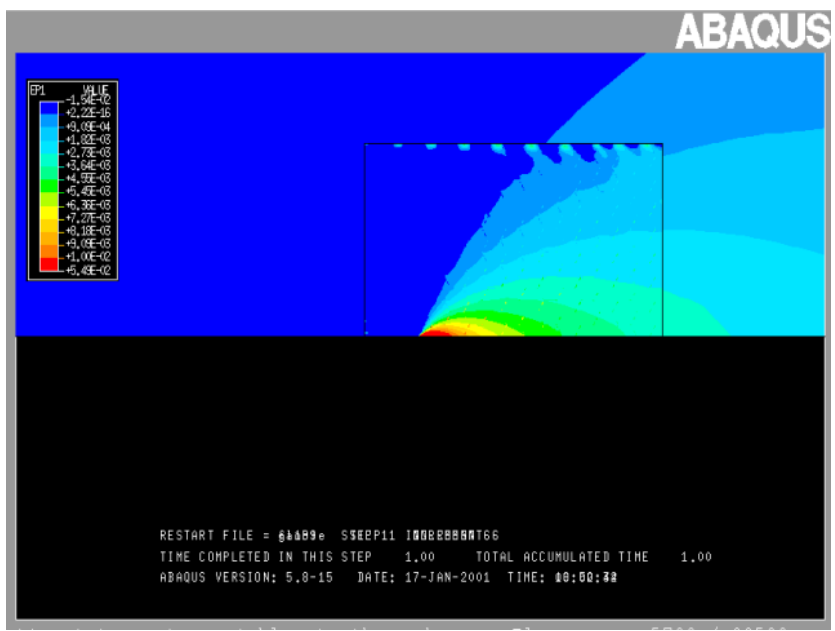

(a)

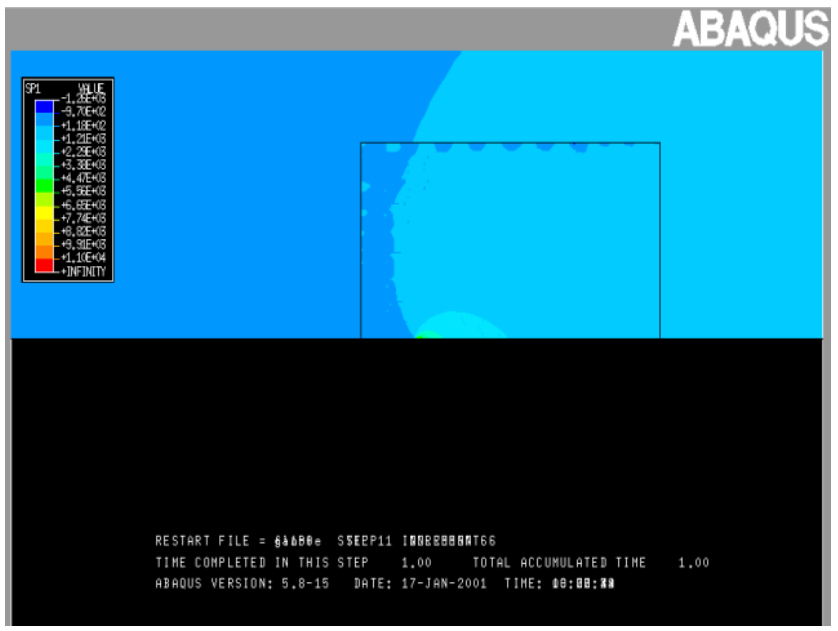

(b)

Fig. 4.7 Superposed contour plots of global model and submodel of FA-189:
(a) principal strain
(b) principal stress 


\subsection{Stress-assisted Hydrogen Diffusion Model}

\subsubsection{Hydrogen in Iron}

Hydrogen as an interstitial solute poses fundamental questions of interest. Hydrogen is the lightest and smallest of solute elements, yet has a significant partial atomic volume in nearly all metals. It is extraordinary mobile, especially in iron and other body-centered cubic elements. Although the metal-hydrogen research and technical literature is extensive, an understanding of the effects of hydrogen on the mechanical properties, remains at a phenomenological level ${ }^{[36]}$.

If we consider a perfect crystal equilibrated with hydrogen gas at $300 \mathrm{~K}$ and one atmosphere pressure the lattice solubility of hydrogen in iron is about one hydrogen atom for every $10^{7}$ or $10^{8}$ atoms of iron. Further, the hydrogen atom is remarkably mobile; the lattice diffusion coefficient is about $8^{*} 10^{-9} \mathrm{~m}^{2} / \mathrm{s}$. In this conditions it is remarkable that hydrogen can exert such a deleterious effect on the mechanical properties of metals. In a steel or iron base alloy hydrogen is not homogeneous distributed, as it would be the case in a perfect iron crystal. Hydrogen will be found not only in the host lattice, but also segregated to atomic and microstructural imperfections such as grain boundaries. Thus, the apparent solubility, or total concentration, may be greater than the lattice solubility.

\subsubsection{The Role of Hydrostatic Stress in Hydrogen Embrittlement}

Since Troiano ${ }^{[37]}$ put forward the hypothesis that hydrogen-induced cracking (HIC) would take place in the highest triaxially stressed region ahead of a crack tip, a considerable number of investigations have pivoted about whether or not HIC depends on the hydrostatic stress ${ }^{[38]}$. 
According to Troiano's suggestion ${ }^{[37]}$, HIC would most likely occur in a dilatant region with elevated hydrostatic tension stress, $\sigma_{\mathrm{ii}} / 3$, ahead of the crack tip.

The concept of an elastic interaction between the hydrostatic pressure (or the volumetric component of a crack-tip stress tensor) and the dilatation associated with an interstitial hydrogen atom has been discussed before by Oriani ${ }^{[39]}$ and by Liu ${ }^{[40]}$ who performed an analysis of the hydrostatic pressure field of a crack under mode $I$ loading coupled with Fick's first law of diffusion. Thus, the localized stress-field in the crack-tip region creates hydrogen concentrations via "up-hill" diffusion that can be considered higher than those away from the crack-tip ${ }^{[41]}$. For the simple case of spherical-hydrogen, the enhanced hydrogen concentration by $\sigma \mathrm{ii} / 3$ in the region has been shown to follow Boltzman statistics ${ }^{[42]}$.

$$
C_{H}=C_{0} \exp \left\{\frac{\sigma_{i i} V_{H}}{3 R T}\right\}
$$

where $\mathrm{C}_{0}$ is the initial concentration and $\mathrm{V}_{\mathrm{H}}$ is the partial molar volume of hydrogen.

The localization of hydrogen atoms can be explained by the effect of stress on the chemical potential of hydrogen atoms.

Regions of hydrostatic stress are regions of low chemical potential and thus diffusion of hydrogen atoms will occur to this region, thereby raising the local concentration of hydrogen atoms. At steady-state the local chemical potential will be that of hydrogen atoms in the bulk material since the system would come to an equilibrium but the local hydrogen atom concentration would be elevated in relation to the surrounding unstressed material ${ }^{[25]}$. 


\subsubsection{Governing equations used for the hydrogen diffusion model}

The governing equations for hydrogen diffusion used in $\mathrm{ABAQUS}{ }^{\mathrm{TM}}$ are an extension of Fick's equations: they allow for nonuniform solubility of the diffusing substance in the base material and for hydrogen diffusion driven by the gradient of pressure as discussed in section 4.2.2.

In $\mathrm{ABAQUS}^{\mathrm{TM}}$ the basic solution variable (used as the degree of freedom at the nodes of the mesh) is the " normalized concentration" (often also referred to as the “activity" of the diffusing material) defined by:

$$
\phi=C / S
$$

where $C$ is the mass concentration of the diffusing hydrogen and,

$S$ is its solubility in the base material.

This variable was chosen because the mesh includes dissimilar materials, that is different Young's modulus values for grains and grain boundaries. In this case the normalized concentration is continuous across the interface between the grain and grain boundary. For example, a diatomic gas that dissociates during diffusion can be described by Sievart's law:

$$
C=S \otimes P^{1 / 2}
$$

where $P$ is the partial pressure of the hydrogen gas.

Combining Sievart's law with the definition of normalized concentration given earlier, $\phi=C / S=P^{1 / 2}$ 
Equilibrium requires the partial pressure to be continuous across an interface, so normalized concentration should be continuous as well.

Generally, mass diffusion behavior is described by Fick's law (Crank,1956):

$$
J=-D \cdot \frac{\partial C}{\partial x}
$$

where $J$ is the flux of concentration of the hydrogen gas and,

$D$ is the diffusivity

Fick's law is offered in ABAQUS ${ }^{\mathrm{TM}}$ as a special case of the general chemical potential relation. To establish the relationship between Fick's law and the general chemical potential, ABAQUS ${ }^{\mathrm{TM}}$ writes Fick's law as:

$$
J=-D \cdot\left(S \frac{\partial \phi}{\partial x}+\phi \frac{\partial S}{\partial x}\right)
$$

An extended form of Fick's law was also chosen taking into account the pressure stress factor, $K_{p}$, providing diffusion driven by the gradient of equivalent pressure stress.

$$
J=-D \cdot\left(\frac{\partial C}{\partial x}+S K p \frac{\partial p}{\partial x}\right)
$$

Stress-assisted diffusion of hydrogen is specified by defining the pressure stress factor, $K_{p}$, as

$$
K_{P}=\frac{\bar{V}_{H} \phi}{R\left(\theta-\theta^{z}\right)}
$$

where $R=8.31432 \mathrm{~J} / \mathrm{molK}$ is the universal gas constant

$V_{H}=2.0 \times 10^{3} \mathrm{~mm}^{3} / \mathrm{mol}$ is the partial molar volume of hydrogen in iron - based metals 
$\Phi$ is the normalized concentration

$\theta$ is the temperature in degrees Celsius and

$\theta^{z}=-273$ is the absolute temperature

The analytical solution for normalized concentration, presented by Liu (1970) and used by $\mathrm{ABAQUS}{ }^{\mathrm{TM}}$ has the form

$$
\phi=\phi_{0} \exp \left(-\frac{V_{H}^{-} p}{R\left(\theta-\theta^{z}\right)}\right)
$$

where $\phi_{0}$ is the normalized concentration obtained in the unstressed state and

$p$ is the equivalent pressure stress.

For the region immediately ahead of the crack, linear elastic fracture mechanics yields the analytical solution for equivalent pressure stress ${ }^{[35]}$ :

$$
p=-\frac{K_{I}(1+v)}{\sqrt{2 \pi r}}-\frac{(1+v) \sigma}{3}
$$

where $K_{I}=\sigma \sqrt{\pi a}$ is the stress intensity factor for a Mode I crack of length $a$ and $\sigma$ is the externally applied distributed load.

This solution dictates that for a crack-tip problem, the concentration follows the singularity of the stresses. Thus, the contours of constant pressure stress should be contours of constant concentration, as indicated by the analytical solution above. 
In this research a sequentially coupled hydrogen diffusion analysis was carried out to determine crack-tip stress state and the extent of hydrogen diffusion at the crack tip region. The sequentially coupled hydrogen diffusion consists of a static stress analysis of the submodels, followed by a hydrogen diffusion analysis.

Equivalent pressure stresses from the static analysis of submodel FA-186 and FA-189, are written to the results file as nodal averaged values.

Subsequently, these pressures are read during the course of hydrogen diffusion analysis to provide a driving force for hydrogen diffusion analysis.

\subsubsection{Material properties related to the hydrogen diffusion model}

According to Völkl and Alefeld (1978) a good estimation of the diffusion constant is given by

$$
D=2.10 \times 10^{-7} \frac{m^{2}}{s} \exp \left(-\frac{6.88 \mathrm{kJmol}^{-1}}{R T}\right)
$$

where $\mathrm{R}=8.31 \mathrm{~J} / \mathrm{molK}$ universal constant of gases and $\mathrm{T}=300 \mathrm{~K}$

Thus, as diffusivity : $\quad \mathrm{D}=0.01329 \mathrm{~mm}^{2} / \mathrm{s}$

The hydrogen stress free equilibrium solubility as a function of environmental pressure and temperature is given by Sievart's law for temperature of interest, that is $\mathrm{T}=300 \mathrm{~K}$,as

$$
S=1.989 \times 10^{26} \sqrt{P} \exp \left(-\frac{\Delta H_{S}}{R T}\right),
$$

where $S$ is the solubility expressed in atoms of $\mathrm{H}_{2}$ gas(under normal conditions of

$$
\text { pressure and temperature) per } \mathrm{m}^{3} \text { of iron }
$$

$P$ is the hydrogen pressure in atmospheres and 
$\Delta \mathrm{H}_{\mathrm{S}}=28.6 \mathrm{~kJ} / \mathrm{mol}$ (Hirth, 1980) is the heat of solution

For normal conditions of pressure, $P=1$ atm of hydrogen gas at $T=300 \mathrm{~K}$, the solubility of hydrogen gas in iron was found:

$$
S=2.08 \times 10^{21} \text { atoms of } \mathrm{H}_{2} / \mathrm{m}^{3} \text { of iron }
$$

Knowing that: (i) the density of iron is $\rho=7.87 \times 10^{3} \mathrm{~kg} / \mathrm{m}^{3}$ at $300 \mathrm{~K}$ and (Smithells Metals Reference Book, 1992) and (ii) the atomic weight $\mathrm{A}=55.8 \times 10^{-3} \mathrm{~kg} / \mathrm{mol}$ at $300 \mathrm{~K}$ (Smithells Metals Reference Book, 1992)

the number of atoms per cubic meter can be computed as $\mathrm{N}=8.4643 \times 10^{28}$ at.iron $/ \mathrm{m}^{3}$ Thus, the solubility of hydrogen gas in iron can be expressed in terms of Sievart's law , as shown in ABAQUS ${ }^{\mathrm{TM}}$, as

$$
\mathrm{S}=0.0778 \text { parts per million } / \mathrm{mmN}^{-1 / 2}
$$

\subsubsection{Boundary conditions}

The specimen is maintained at a constant temperature of $\mathrm{T}=300 \mathrm{~K}$ (or in ABAQUS ${ }^{\mathrm{TM}}$ formulation $\theta-\theta^{\mathrm{z}}=300 \mathrm{~K}$ ) throughout the analysis.

Under the initial steady-state conditions the specimen and subsequently the submodels have a uniform concentration as dictated by Sievart's law:

$$
C=P^{1 / 2} \times S=0.024 \mathrm{ppm}
$$

The crack surface is assumed to be "open" and to allow equilibration with the hydrogen gas, such that the dominant process will be the transport of hydrogen from the crack tip. The crack surface is also assumed to be traction free, as shown in Figure 4.8. 


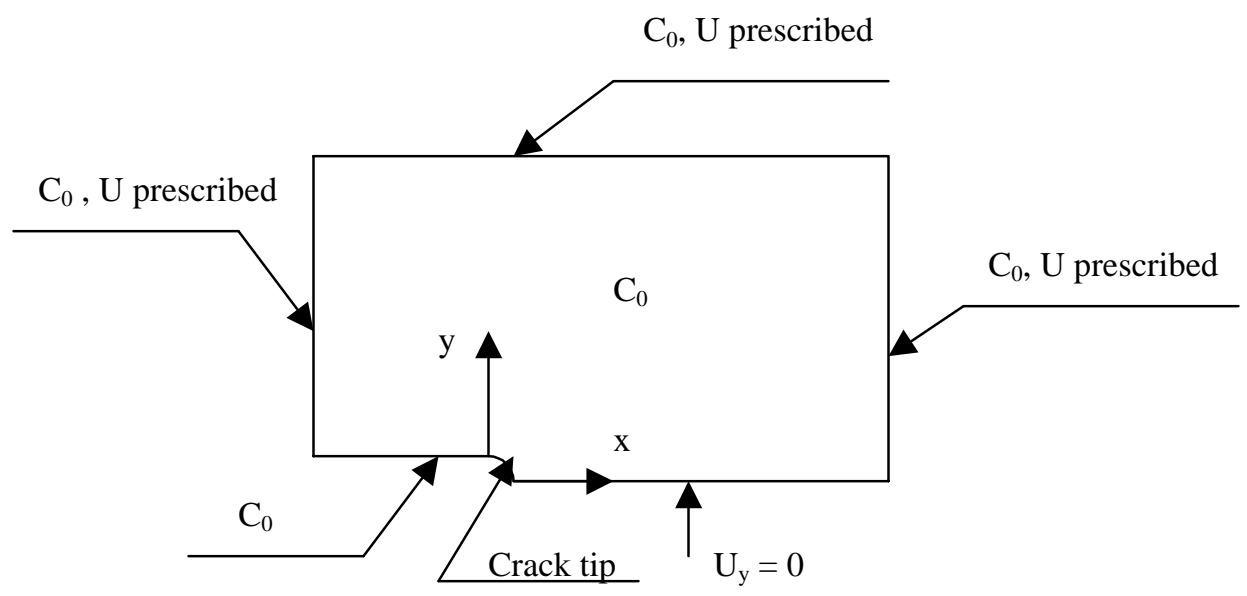

Fig. 4.8 Boundary conditions

\section{Steady state analysis}

Steady state hydrogen diffusion analysis provides the steady -state solution directly: the rate of change of concentration with respect to time is omitted from the governing diffusion equations in steady-state analysis.

\subsection{Steps of Simulating Intergranular Fracture Due to Hydrogen Embrittlement}

\section{Simulations in Air}

(1) Finite element stress/strain analysis of the global model,

(2) Finite element stress/strain analysis of the submodel at the crack-tip region,

(3) Steady state hydrogen diffusion analysis based on the hydrogen diffusion model coupled with the results from (2),

(4) Degrade the material properties in the high hydrogen concentration zone,

(5) Finite element stress/strain analysis (similar to steps (1) and (2)),

(6) Apply maximum principal strain failure criterion and simulate intergranular crack growth, 
(7) Go to step 1 and repeat the cycle.

\section{Simulations in Vacuum}

(1) Finite element stress/strain analysis of the global model,

(2) Finite element stress/strain analysis of the submodel at the crack-tip region,

(3) Apply maximum principal strain failure criterion and simulate intergranular crack growth,

(4) Go to step 1 and repeat the cycle.

Overall this is a quasi-statically simulation because no time-dependence is involved either in the static analyses or the diffusion analyses.

In order to compare the fracture behavior of these two iron aluminides and then to compare with the experimental results related to fracture path and to maximum principal strain distribution, several simulations have been carried out at two values of stress intensity factors both for FA-186 and FA-189, in air and in vacuum. Finite element simulations of the fracture paths in air for both FA-186 and FA-189 are conducted and the results are compared to the fracture paths from the experimental results. The proper failure strains for each of the two iron aluminides are assumed, i.e. failure strain for FA-186 is $4 \%$ and the failure strain for FA-189 is $6 \%$. These assumptions were based also on the fact that, adding a small amount of boron in FA-189 was to improve the strength of the grain boundaries, therefore the failure strain for FA189 should be larger than that of FA-186.

Using the same failure strains, 4\% for FA-186 and 6\% for FA-189, the next step is to run the same simulations, for the same $\mathrm{K}_{\mathrm{I}}$ values but in vacuum. The vacuum 
simulations were needed in order to evaluate the intrinsically fracture behavior of the two iron aluminides. Further details of finite element analysis steps:

(1) a static stress analysis of the global model is carried out to determine the nodal displacements used to drive the local solutions.

(2) a static stress analysis of the submodel is carried out to obtain the hydrostatic stresses needed do drive the hydrogen diffusion model .

(3) a hydrogen diffusion analysis is carried out in order to determine the areas of high hydrogen concentrations.

(4) Material degradation is assumed to occur at the stress-assisted hydrogen concentration region. Accordingly, the material property (Young's modulus in this analysis) is reduced both at the matrix and grain boundary region.

In the hydrogen embrittlement model, which relates the reduction of the material properties to the concentration of the hydrogen diffusing gas, the following formula was adopted:

\begin{tabular}{|l|l|}
\hline Normalized concentration ratio & \% of reduction of Young's modulus \\
\hline 1 to 3 & $20 \%$ \\
\hline 3 to 6 & $30 \%$ \\
\hline 6 to 10 & $40 \%$ \\
\hline 10 to 15 & $50 \%$ \\
\hline
\end{tabular}

Table 5. Reduction of Young's modulus 
(5) a new static analysis of the submodel is carried out, but using the modified Young's modulus values for the grains and grain boundaries affected by the hydrogen diffusion. New stress state is thus determined.

(6) The maximum principal strain failure criterion is applied and the intergranular crack growth is simulated.

The breaking of the grain boundary is realized by doubling the nodes shared by two grain boundary elements and then assigning one node to an element and the other to the other element.

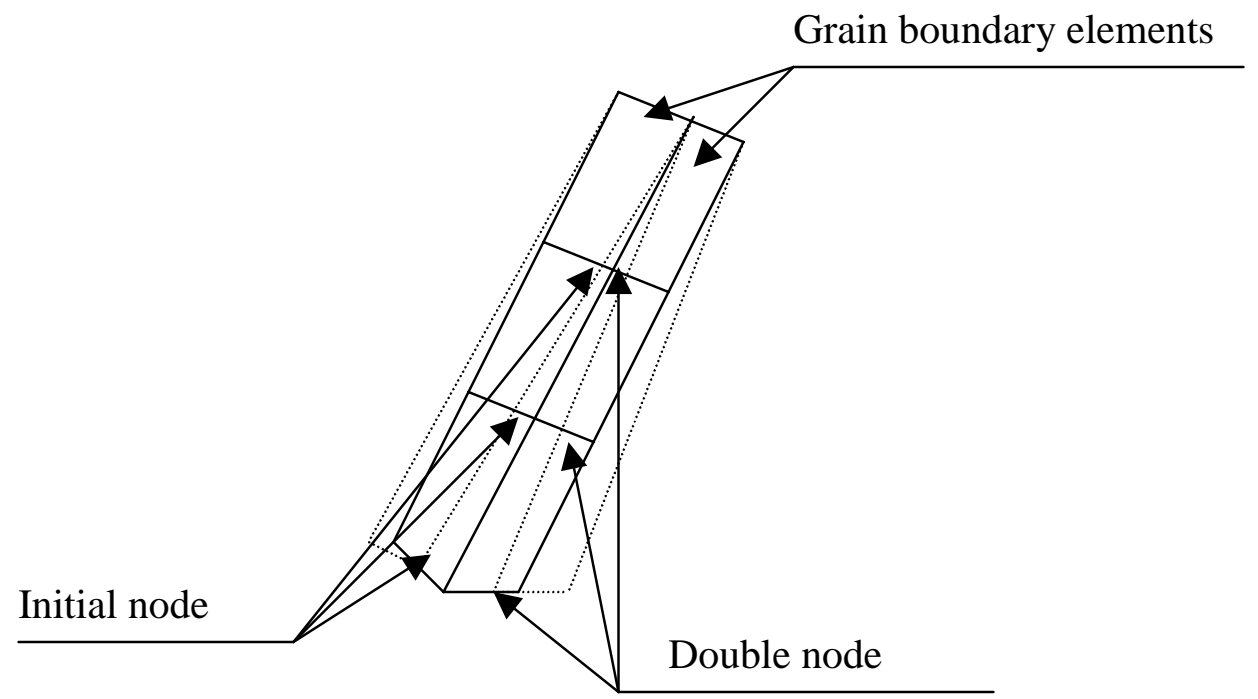

Fig.4.9 Schematic intergranular crack growth simulation

Represents the coherent grain boundary

Represents the separated grain boundary after intergranular fracture

(7) The same simulations are repeated with updated crack length and material property of the global model elements corresponding to the submodel area in order to satisfy the compatibility of the displacements at the boundary region. This is done at every 4 steps at which the new Young's modulus of the submodel is determined based on the rule of mixture approach and the modified material properties of grains and grain boundaries . 
Tables with model validity checks for FA-189 and FA-186 in vacuum and in air are presented in Appendix B.

For example,

- $\quad$ after the $7^{\text {th }}$ step of FA-189 in air, $\mathrm{K}_{\mathrm{I}}=17.36 \mathrm{MPa} \sqrt{\mathrm{m}}$, the following changes in the submodel are :

- $\mathrm{G} 1=722$ grain elements from $\mathrm{E}=1.443 \mathrm{E}+5$ to $\mathrm{E}_{\mathrm{G} 1}=1.29 \mathrm{E}+5 \mathrm{MPa}$

- $\mathrm{G} 2=346$ grain elements from $\mathrm{E}=1.443 \mathrm{E}+5$ to $\mathrm{E}_{\mathrm{G} 2}=1.035 \mathrm{E}+5 \mathrm{MPa}$

- $\mathrm{G} 3=336$ grain elements from $\mathrm{E}=1.443 \mathrm{E}+5$ to $\mathrm{E}_{\mathrm{G} 3}=0.909 \mathrm{E}+5 \mathrm{MPa}$

- $\quad \mathrm{B} 1=176$ grain boundary elements from $\mathrm{E}=0.987 \mathrm{E}+5$ to $\mathrm{E}_{\mathrm{B} 1}=0.888 \mathrm{E}+5 \mathrm{MPa}$

- $\quad \mathrm{B} 2=125$ grain boundary elements from $\mathrm{E}=0.987 \mathrm{E}+5$ to $\mathrm{E}_{\mathrm{B} 2}=0.71 \mathrm{E}+5 \mathrm{MPa}$

- $\quad \mathrm{B} 3=57$ grain boundary elements from $\mathrm{E}=0.987 \mathrm{E}+5$ to $\mathrm{E}_{\mathrm{B} 3}=0.62 \mathrm{E}+5 \mathrm{MPa}$

Then, the rule of mixture was applied to compute the new $\mathrm{E}$ of the submodel knowing that : Area of one grain element $=3.5 \mathrm{E}-5 \mathrm{~mm}^{2}$

Area of one grain boundary element $=7.953 \mathrm{E}-6 \mathrm{~mm}^{2}$

Total Area $=0.62352 \mathrm{~mm}^{2}$

Total number of grain elements $=16384$

Total number of grain boundary elements $=6272$

Total number of elements modified in global model: 104

Crack growth in global model : $0.08 \mathrm{~mm}$ ( 4 nodes )

Rule of Mixture:

E new submodel $=(\mathrm{A}$ unchanged matrix $/ \mathrm{A}) \mathrm{E}$ matrix $+\left(\mathrm{A}_{\mathrm{G} 1} / \mathrm{A}\right) \mathrm{E}_{\mathrm{G} 1}+\left(\mathrm{A}_{\mathrm{G} 2} / \mathrm{A}\right) \mathrm{E}_{\mathrm{G} 2}$ $+\left(\mathrm{A}_{\mathrm{G} 3} / \mathrm{A}\right) \mathrm{E}_{\mathrm{G} 3}+\left(\mathrm{A}_{\mathrm{B} 1} / \mathrm{A}\right) \mathrm{E}_{\mathrm{B} 1}+\left(\mathrm{A}_{\mathrm{B} 2} / \mathrm{A}\right) \mathrm{E}_{\mathrm{B} 2}+\left(\mathrm{A}_{\mathrm{B} 3} / \mathrm{A}\right) \mathrm{E}_{\mathrm{B} 3}+(\mathrm{A}$ unchanged $\mathrm{GB} / \mathrm{A}) \mathrm{E}_{\mathrm{GB}}$ E new submodel $=1.3817 \mathrm{E}+5 \mathrm{MPa}$ 
- $\quad$ after the $23^{\text {rd }}$ step of FA-189 in air, $\mathrm{K}_{\mathrm{I}}=17.36 \mathrm{MPa} \sqrt{\mathrm{m}}$, the following changes in the submodel are :

- $\mathrm{G} 1=640$ grain elements from $\mathrm{E}=1.443 \mathrm{E}+5$ to $\mathrm{E}_{\mathrm{G} 1}=0.7 \mathrm{E}+5 \mathrm{MPa}$

- $\mathrm{G} 2=1395$ grain elements from $\mathrm{E}=1.443 \mathrm{E}+5$ to $\mathrm{E}_{\mathrm{G} 2}=0.8 \mathrm{E}+5 \mathrm{MPa}$

- $\quad \mathrm{B} 1=168$ grain boundary elements from $\mathrm{E}=0.987 \mathrm{E}+5$ to $\mathrm{E}_{\mathrm{B} 1}=0.5 \mathrm{E}+5 \mathrm{MPa}$

- $\quad \mathrm{B} 2=125$ grain boundary elements from $\mathrm{E}=0.987 \mathrm{E}+5$ to $\mathrm{E}_{\mathrm{B} 2}=0.6 \mathrm{E}+5 \mathrm{MPa}$

At this stage a total number of 2035 grain elements and 442 grain boundary elements were changed, yielding a new E value for the submodel:

E new submodel $=1.3246 \mathrm{E}+5 \mathrm{MPa}$

Updated crack length in global model $=0.2 \mathrm{~mm}$ (corresponding to 10 nodes)

- $\quad$ after the $48^{\text {th }}$ step of FA-189 in air, $\mathrm{K}_{\mathrm{I}}=17.36 \mathrm{MPa} \sqrt{\mathrm{m}}$, the following changes in the submodel are:

- $\mathrm{G} 1=3360$ grain elements from $\mathrm{E}=1.443 \mathrm{E}+5$ to $\mathrm{E}_{\mathrm{G} 1}=0.67 \mathrm{E}+5 \mathrm{MPa}$

- $\mathrm{G} 2=2027$ grain elements from $\mathrm{E}=1.443 \mathrm{E}+5$ to $\mathrm{E}_{\mathrm{G} 2}=0.78 \mathrm{E}+5 \mathrm{MPa}$

- $\quad \mathrm{B} 1=744$ grain boundary elements from $\mathrm{E}=0.987 \mathrm{E}+5$ to $\mathrm{E}_{\mathrm{B} 1}=0.45 \mathrm{E}+5 \mathrm{MPa}$

- $\quad \mathrm{B} 2=1248$ grain boundary elements from $\mathrm{E}=0.987 \mathrm{E}+5$ to $\mathrm{E}_{\mathrm{B} 2}=0.56 \mathrm{E}+5 \mathrm{MPa}$

At this stage a total number of 5387 grain elements and 1992 grain boundary elements were changed, yielding a new E value for the submodel:

E new submodel $=1.21 \mathrm{E}+5 \mathrm{MPa}$

Updated crack length in global model $=0.56 \mathrm{~mm}$ (corresponding to 16 nodes)

All the boundary displacements for submodel and global model were checked for these examples and they are shown in Appendix B. Also, a schematic illustration of these changes is shown in Figure 4.10. 


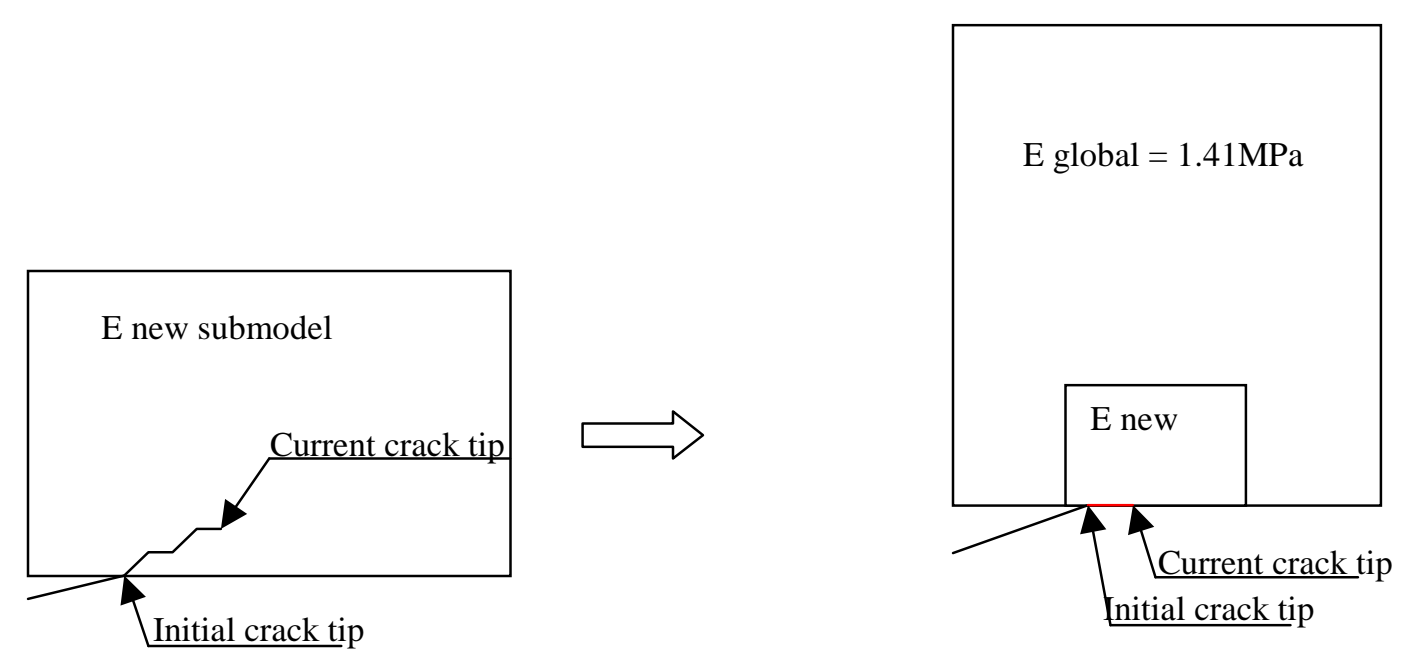

Fig. 4.10 Submodel and corresponding adjusted global model 


\section{CHAPTER 5}

\section{RESULTS AND DISCUSSIONS}

Table 3 shows the finite element simulation matrix. As shown a total of 12 comparative

finite element simulations under vacuum and air were carried out in this research.

Table 6. Finite element simulation matrix

\begin{tabular}{|c|c|c|c|c|}
\hline $\begin{array}{l}\text { Stress } \\
\text { Intensity } \\
\text { Factor,K }\end{array}$ & $\begin{array}{l}\text { Failure } \\
\text { Strain }\end{array}$ & Environment & $\begin{array}{c}\text { Fracture behavior } \\
\text { FA } 186\end{array}$ & $\begin{array}{l}\text { Fracture } \\
\text { behavior } \\
\text { FA } 189\end{array}$ \\
\hline \multirow{4}{*}{$\mathrm{K}=17.3 \mathrm{MPa} \sqrt{\mathrm{m}}$} & \multirow[t]{2}{*}{$4 \%$} & Vacuum & $\begin{array}{l}\text { Slow and straight } \\
\text { Stopped after } 0.6 \mathrm{~mm}\end{array}$ & $\begin{array}{l}\text { Very slow } \\
\text { Blunting effect } \\
\text { Stopped after } \\
0.51 \mathrm{~mm}\end{array}$ \\
\hline & & Air & $\begin{array}{l}\text { Very slow and straight, } \\
\text { Stopped after } 0.63 \mathrm{~mm}\end{array}$ & $\begin{array}{l}\text { Straight crack } \\
\text { growth after } 0.4 \\
\text { mm it changed } \\
\text { to multiple } \\
\text { cracking }\end{array}$ \\
\hline & \multirow[t]{2}{*}{$6 \%$} & Vacuum (5\%) & $\begin{array}{l}\text { Slow and straight } \\
\text { Stopped after } 0.376 \mathrm{~mm}\end{array}$ & $\begin{array}{l}\text { Stopped } \\
\text { immediately } \\
\text { after } 0.0325 \\
\text { mm } \\
\text { Almost no } \\
\text { crack growth }\end{array}$ \\
\hline & & Air & No growth & $\begin{array}{l}\text { Straight crack } \\
\text { extension }\end{array}$ \\
\hline \multirow{4}{*}{$\mathrm{K}=36.9 \mathrm{MPa} \sqrt{\mathrm{m}}$} & \multirow[t]{2}{*}{$4 \%$} & Vacuum & $\begin{array}{l}\text { Wide spread micro-cracks } \\
\text { growth relatively fast and } \\
\text { stopped after } 1.08 \mathrm{~mm}\end{array}$ & \\
\hline & & Air & $\begin{array}{l}\text { Wide spread initial micro- } \\
\text { cracks; more pronounced } \\
\text { blunting effect, quicker } \\
\text { stress redistribution, } \\
\text { expanding damage zone } \\
\text { growth }\end{array}$ & \\
\hline & \multirow[t]{2}{*}{$6 \%$} & Vacuum & $\begin{array}{l}\text { Slow and straight, } \\
\text { blunting effect, } \\
\text { stopped after } 0.89 \mathrm{~mm}\end{array}$ & $\begin{array}{l}\text { Crack grows } \\
\text { straight and } \\
\text { stops after } 0.56 \\
\text { mm }\end{array}$ \\
\hline & & Air & $\begin{array}{l}\text { Less initial micro- } \\
\text { cracks(comparing to } 4 \% \text { ) } \\
\text { and less initial crack tip } \\
\text { blunting }\end{array}$ & \\
\hline
\end{tabular}


Figures 5.1 and 5.2 show the maximum principal strain distribution and intergranular crack growth of FA-186 in vacuum, $\mathrm{K}_{\mathrm{I}}=17.36 \mathrm{MPa} \sqrt{\mathrm{m}}$, with failure strain either $4 \%$ or 5\%. Figures 5.3 and 5.4 show the maximum principal strain distribution and intergranular crack growth of FA-186 in vacuum, $\mathrm{K}_{\mathrm{I}}=36.9 \mathrm{MPa} \sqrt{\mathrm{m}}$, with failure strain either $4 \%$ or $6 \%$. Figures 5.5 shows the sequence of hydrogen diffusion zone, maximum principal strain distribution and intergranular crack growth of FA-186 in air, $\mathrm{K}_{\mathrm{I}}=17.36$ $\mathrm{MPa} \sqrt{ }$, with failure strain $4 \%$. Figures 5.6 and 5.7 show the sequence of hydrogen diffusion zone, maximum principal strain distribution and intergranular crack growth of FA-186 in air, $\mathrm{K}_{\mathrm{I}}=36.9 \mathrm{MPa} \sqrt{\mathrm{m}}$, with failure strain either $4 \%$ or $6 \%$.

Figures 5.8 and 5.9 show the maximum principal strain distribution and intergranular crack growth of FA-189 in vacuum, $\mathrm{K}_{\mathrm{I}}=17.36 \mathrm{MPa} \sqrt{\mathrm{m}}$, with failure strain either $6 \%$ or 4\%. Figure 5.10 shows the maximum principal strain distribution and intergranular crack growth of FA-189 in vacuum, $\mathrm{K}_{\mathrm{I}}=36.9 \mathrm{MPa} \sqrt{\mathrm{m}}$, with failure strain of $6 \%$.

Figures 5.11 and 5.12 show the hydrogen diffusion zone, maximum principal strain distribution and intergranular crack growth of FA-189 in air, $\mathrm{K}_{\mathrm{I}}=17.36 \mathrm{MPa} \sqrt{\mathrm{m}}$, with failure strain either $6 \%$ or $4 \%$.

Appendix A shows the experimental maximum principal strain distribution for FA186, air, $\mathrm{K}_{\mathrm{I}}=36.9 \mathrm{MPa} \sqrt{\mathrm{m}}, \mathrm{t}=0 \mathrm{~min}$ and $\mathrm{t}=5 \mathrm{~min}$ and the experimental maximum principal strain distribution for FA-189, air, $\mathrm{K}_{\mathrm{I}}=17.36 \mathrm{MPa} \sqrt{\mathrm{m}}, \mathrm{t}=0 \mathrm{~min}, \mathrm{t}=2.5 \mathrm{~min}, \mathrm{t}$ $=3.5 \mathrm{~min}, \mathrm{t}=4.5 \mathrm{~min}$. 
From the comparison between experimental results and finite element simulations in air of FA-189 at $\mathrm{K}_{\mathrm{I}}=17.36 \mathrm{MPa} \sqrt{\mathrm{m}}$ and FA-186 at $\mathrm{K}_{\mathrm{I}}=36.9 \mathrm{MPa} \sqrt{\mathrm{m}}$, the selections of $6 \%$ failure strain for FA-189 and 4\% failure strain for FA-186 showed good correlation. As shown in Table 6 and Figure 5.5, for FA-186 in air, $\mathrm{K}_{\mathrm{I}}=17.36 \mathrm{MPa} \sqrt{\mathrm{m}}$, the results indicate small maximum principal strain distribution at the crack tip region (all are below 6\%) and thus small amount of crack growth is predicted. However, if the applied stress intensity factor is increased to $\mathrm{K}_{\mathrm{I}}=36.9 \mathrm{MPa} \sqrt{\mathrm{m}}$, a much larger and wider hydrogen diffusion zone and maximum principal strain distribution are noted, i.e. hydrogen diffused everywhere in the submodel and the concentrations are four times higher than in the previous case. By selecting $6 \%$ as the failure strain, less initial microcracks are observed, leading to a smaller damage zone, as shown in Figure 5.7. If a lower value of failure strain is selected, say $4 \%$, multiple cracks can be initiated, as indicated in step 1 of Figure 5.6, which will lead to an expanding damage zone, which was observed in the experimental results (see Appendix A). Also, at the low stress intensity factor, experimental results showed for FA-189 a straight and continuous crack growth, which correlates very well to the finite element result for FA-189 in air using $6 \%$ as failure strain (see Fig.5.11) while at $4 \%$ strain, the initial single crack changed to multiple cracking. (see Fig. 5.12)

The above assessment may be justified, as discussed in chapter 4, with the assumption that, comparing to FA-189, the ternary alloy FA-186 has a weaker grain boundary cohesive strength. 
The intrinsic fracture behavior of FA-186 and FA-189 can be verified using the finite element simulations in vacuum, where there is no degrading of the material properties caused by hydrogen embrittlement.

As shown in Table 6 and Figures 5.8, 5.9 and 5.1, 5.2 the results in vacuum indicate almost no crack growth for FA-189 (crack grew for $0.0325 \mathrm{~mm}$ and stopped) comparative to a slow and straight crack growth of FA-186 (crack grew for $0.6 \mathrm{~mm}$ and then stopped) under the same conditions of load and environment $\left(\mathrm{K}_{\mathrm{I}}=17.36 \mathrm{MPa} \sqrt{\mathrm{m}}\right)$. Almost the same behavior is noted at high stress intensity factor, $\mathrm{K}_{\mathrm{I}}=36.9 \mathrm{MPa} \sqrt{\mathrm{m}}$, when FA-189 shows a crack growth for $0.56 \mathrm{~mm}$ and FA-186 shows wide spread microcracks which will stop after 1.08 mm.(see Fig.5.10 and Fig.5.3)

From all these results it can be concluded that FA-189 intrinsically has better fracture resistance comparing to FA-186, especially at high stress intensity factors.

If these two iron aluminides are studied from an extrinsic point of view, subjected to a hydrogen or moisture environment, interesting results can be noted from the diffusion analyses. As shown in Figures 5.11 and 5.5, the hydrogen diffusion zone is larger for FA-189 than for FA-186 and in the same time the hydrogen concentration level is almost 3 times higher at the crack-tip region of FA-189 than that at the crack-tip region of FA186(maximum normalized concentration for FA-189 is 4.69 and for FA-186 is 1.688).

This could be a reason for the faster crack growth rate of FA-189 in air observed during the experiment and it may be related to grain boundary size effect. Note that the grain size of FA-189 is almost 3 times larger than that of FA-186. 
According to the experimental results, the ternary alloy FA-186 tested in air showed some small amount of crack growth, which correlates well with the finite element predictions behavior where crack stopped after $0.63 \mathrm{~mm}$ crack extension.

This was not the case for FA-189 alloy which showed a fast crack growth in air and a clear single crack growth pattern as predicted by the finite element simulation in air, $\mathrm{K}_{\mathrm{I}}=$ 17.36 MPa $\sqrt{\mathrm{m}}$ (see Fig.5.11). The same clear fracture path was obtained by processing the original moiré fringe pattern and plotting the maximum principal strain distribution ahead of the crack-tip with crack growth (see Appendix A).

For alloy FA-186 tested in air at $\mathrm{K}_{\mathrm{I}}=36.9 \mathrm{MPa} \sqrt{\mathrm{m}}$ the test results indicate that multiple cracks were formed as soon as the initial crack started to grow (e.g. Appendix A). The extension of these multiple micro-cracks formed an expanding damage zone, which grew slowly leading to the catastrophic failure. This feature of extensive initial micro-cracks and large hydrogen affected area was found in the stress/strain and diffusion analyses carried out for FA-186 in air at the same stress intensity factor (e.g.Fig.5.6) and also in the sequence of maximum principal strain distributions obtained from the original moiré fringe patterns. (see Appendix A)

Overall the numerical modeling analyses validated the assertion that grain boundary morphology plays an important role on the extrinsic fracture behavior of iron aluminides in the presence of hydrogen embrittlement. The finite element predictions showed good agreement with experimental results concluding that the ternary alloy FA-186 has the best fracture resistance, highest fracture toughness and least sensitivity to hydrogen embrittlement. For FA-189, because of its small grain size, it is extrinsically more susceptible to hydrogen embrittlement than FA-186 under low strain loading condition. 
However, intrinsically, FA-189 has higher fracture toughness than that of FA-186 due to the addition of small amount of boron which improved the grain boundary cohesive strength.

It should also be noted that in the absence of direct experimental measurements of the diffusivity of grain boundaries it was used the same value as the diffusivity of matrix. It was also used the diffusivity and solubility of hydrogen in iron, but these values should be considered approximate because no definitive data related to iron aluminides appears in the literature. 


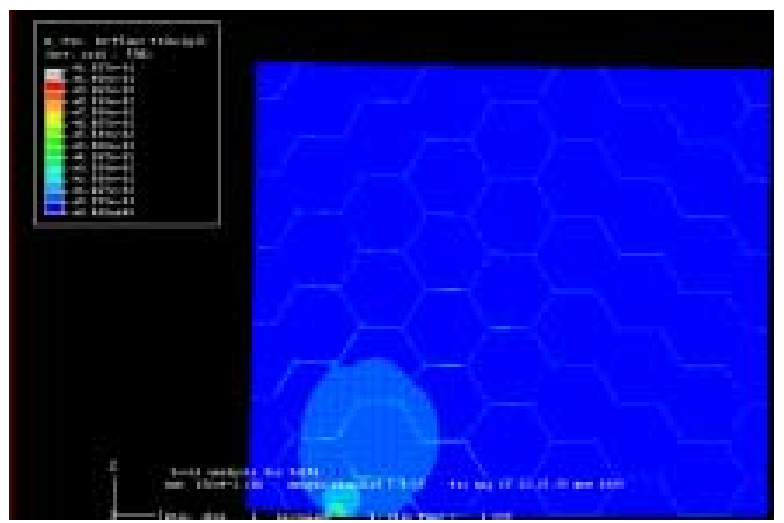

Principal strain distribution, step1

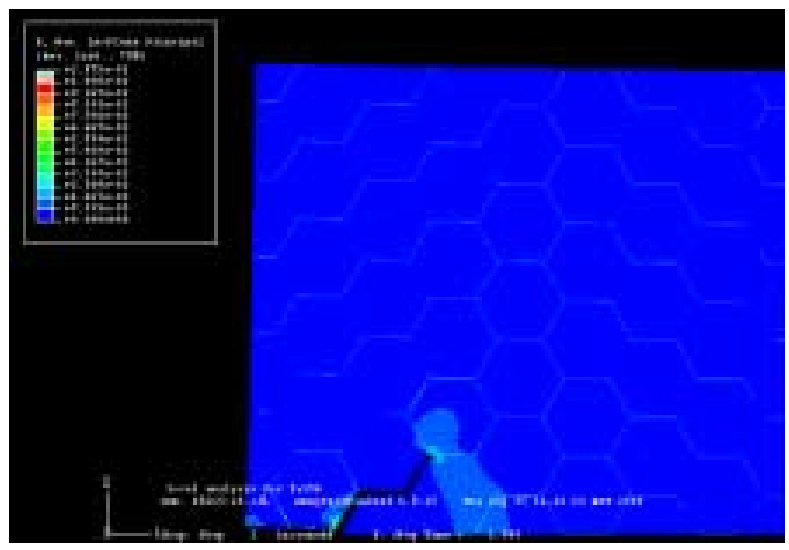

Principal strain distribution, step15

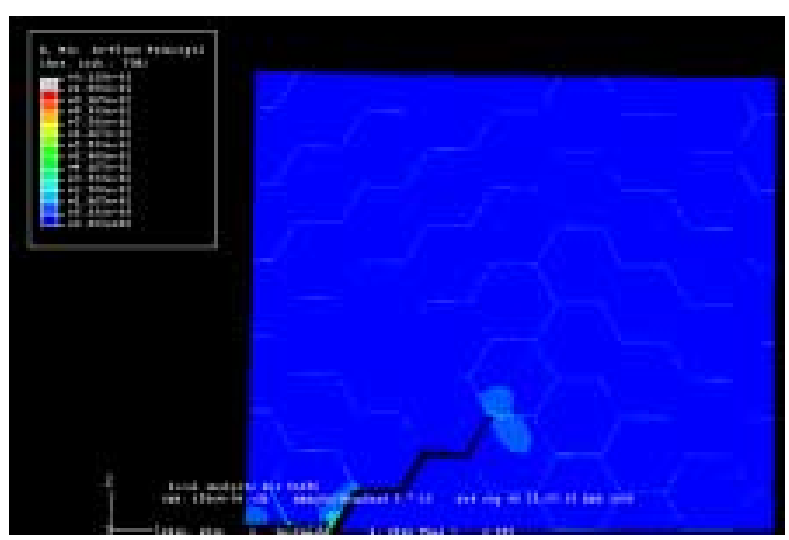

Principal strain distribution, step29

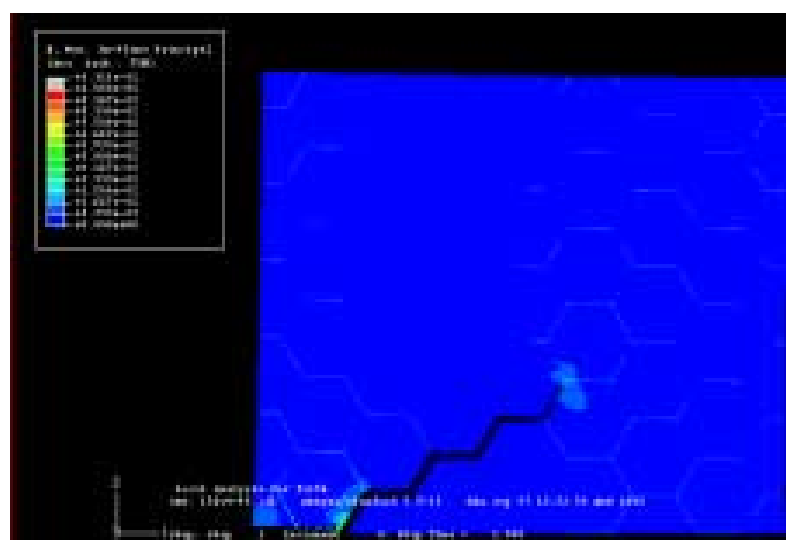

Principal strain distribution, step43 (stopped)

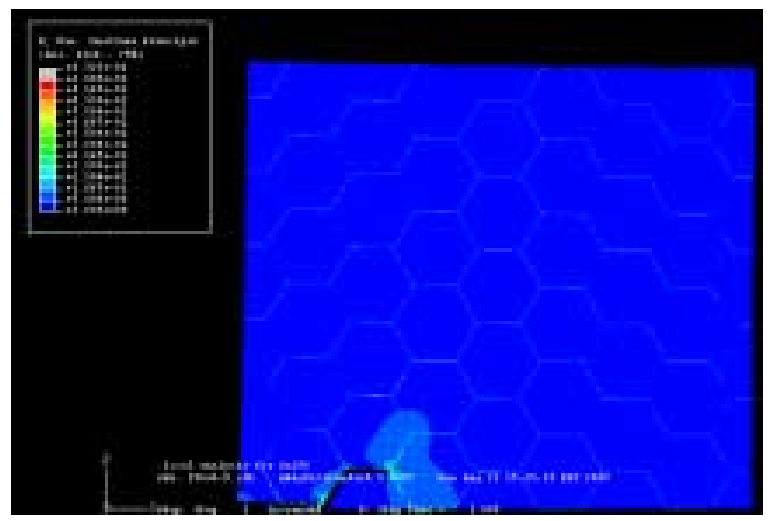

Principal strain distribution, step8

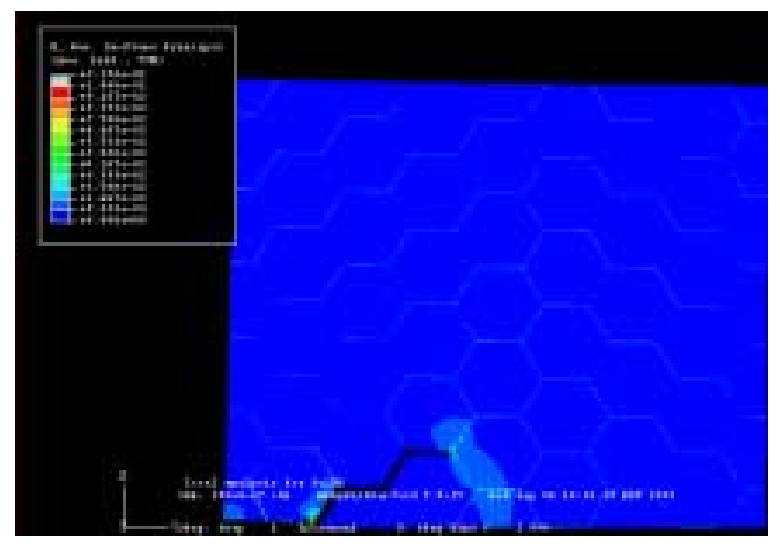

Principal strain distribution, step22

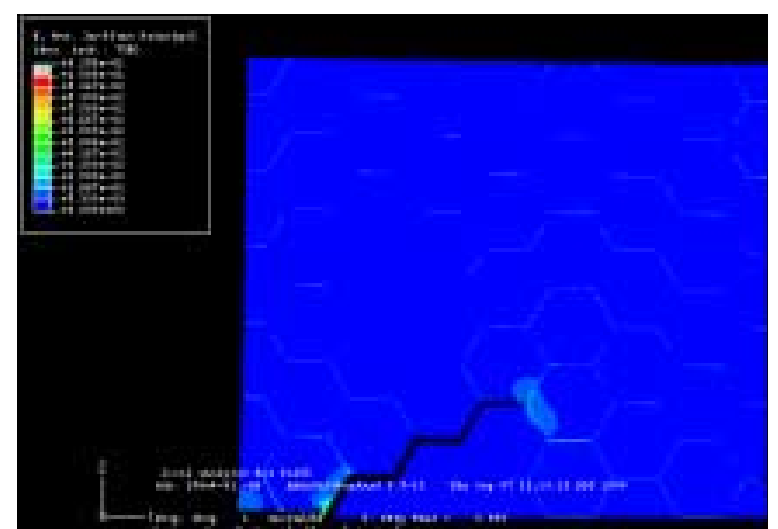

Principal strain distribution, step36

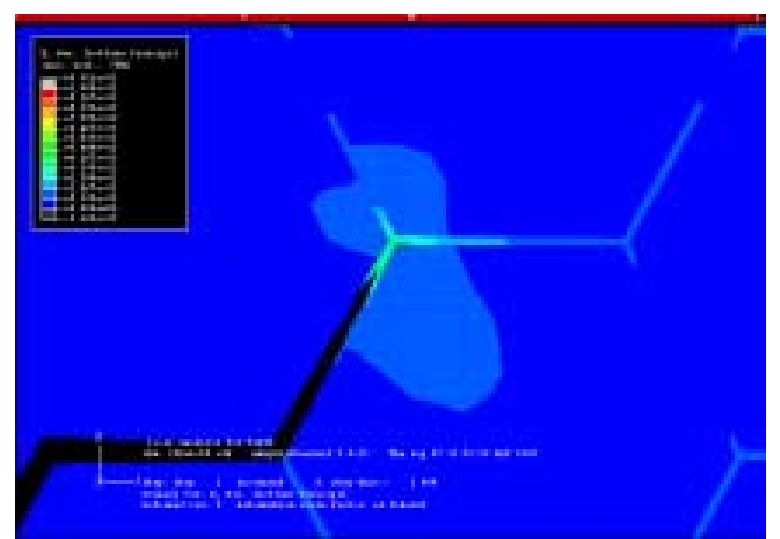

Step 43, detail

Fig. 5.1 Principal strain distribution for FA-186, $\mathrm{K}_{\mathrm{I}}=17.36 \mathrm{MPa} \sqrt{ } \mathrm{m}$, Vacuum, failure strain $4 \%$ 


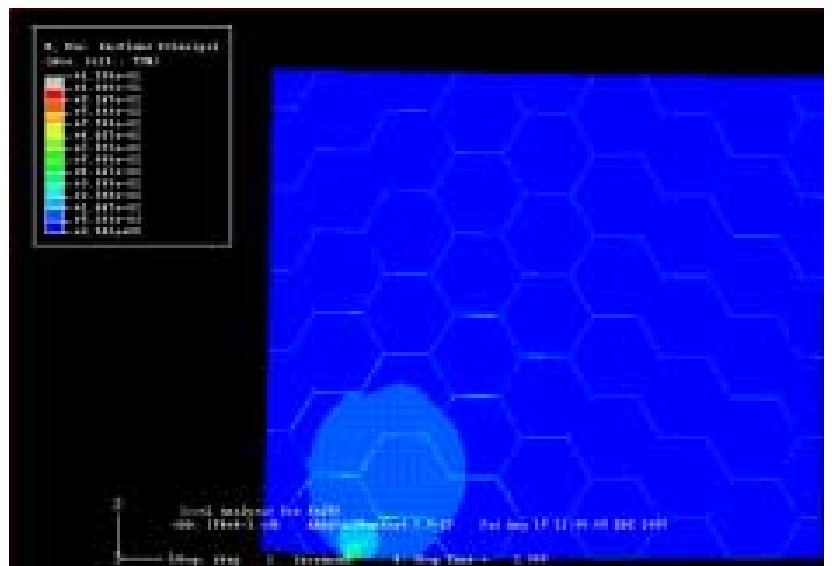

Principal strain distribution, step 1

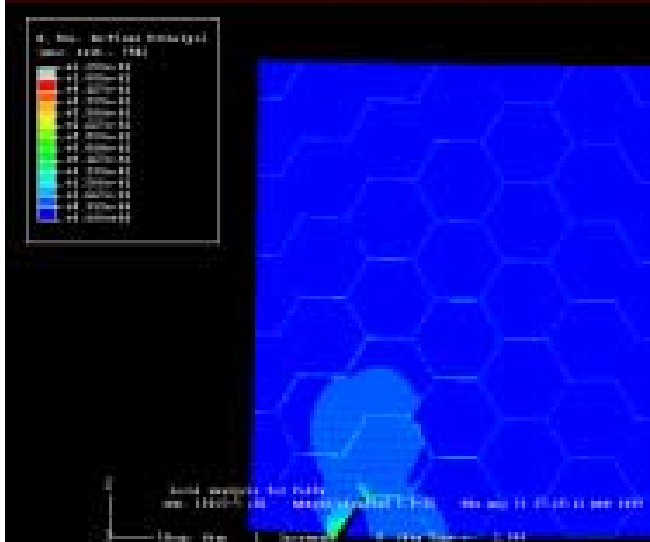

Principal strain distribution, step 7

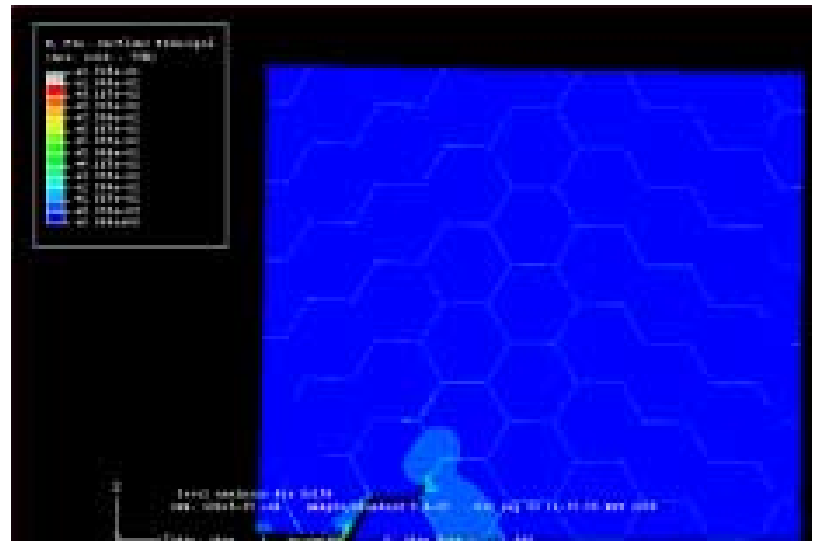

Principal strain distribution, step 15

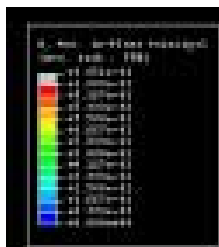

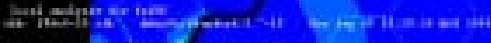

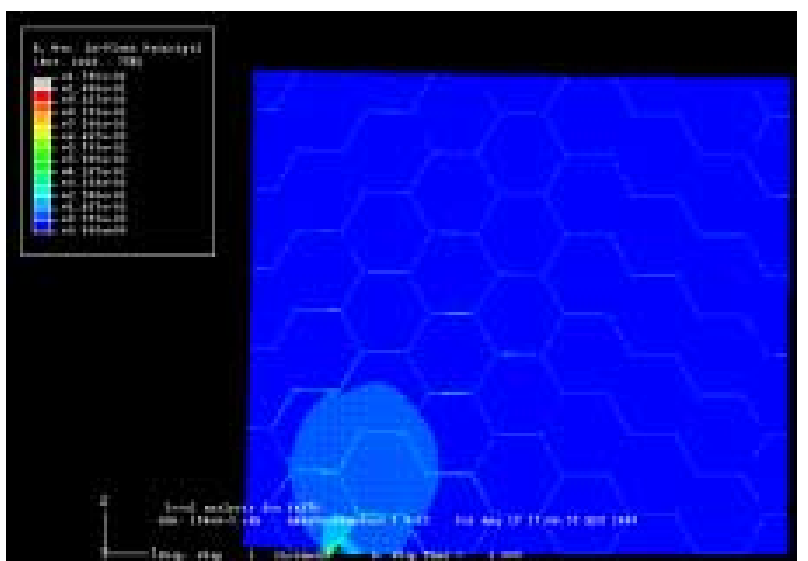

Principal strain distribution, step 3

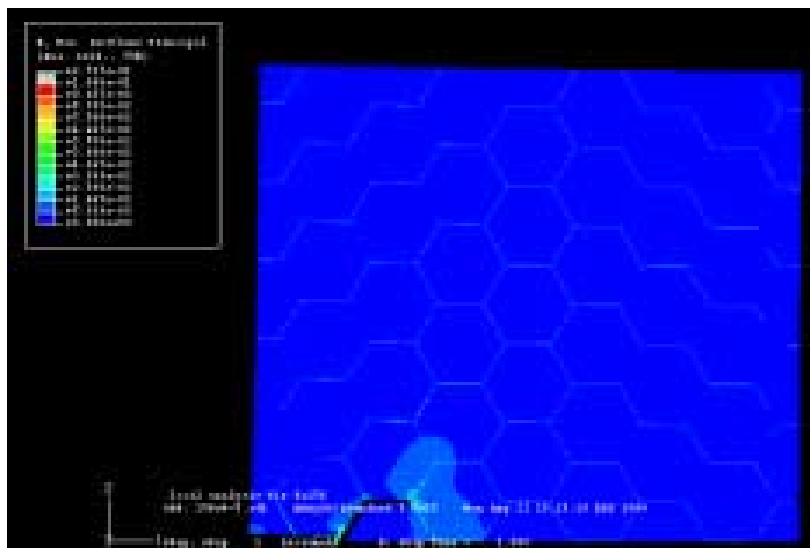

Principal strain distribution, step 12

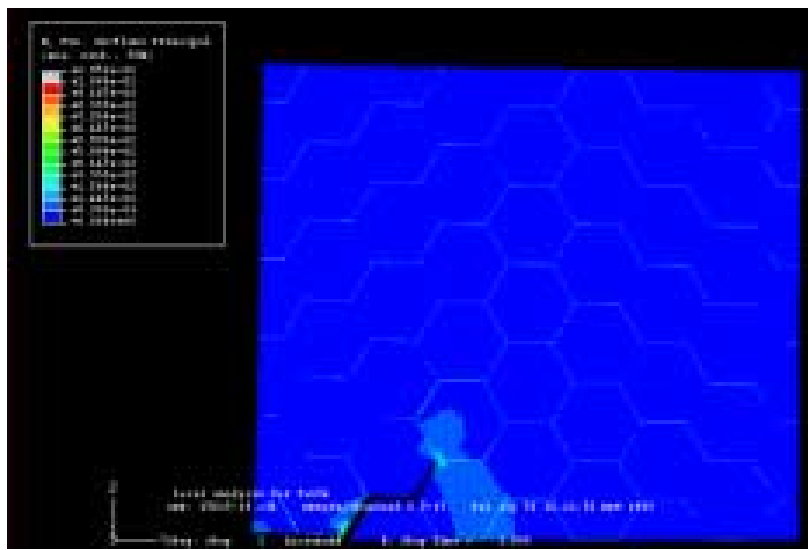

Principal strain distribution, step 19

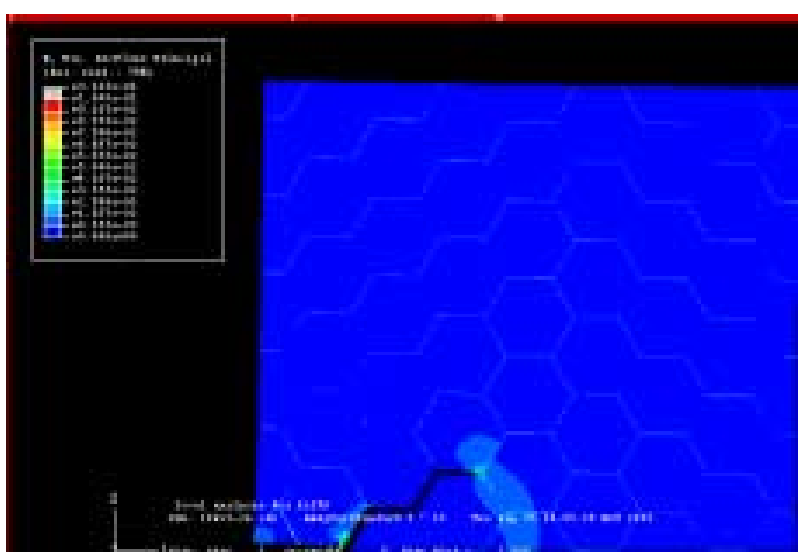

Fig. 5.2 Principal strain distribution for FA-186, $\mathrm{K}_{\mathrm{I}}=17.36 \mathrm{MPa} \sqrt{\mathrm{m}}$, Vacuum, failure strain $5 \%$ 


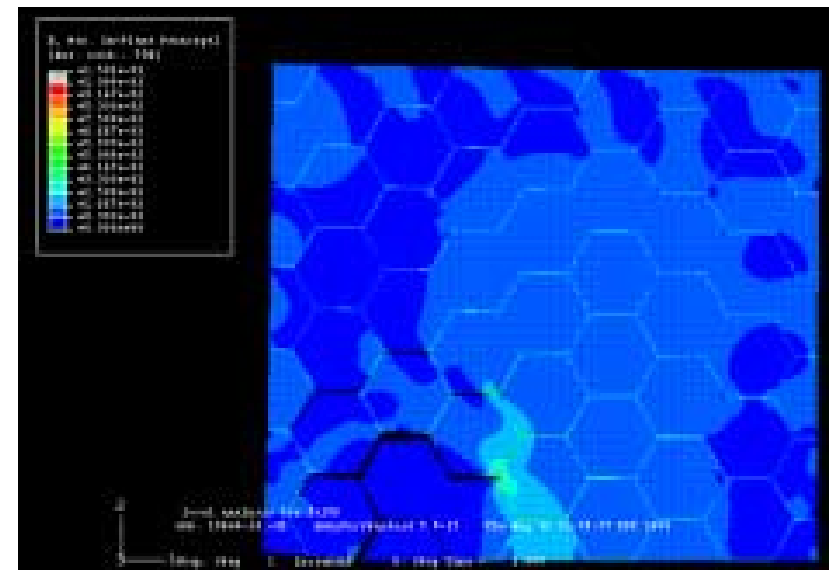

Principal strain distribution, step 1

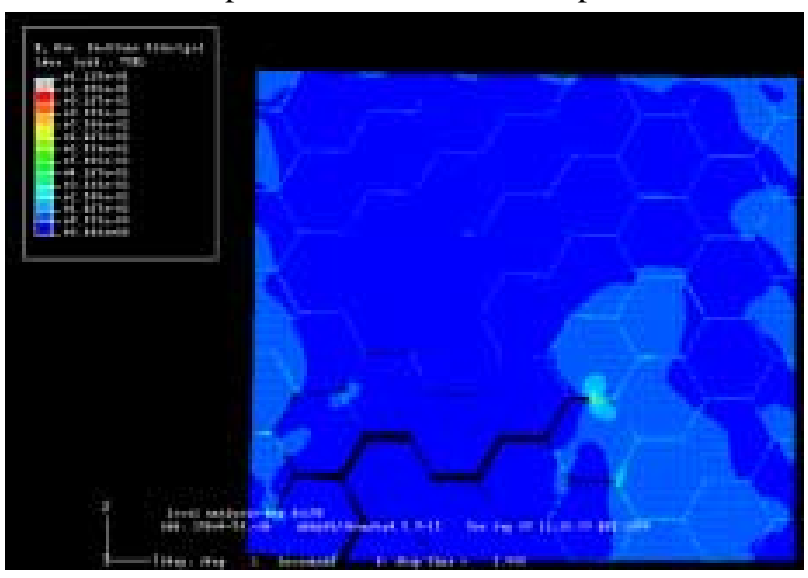

Principal strain distribution, step 5

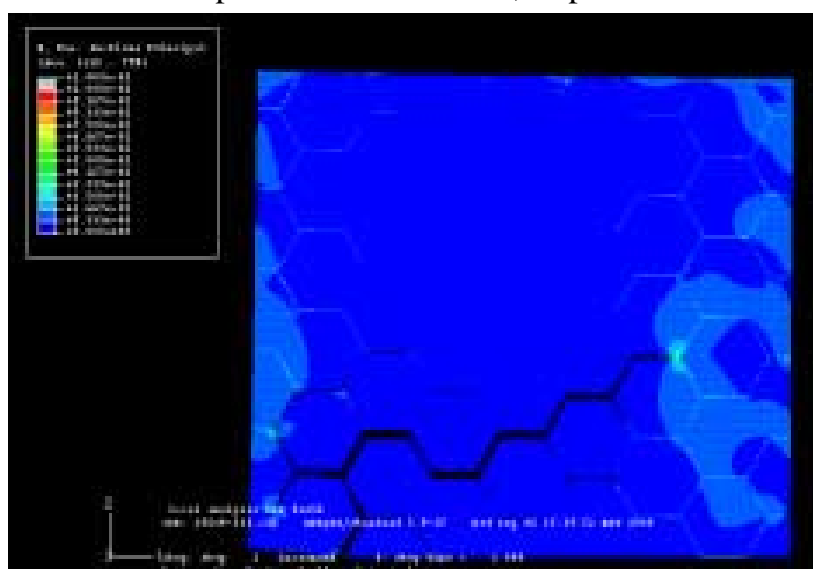

Principal strain distribution, step 13

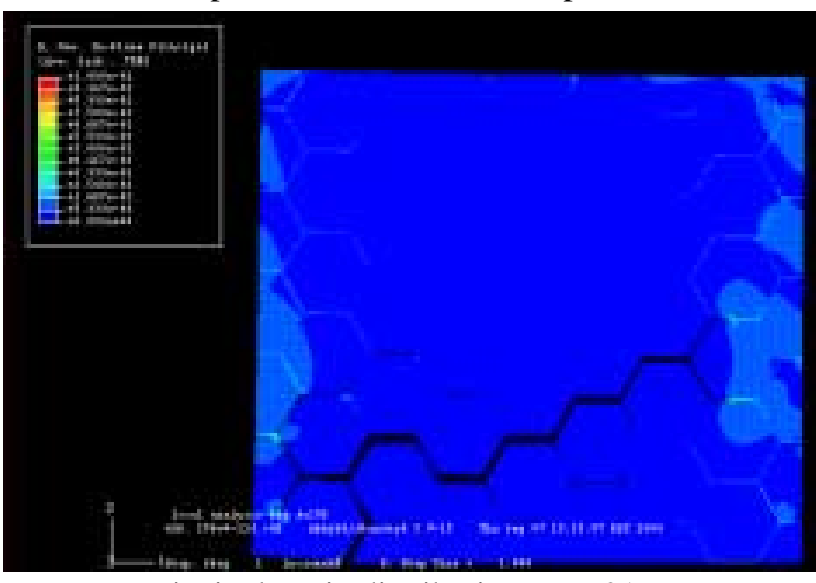

Principal strain distribution, step 21

Fig. 5.3 Principal strain distribution for FA-186, $\mathrm{K}_{\mathrm{I}}=36.9 \mathrm{MPa} \sqrt{\mathrm{m}}$, Vacuum, failure strain $4 \%$
Principal strain distribution, step 3

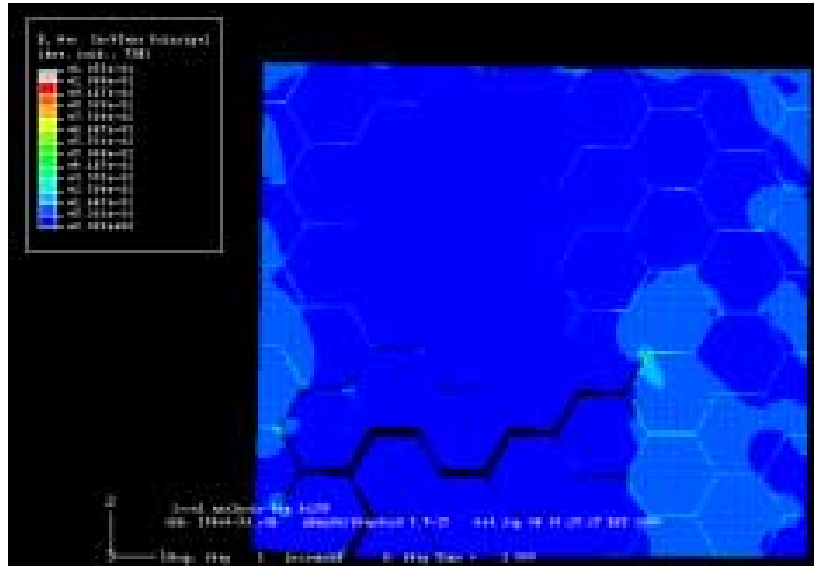

Principal strain distribution, step 9

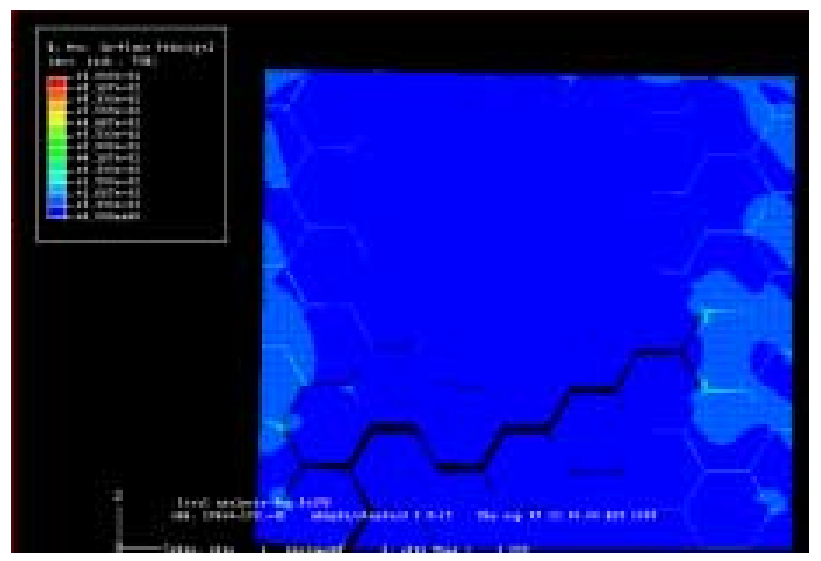

Principal strain distribution, step 17

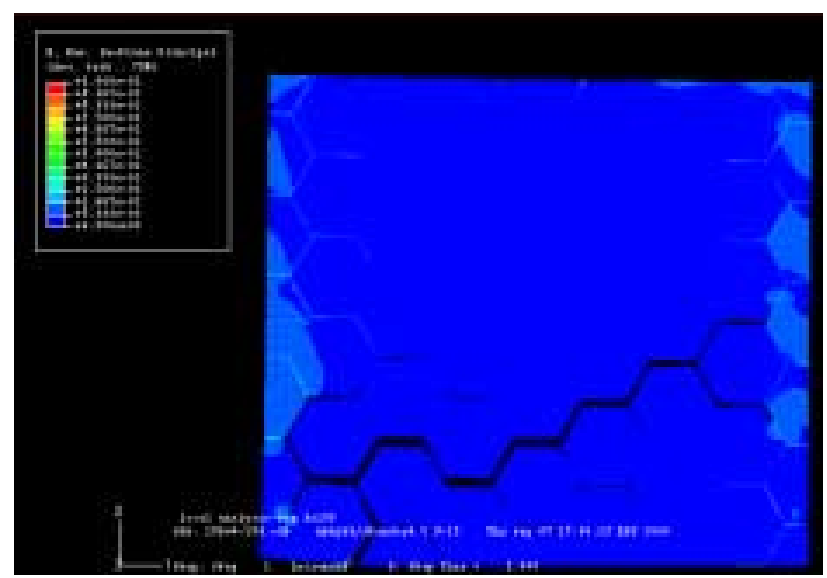

Principal strain distribution, step 28 (stopped) 


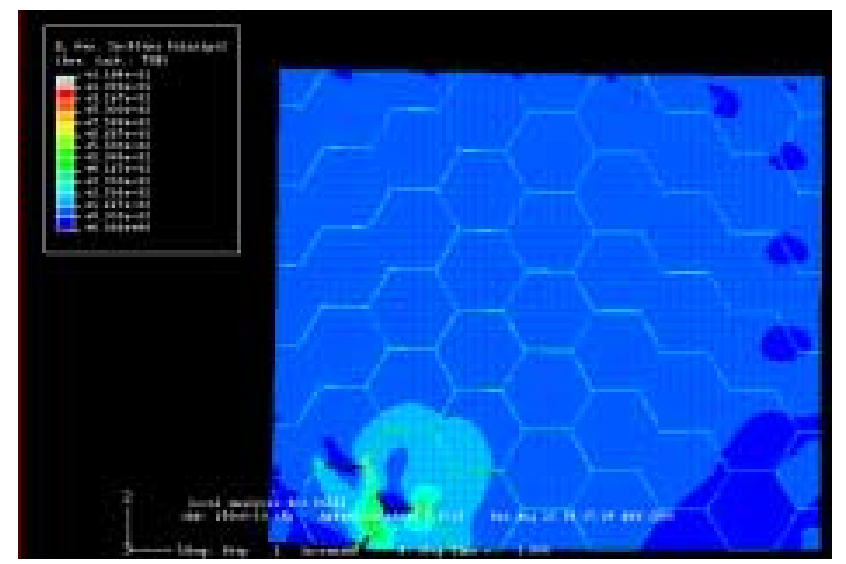

Principal strain distribution, step 1

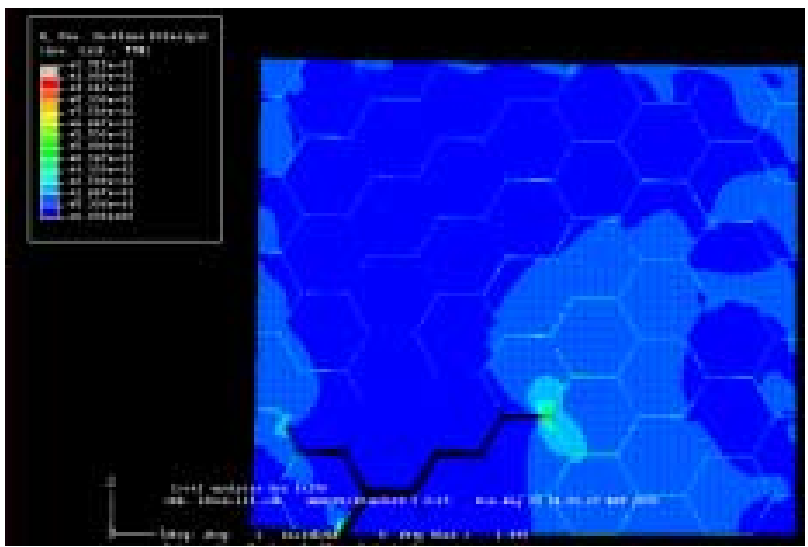

Principal strain distribution, step 11

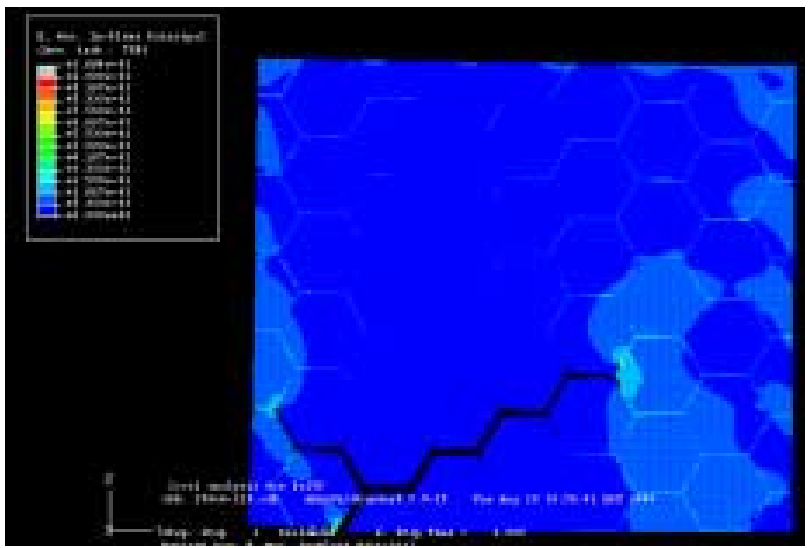

Principal strain distribution, step 21

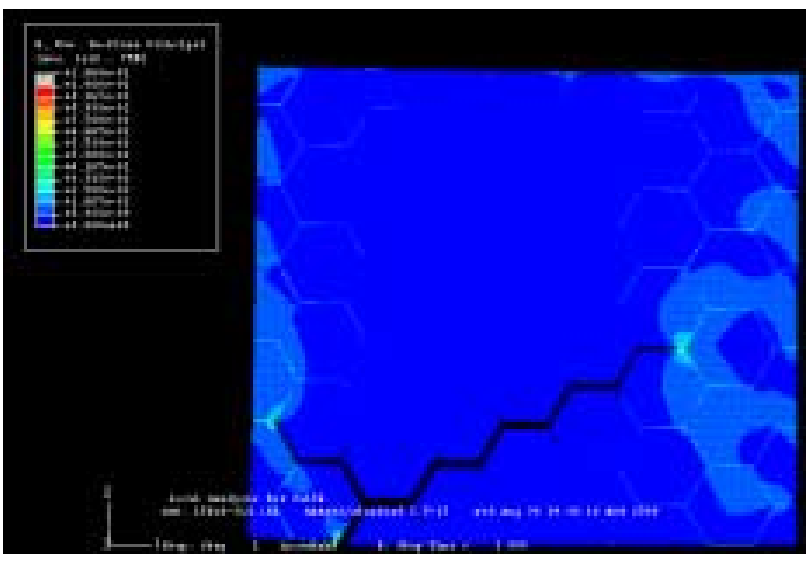

Principal strain distribution, step 31

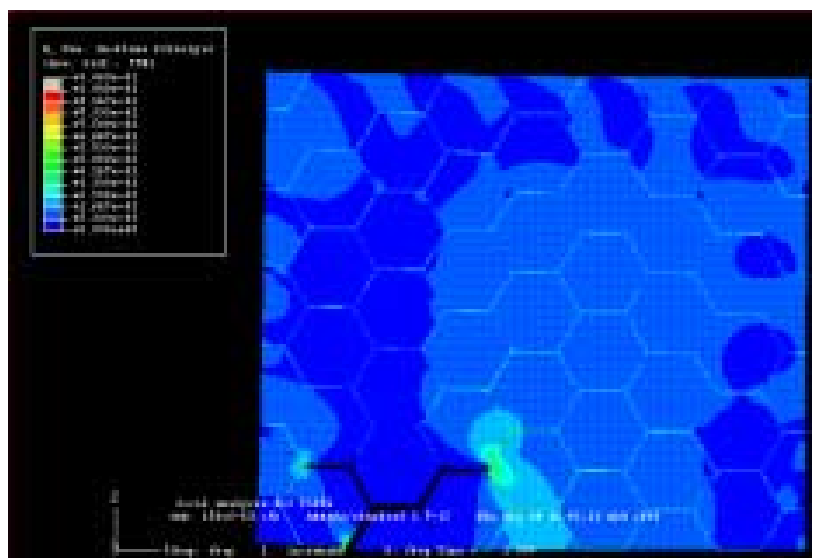

Principal strain distribution, step 6

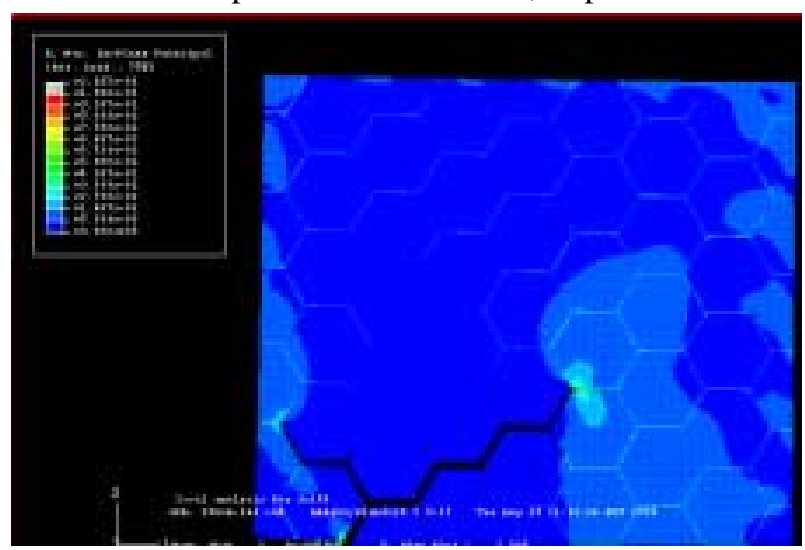

Principal strain distribution, step 16

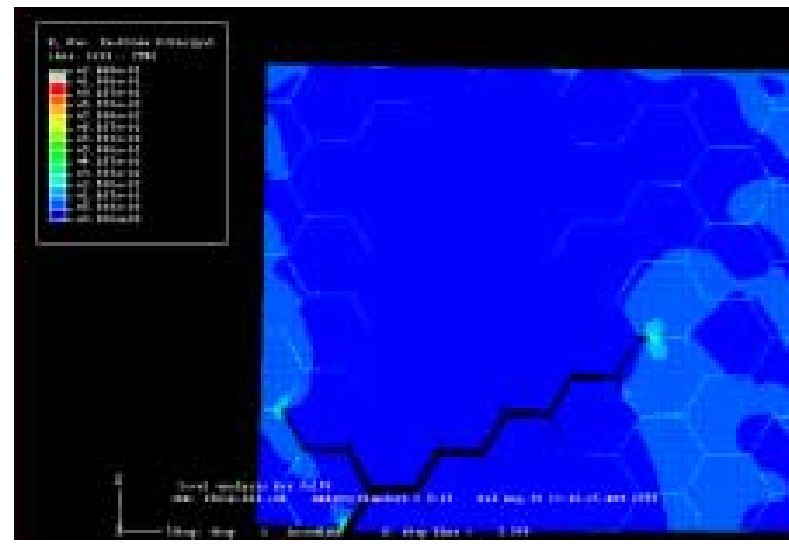

Principal strain distribution, step 26

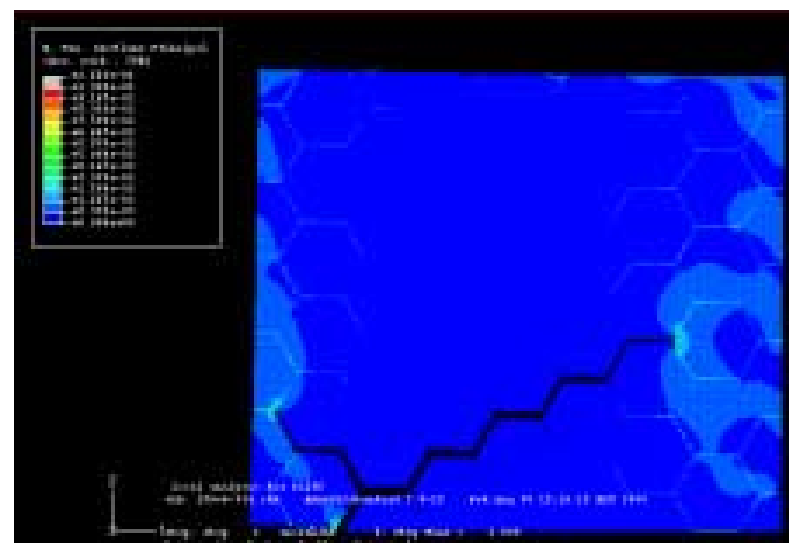

Principal strain distribution, step 33(stopped)

Fig. 5.4 Principal strain distribution for FA-186, $\mathrm{K}_{\mathrm{I}}=36.9 \mathrm{MPa} \sqrt{\mathrm{m}}$, Vacuum, failure strain $6 \%$ 


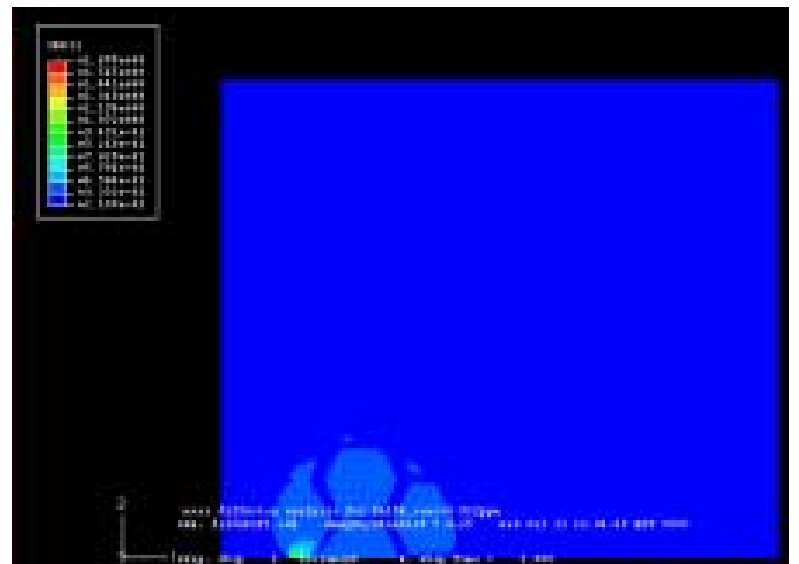

Hydrogen diffusion zone, step 1

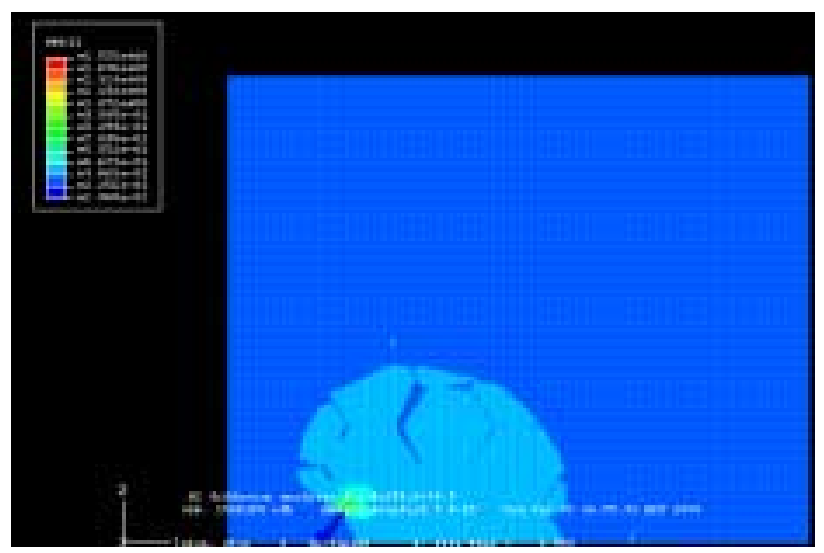

Hydrogen diffusion zone, step 4

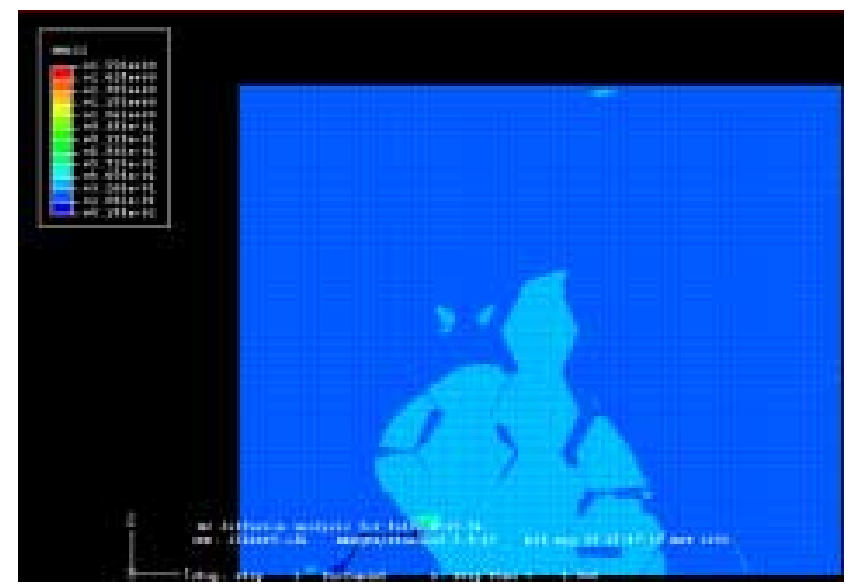

Hydrogen diffusion zone, step 9

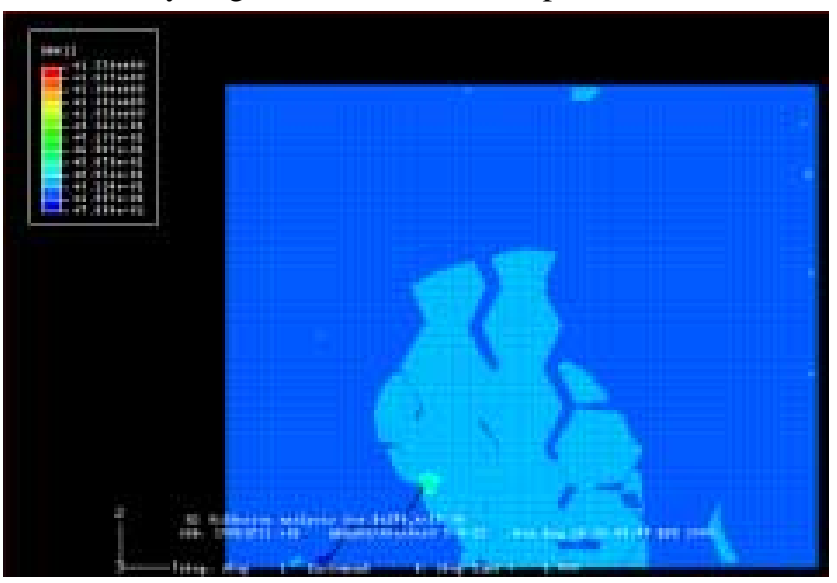

Hydrogen diffusion zone, step 12

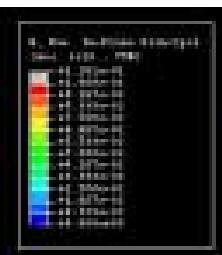

H.

Principal strain distribution, step 1, crack growth

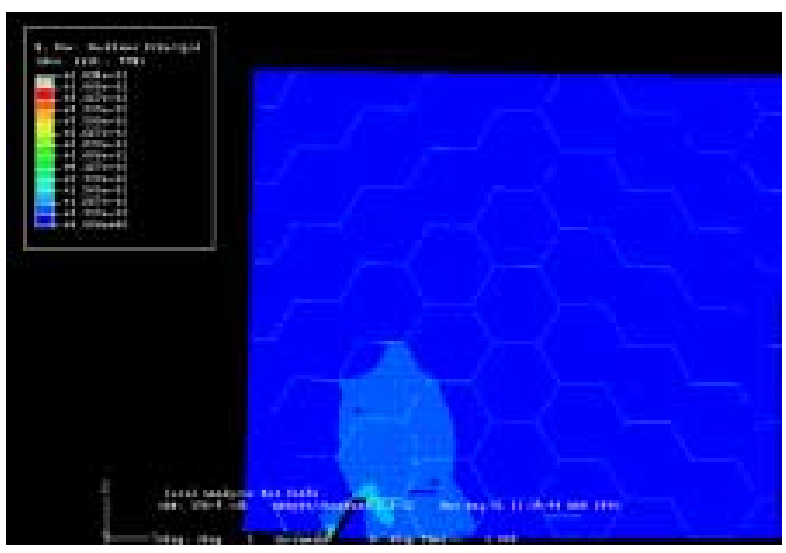

Principal strain distribution, step 4,crack growth

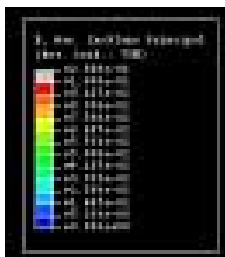

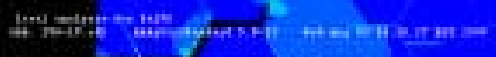

Principal strain distribution, step 9,crack growth
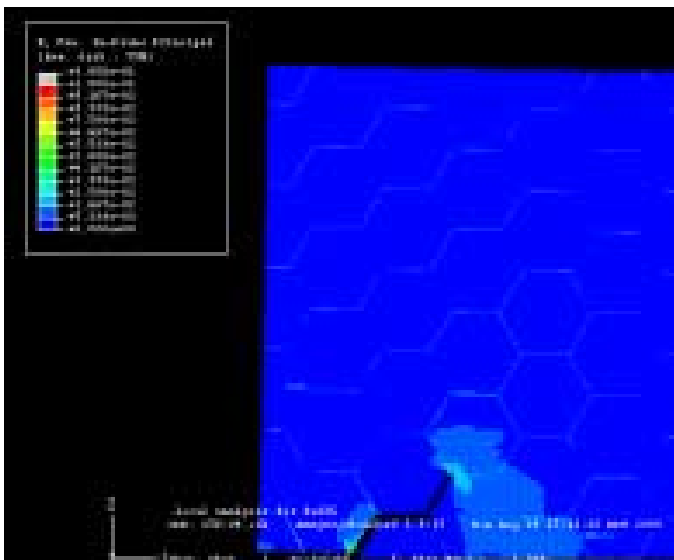

Principal strain distribution, step 12,crack growth 


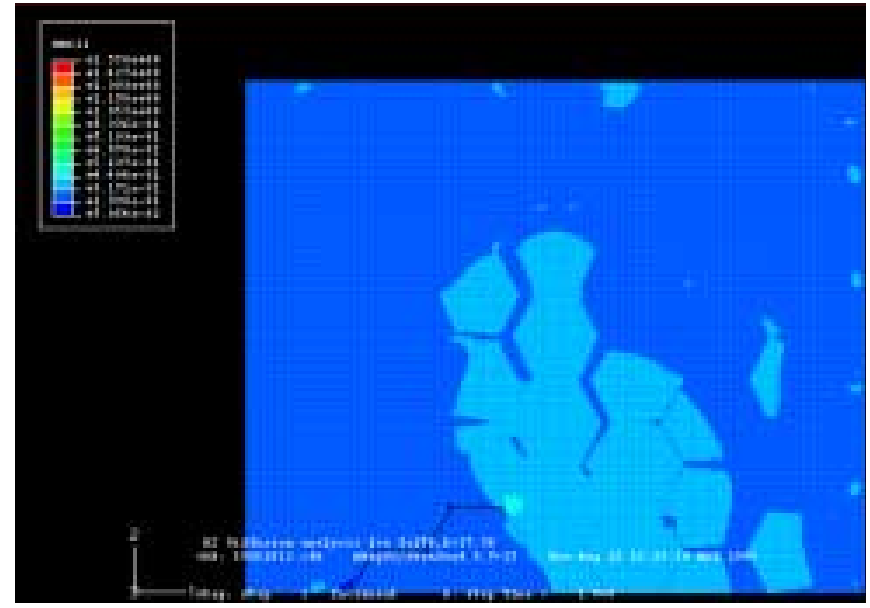

Hydrogen diffusion zone, step 17

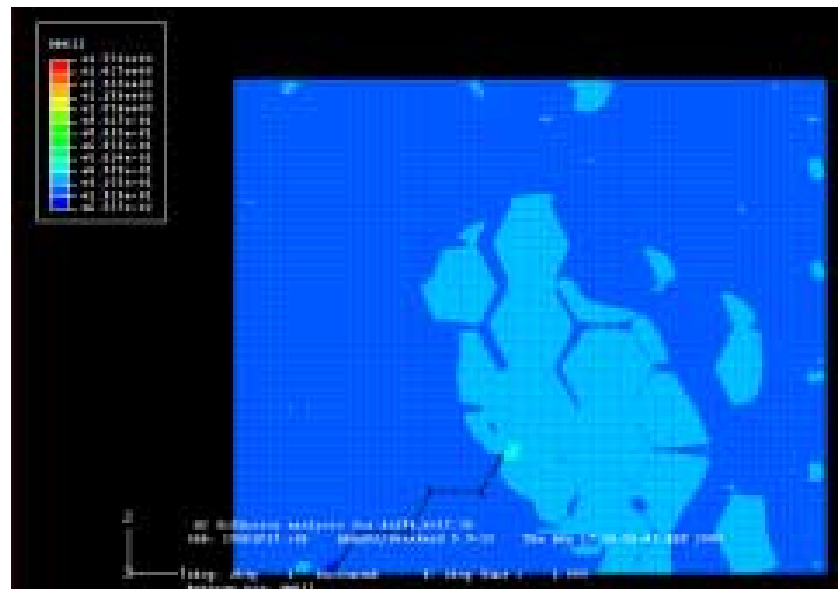

Hydrogen diffusion zone, step 24

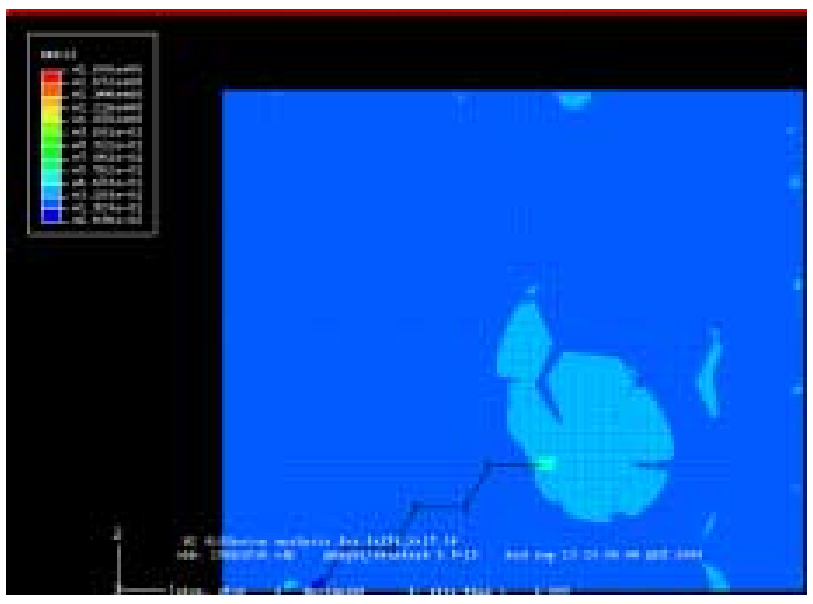

Hydrogen diffusion zone, step 33

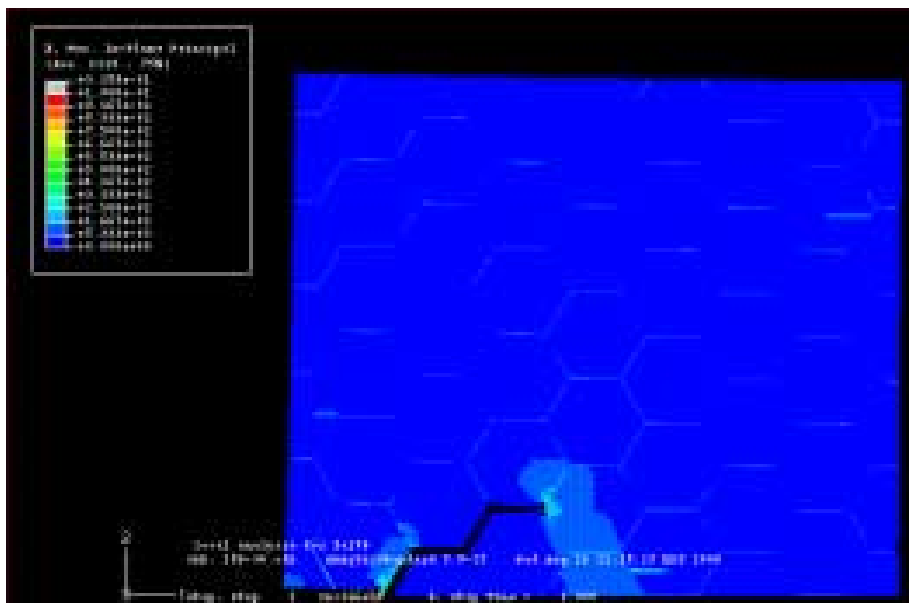

Principal strain distribution, step 17,crack growth

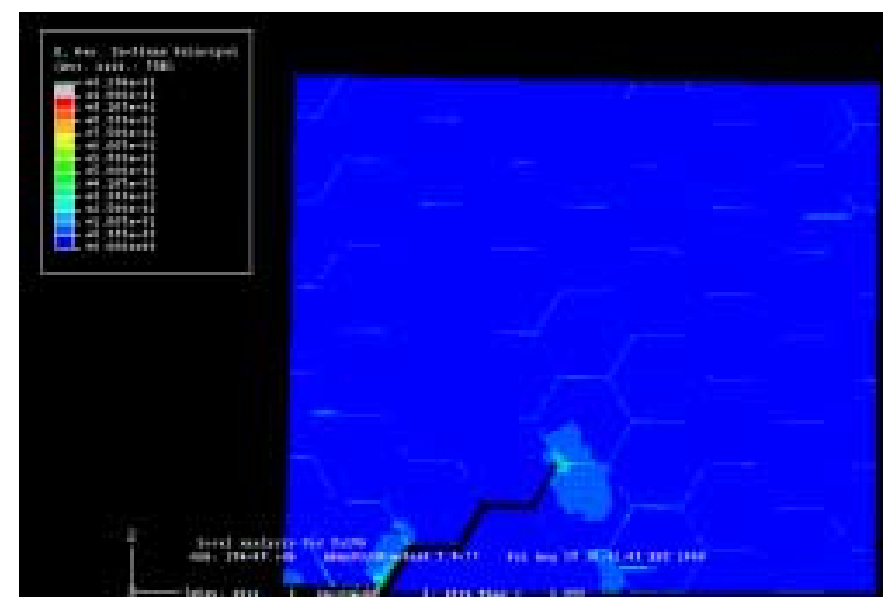

Principal strain distribution, step 24,crack growth

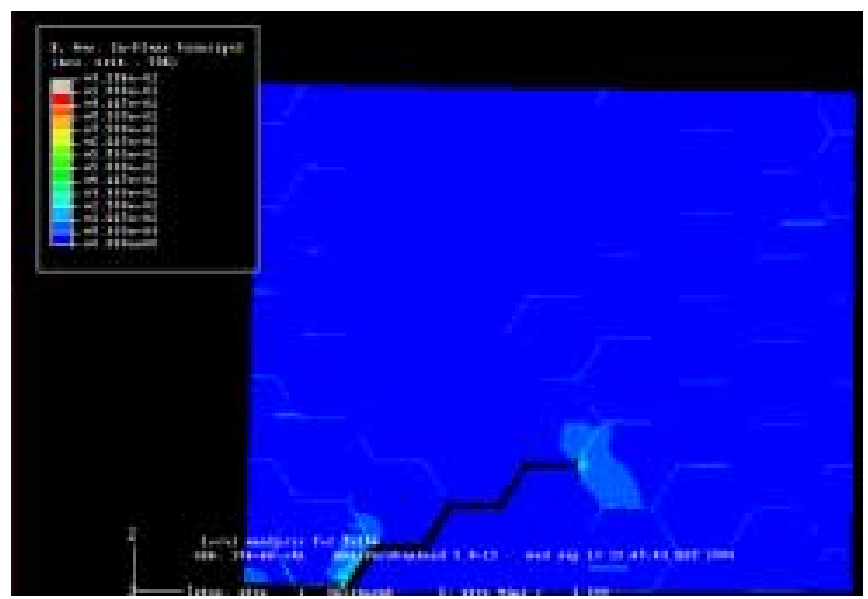

Principal strain distribution, step 33 (stopped)

Fig. 5.5 Hydrogen diffusion zones and principal strain distributions for FA-186, $\mathrm{K}_{\mathrm{I}}=17.36 \mathrm{MPa} \sqrt{\mathrm{m}}$, Air, failure strain $4 \%$ 


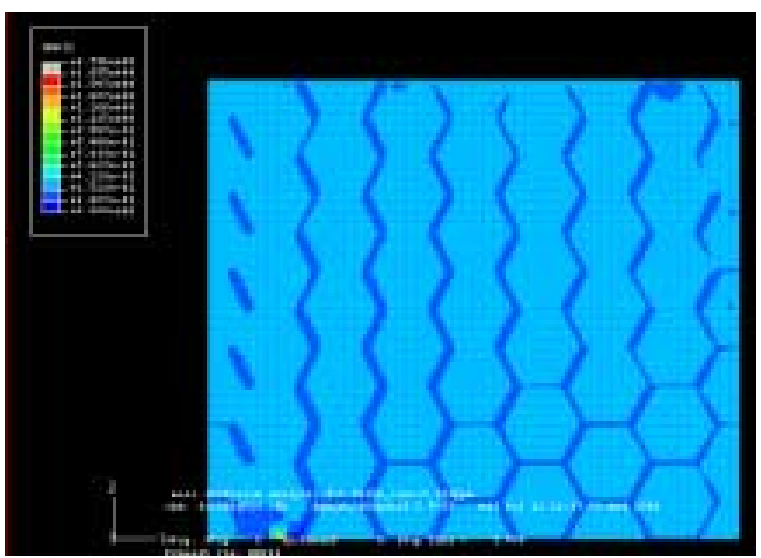

Hydrogen diffusion zone, step 1

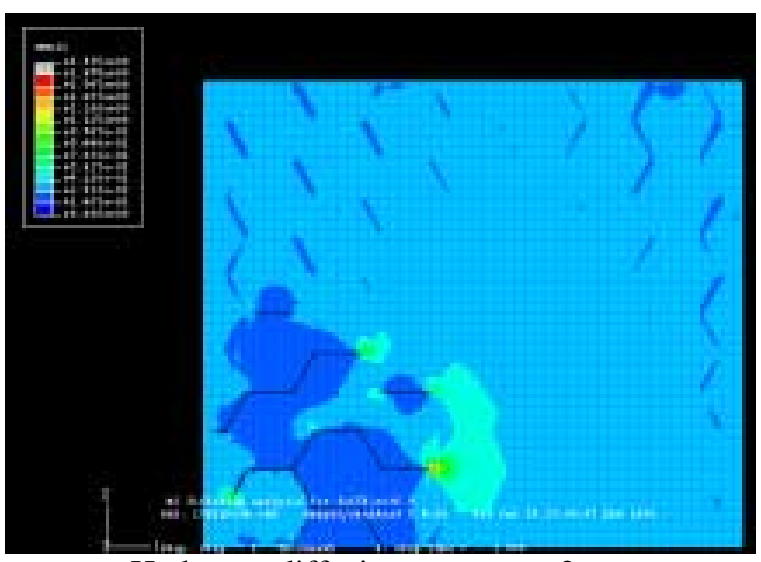

Hydrogen diffusion zone, step 2

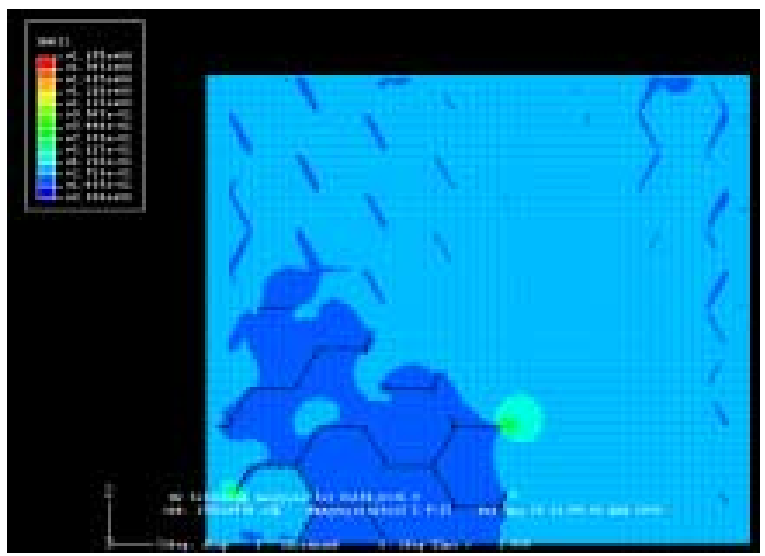

Hydrogen diffusion zone, step 4

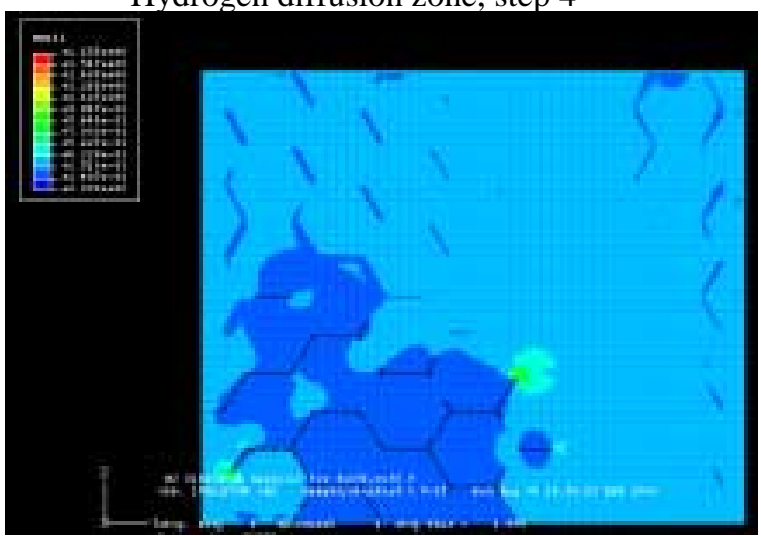

Hydrogen diffusion zone, step 6

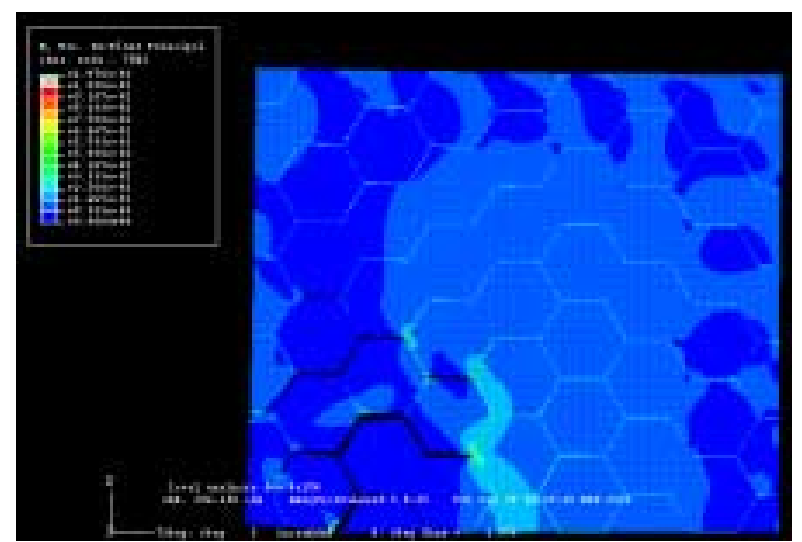

Principal strain distribution, step 1, crack growth

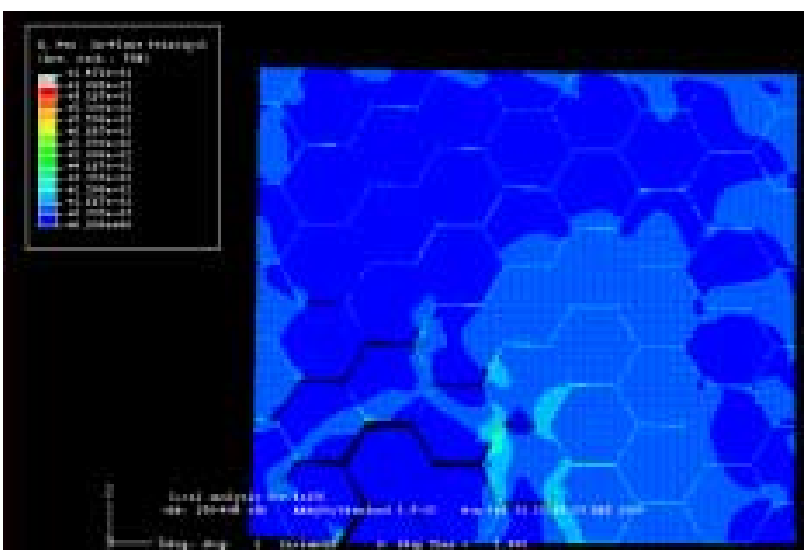

Principal strain distribution, step 2,crack growth

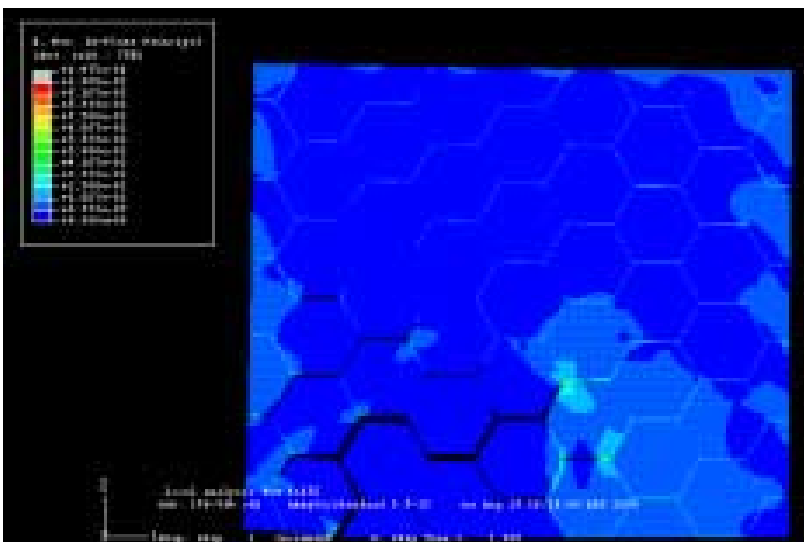

Principal strain distribution, step 4,crack growth

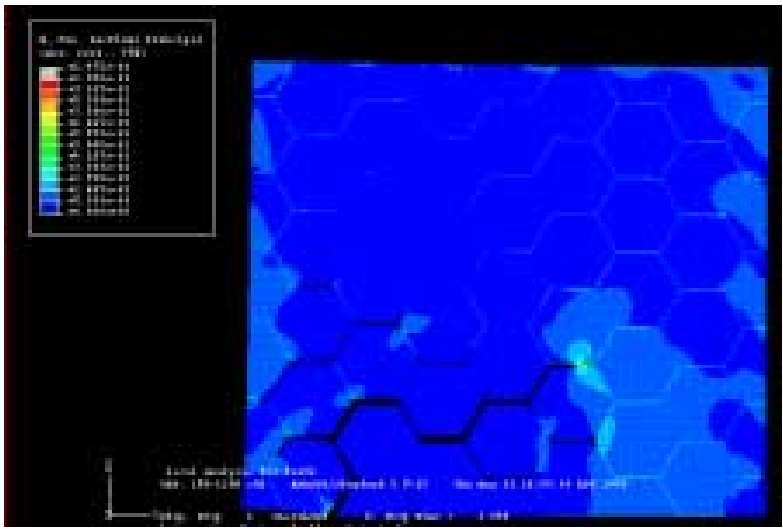

Principal strain distribution, step 6,crack growth

Fig. 5.6 Hydrogen diffusion zones and principal strain distributions for FA-186, $\mathrm{K}_{\mathrm{I}}=36.9 \mathrm{MPa} \vee \mathrm{m}$, Air, failure strain $4 \%$ 


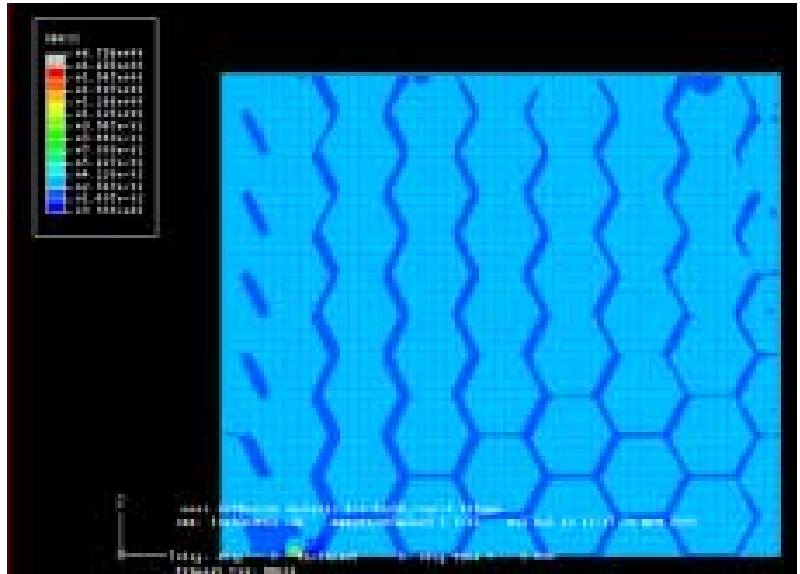

Hydrogen diffusion zone, step 1

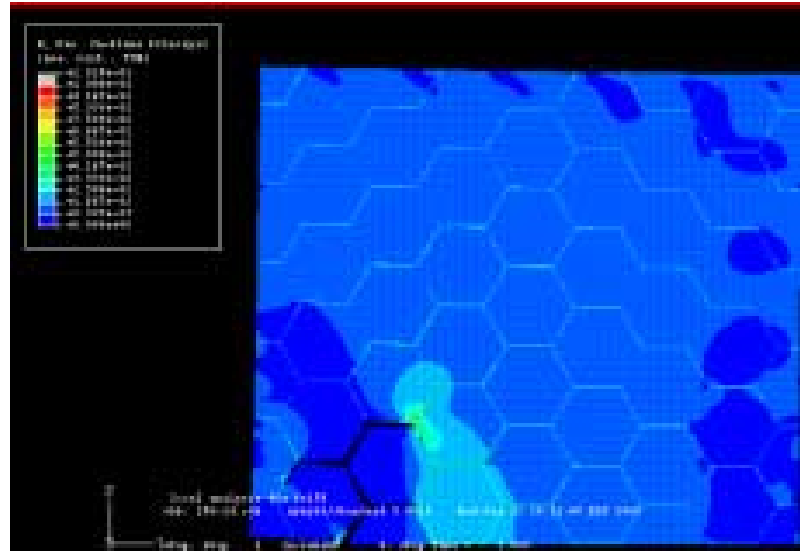

Principal strain distribution, step 1, crack growth

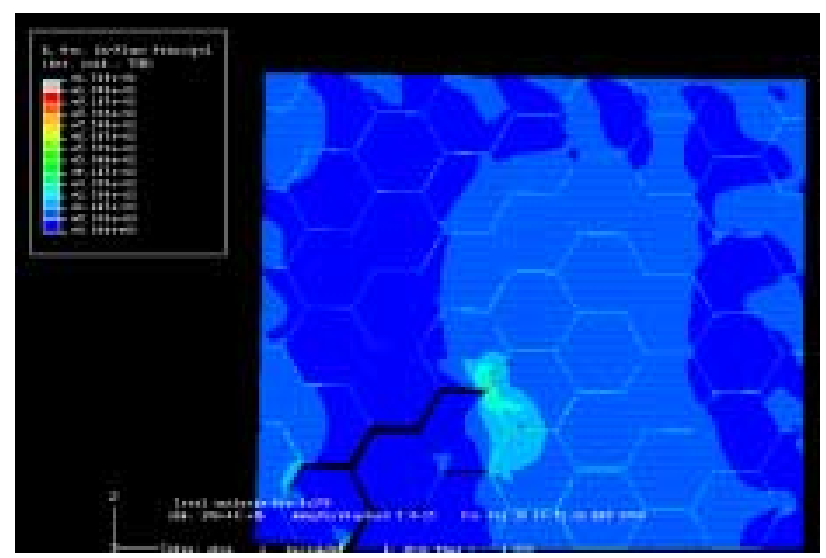

Principal strain distribution, step 2, crack growth

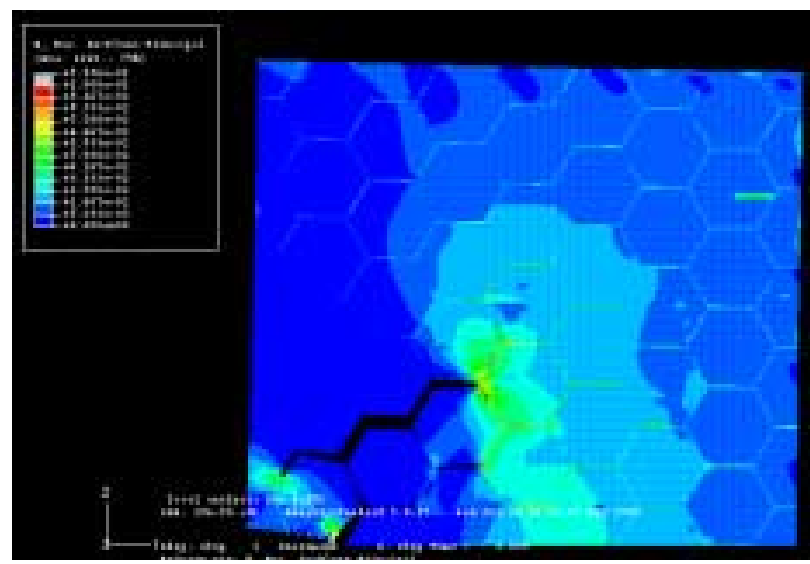

Principal strain distribution after diffusion 3

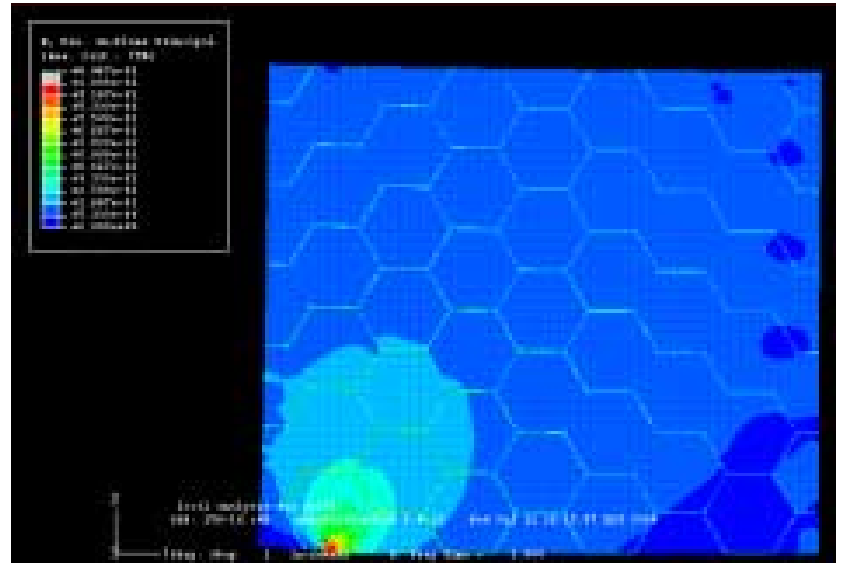

Principal strain distribution after diffusion 1

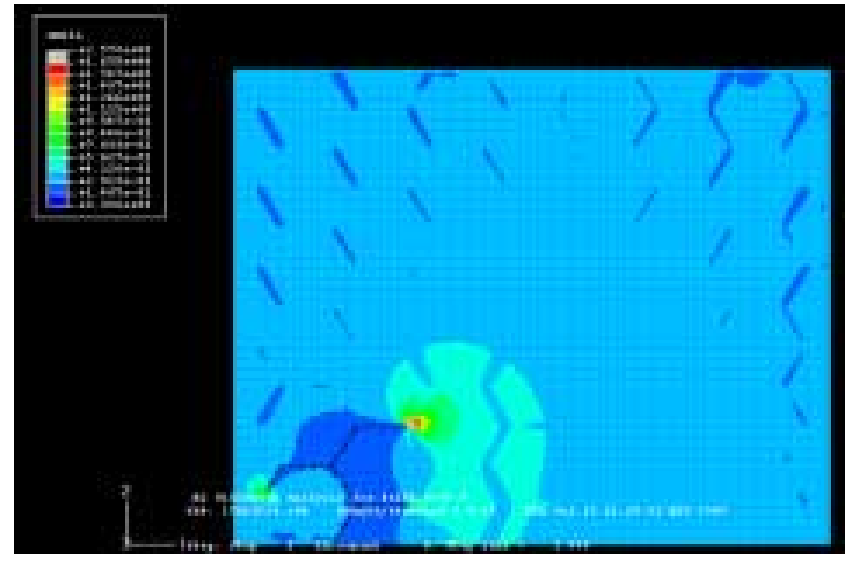

Hydrogen diffusion zone, step 2

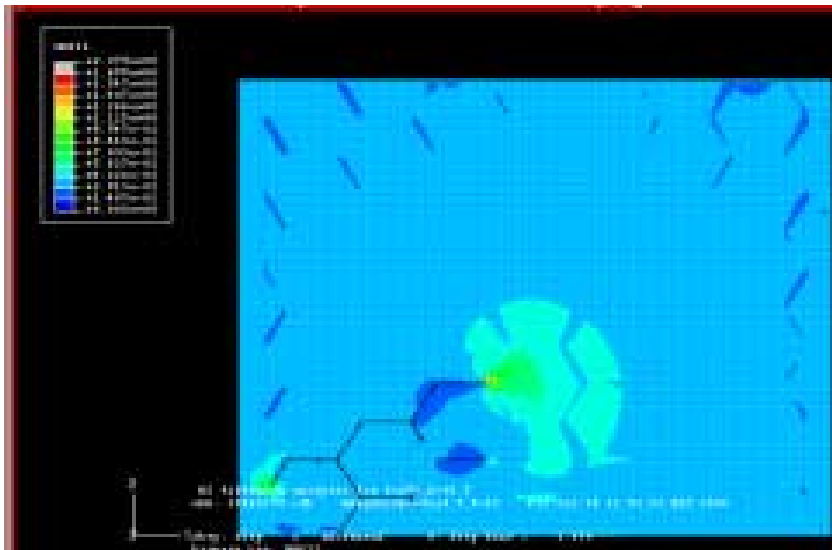

Hydrogen diffusion zone, step 3

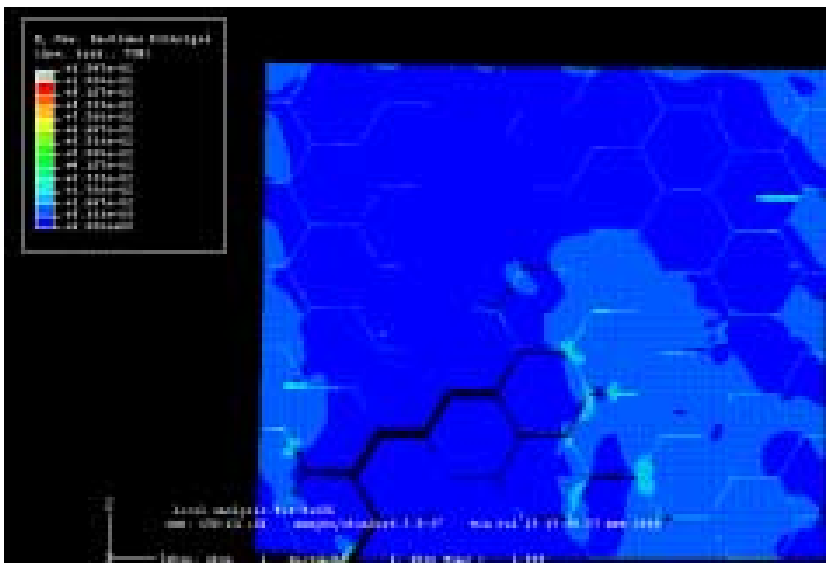

Principal strain distribution, step 3, crack growth

Fig. 5.7 Hydrogen diffusion zones and principal strain distributions for FA-186, $\mathrm{K}_{\mathrm{I}}=36.9 \mathrm{MPa} \sqrt{\mathrm{m}}$, Air, failure strain $6 \%$ 


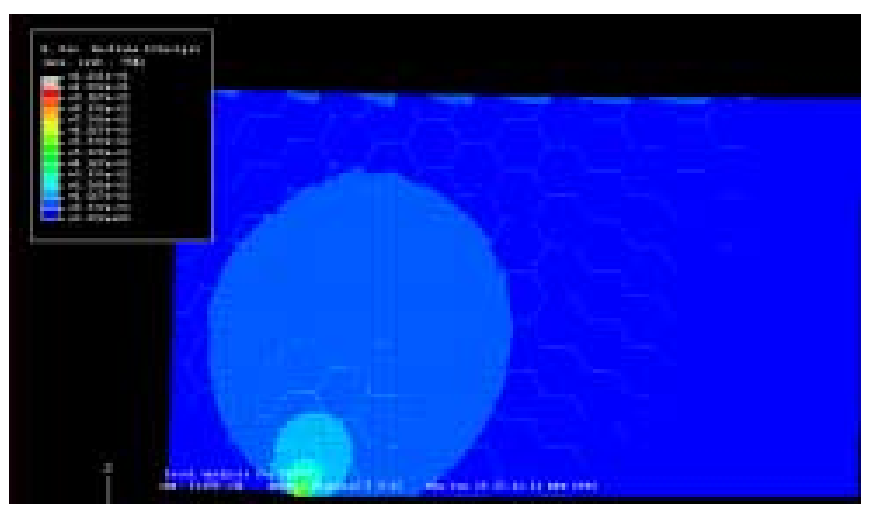

Initial principal strain distribution

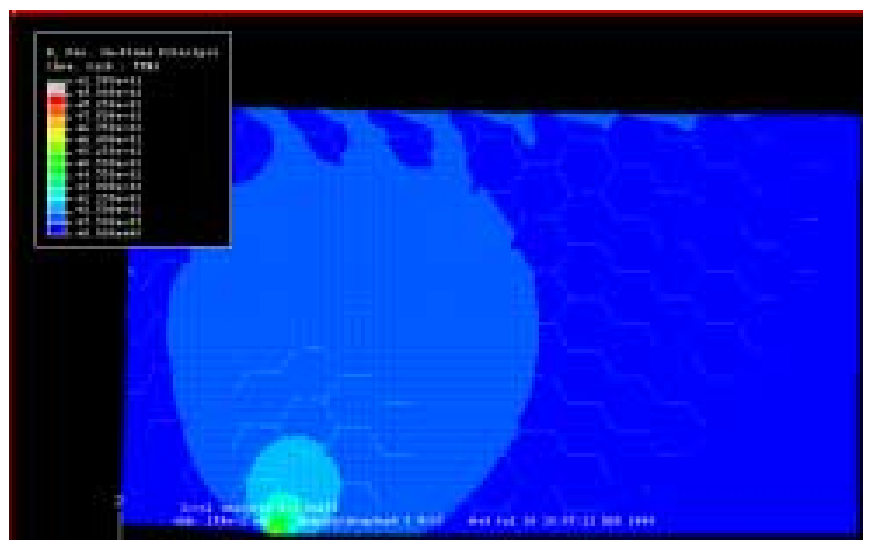

Principal strain distribution, step 2

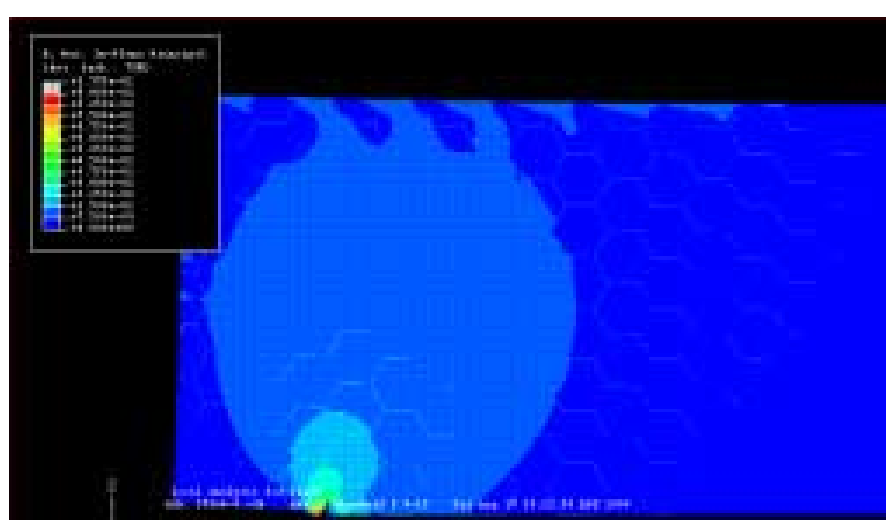

Principal strain distribution, step 4

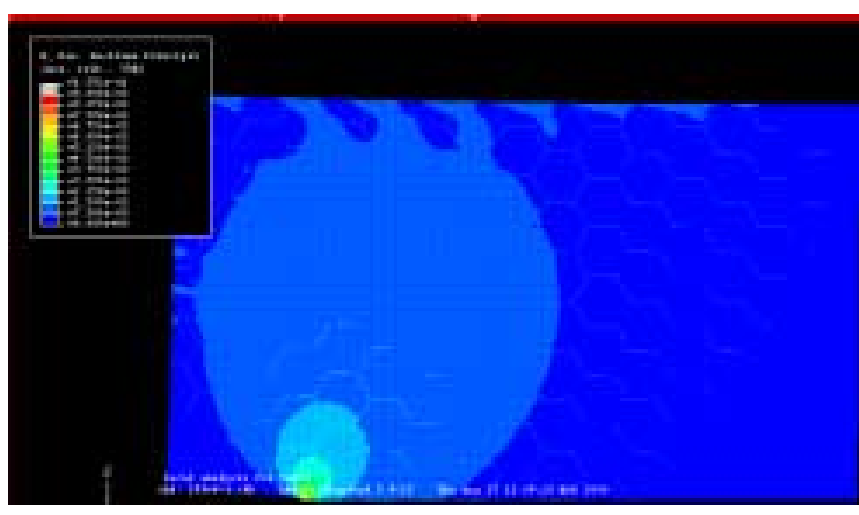

Principal strain distribution, step 1

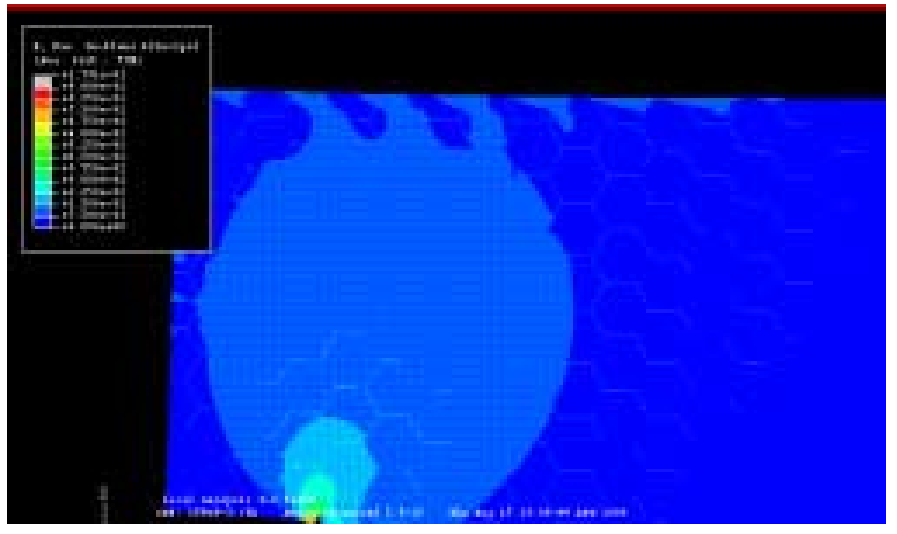

Principal strain distribution, step 3

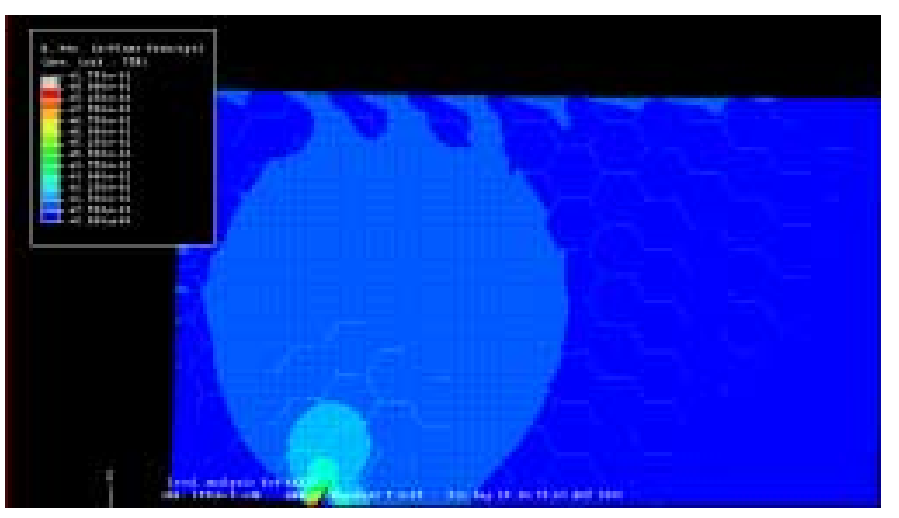

Principal strain distribution, step 5 (stopped)

Fig. 5.8 Principal strain distribution for FA-189, $\mathrm{K}_{\mathrm{I}}=17.36 \mathrm{MPa} \sqrt{ } \mathrm{m}$, Vacuum, failure strain $6 \%$ 


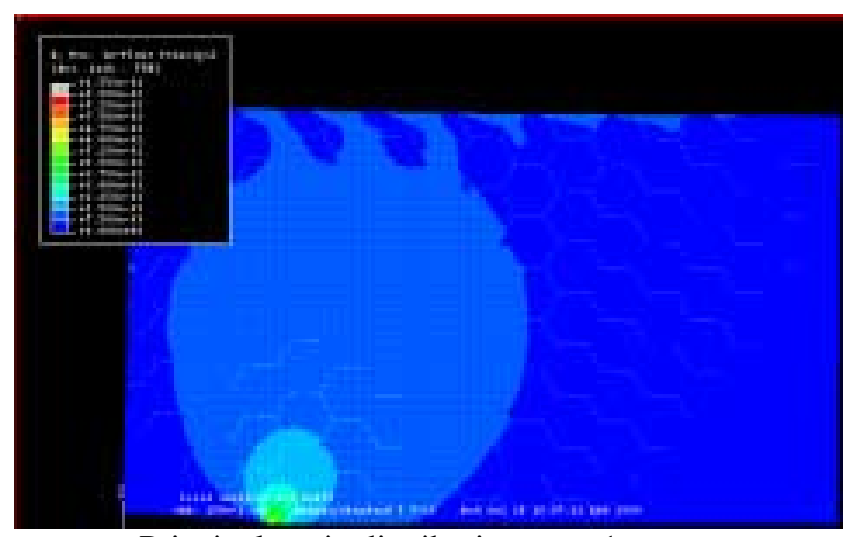

Principal strain distribution, step 1

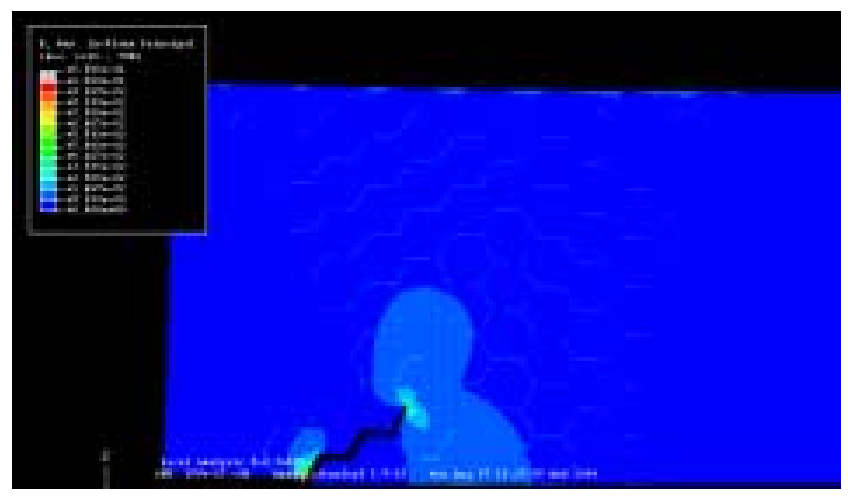

Principal strain distribution, step 17

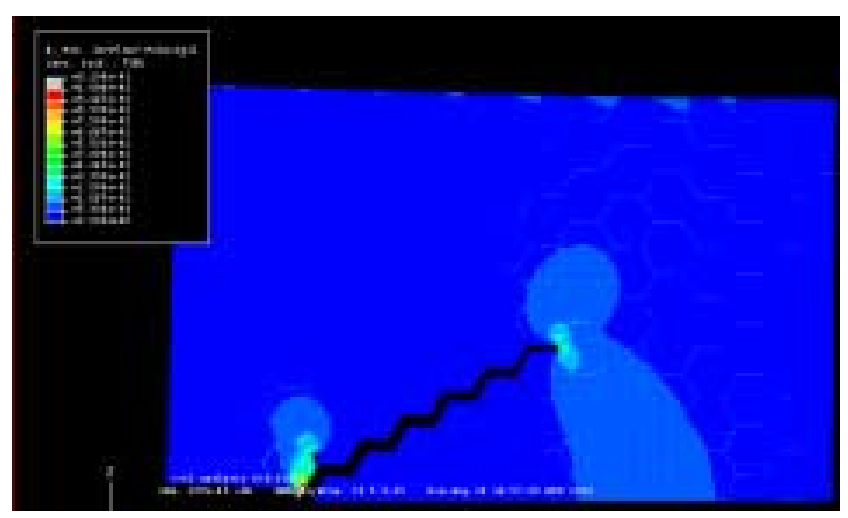

Principal strain distribution, step 43

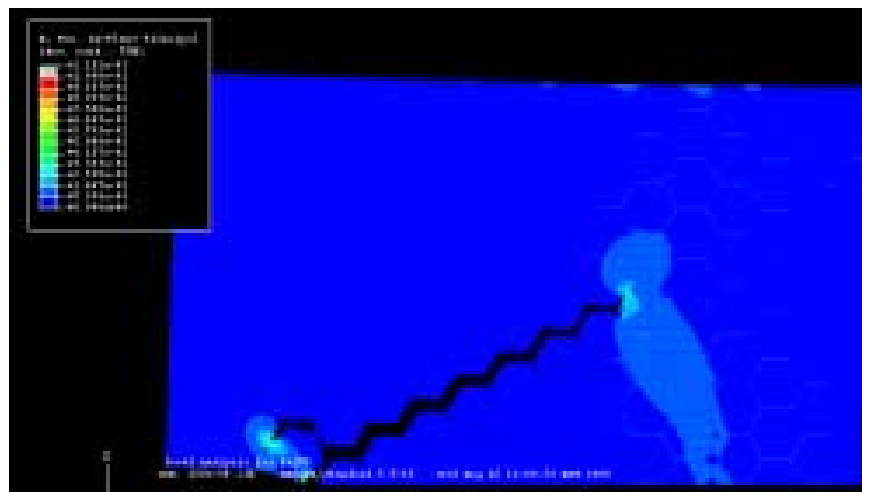

Principal strain distribution, step 54

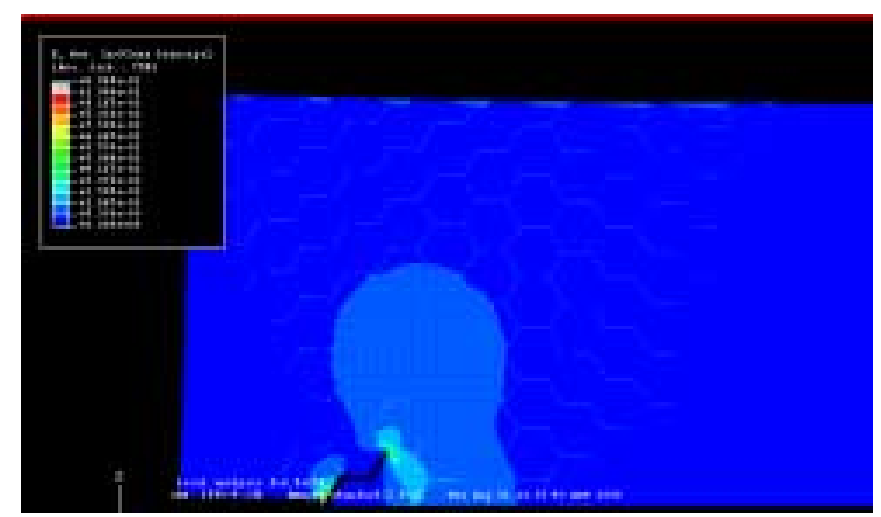

Principal strain distribution, step 9

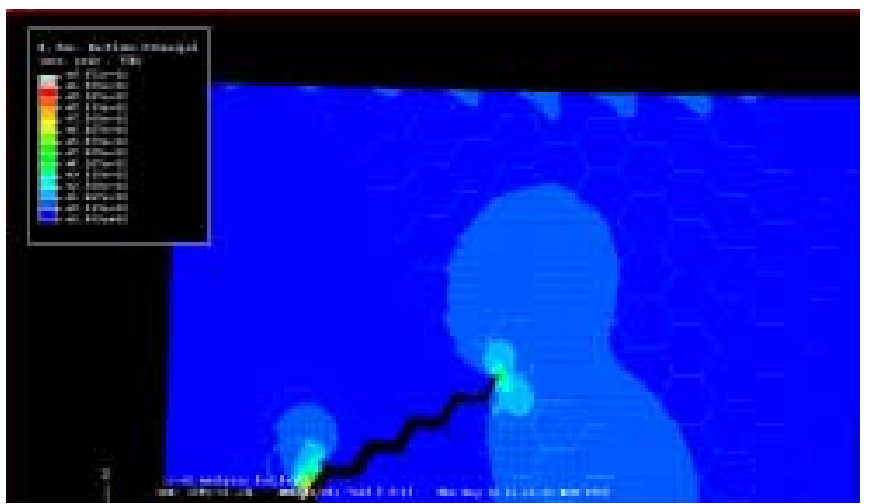

Principal strain distribution, step 32

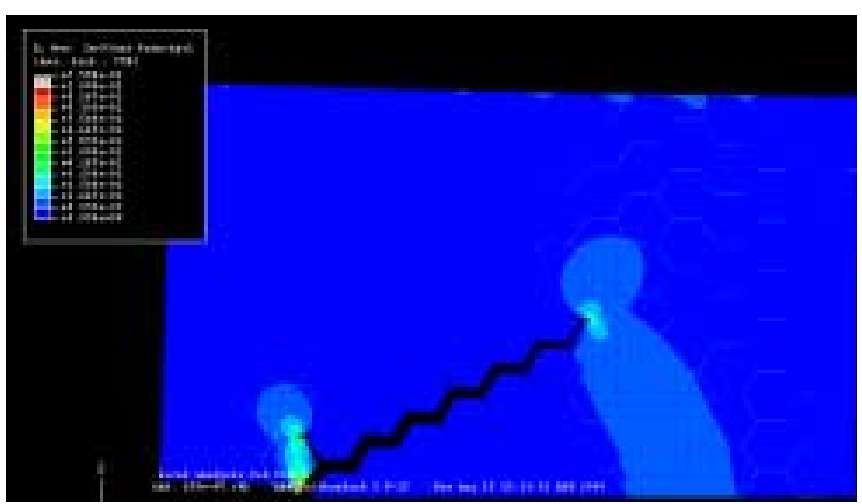

Principal strain distribution, step 48

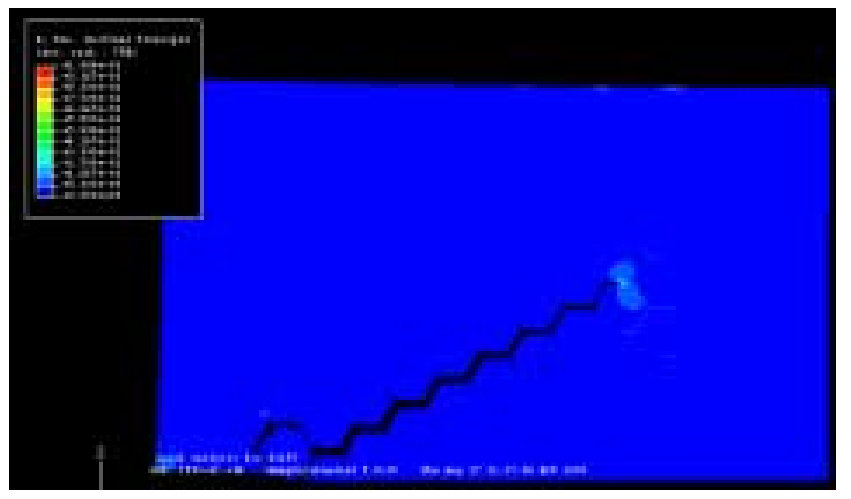

Principal strain distribution, step 62 (stopped)

Fig. 5.9 Principal strain distribution for FA-189, $\mathrm{K}_{\mathrm{I}}=17.36 \mathrm{MPa} \sqrt{\mathrm{m}}$, Vacuum, failure strain $4 \%$ 


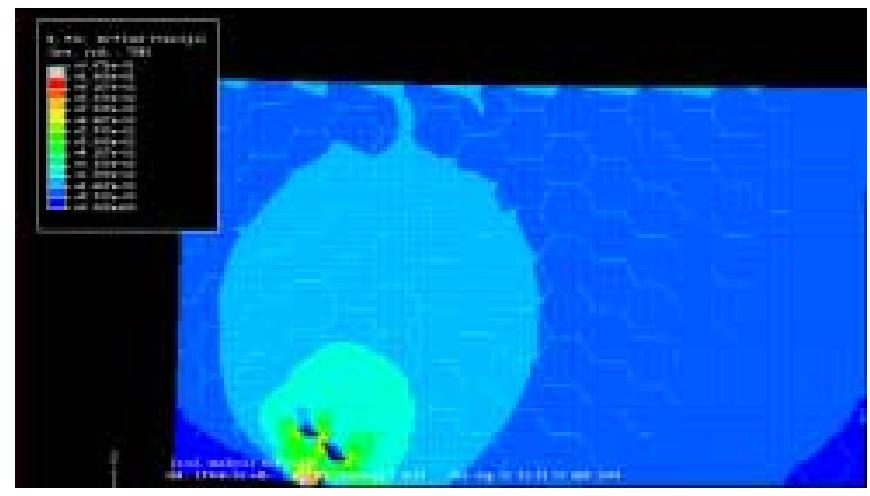

Principal strain distribution, step 1

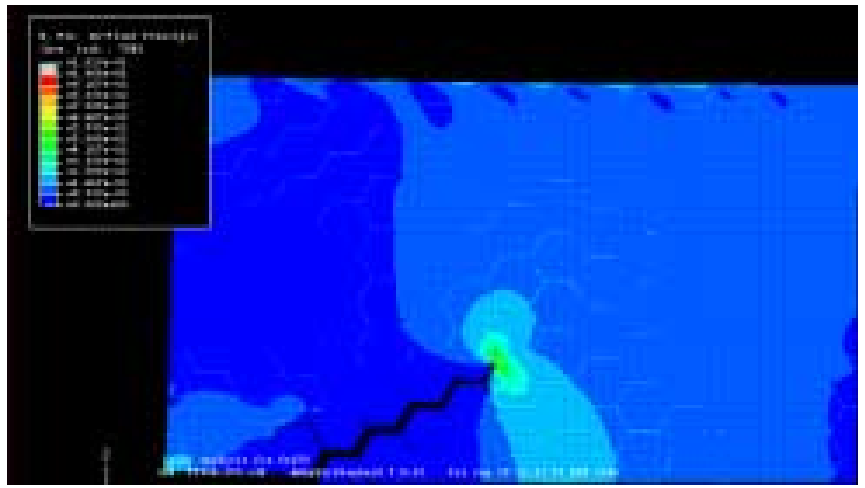

Principal strain distribution, step 18

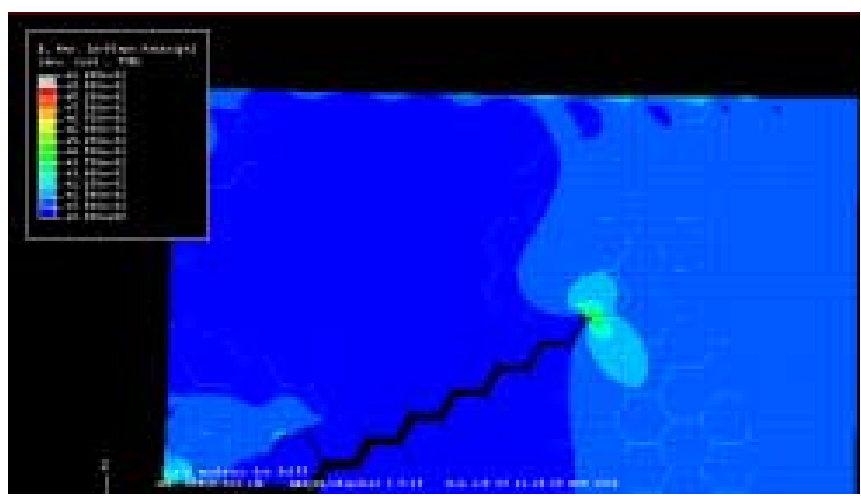

Principal strain distribution, step 36

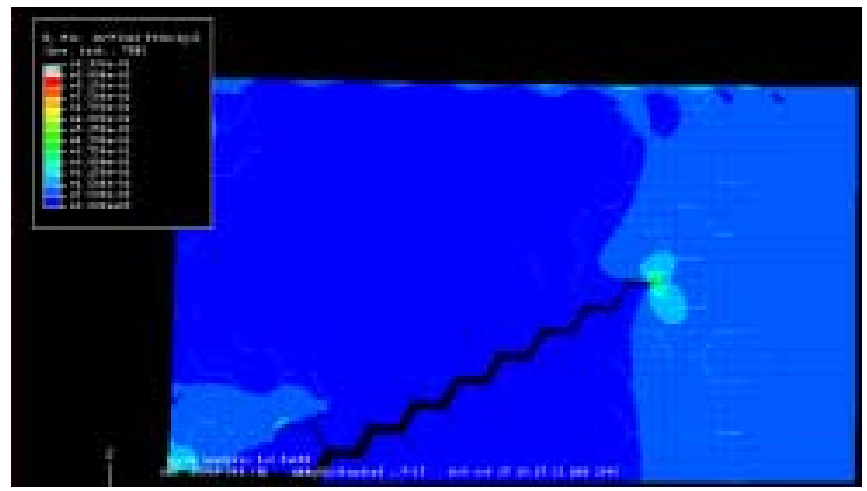

Principal strain distribution, step 54

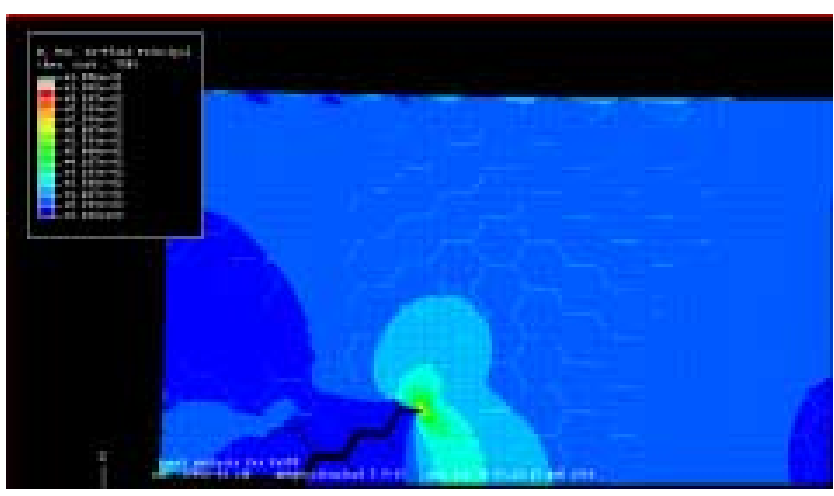

Principal strain distribution, step 9

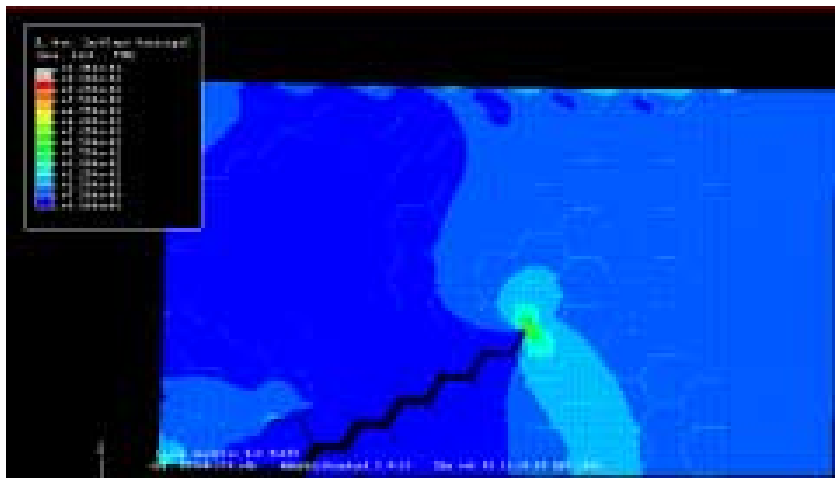

Principal strain distribution, step 27

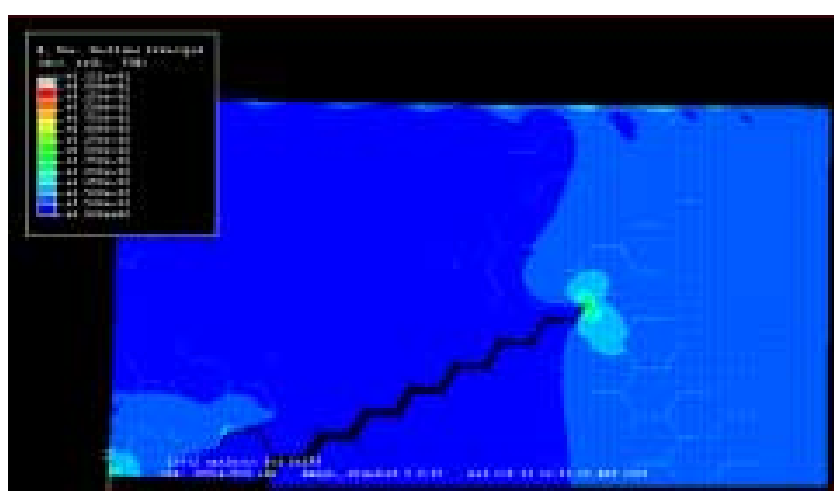

Principal strain distribution, step 45

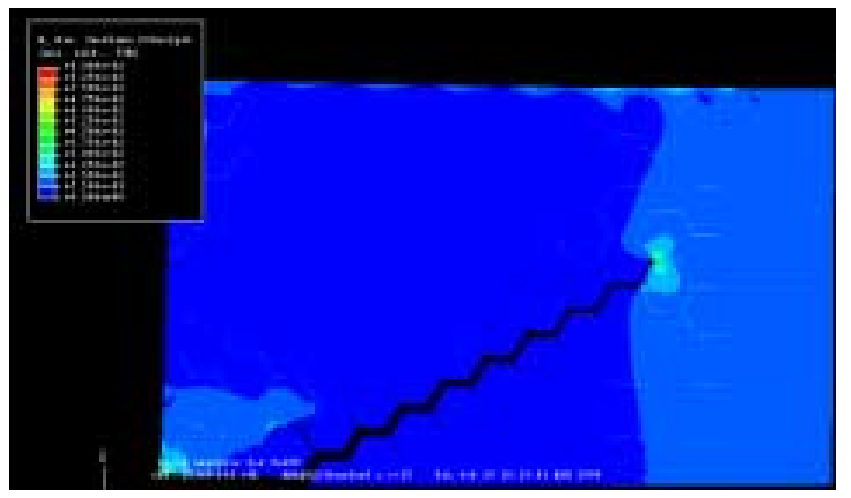

Principal strain distribution, step 63 (stopped)

Fig. 5.10 Principal strain distribution for FA-189, $\mathrm{K}_{\mathrm{I}}=36.9 \mathrm{MPa} \sqrt{\mathrm{m}}$, Vacuum, failure strain $6 \%$ 


\section{FA-189, Air, $K=17.36 \mathrm{MPa} \sqrt{\mathrm{m}}$, failure strain $6 \%$}

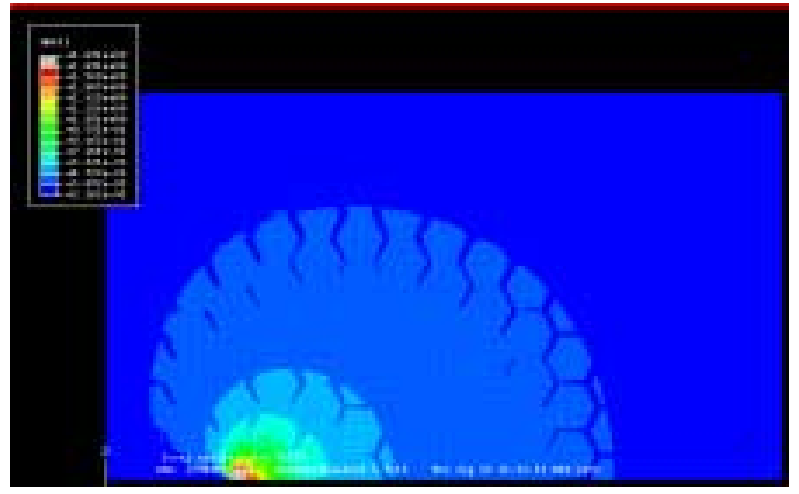

Hydrogen diffusion zone, step 1

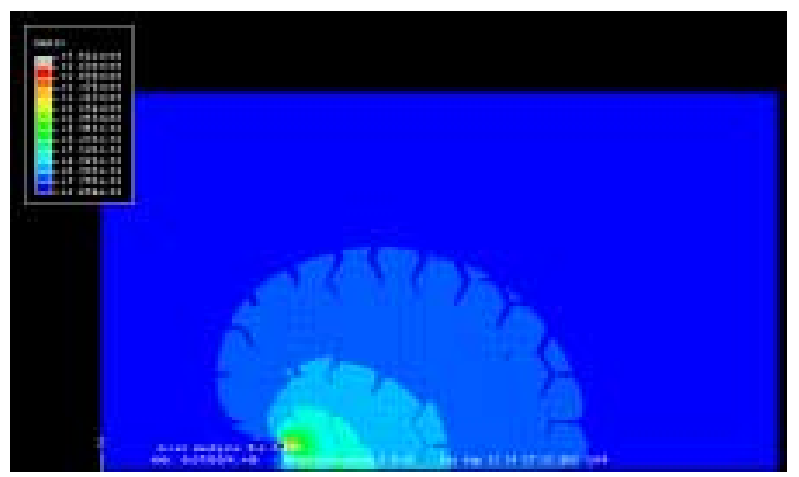

Hydrogen diffusion zone, step 8

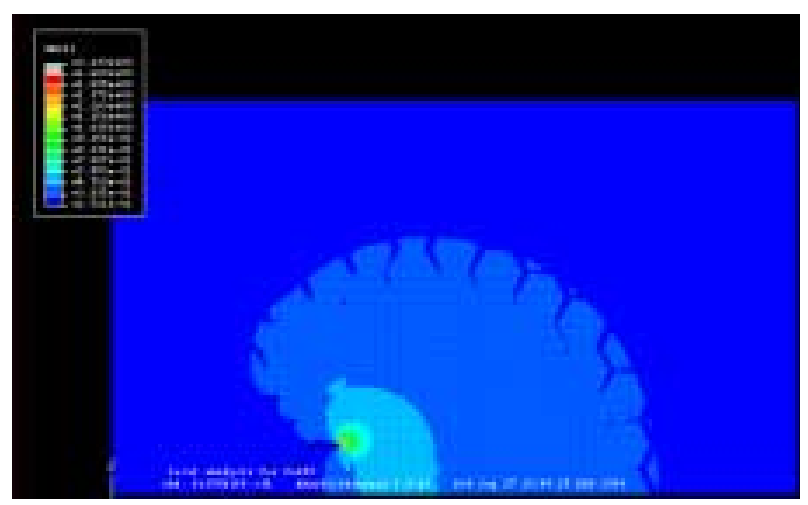

Hydrogen diffusion zone, step 16

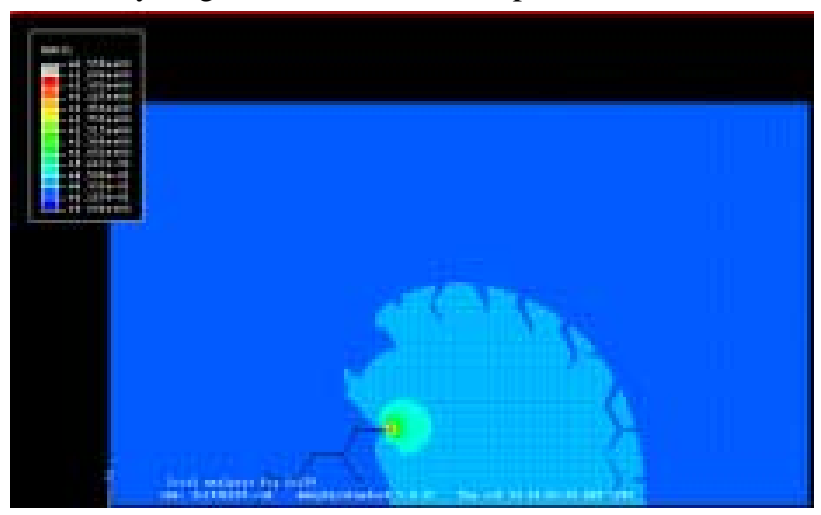

Hydrogen diffusion zone, step 24

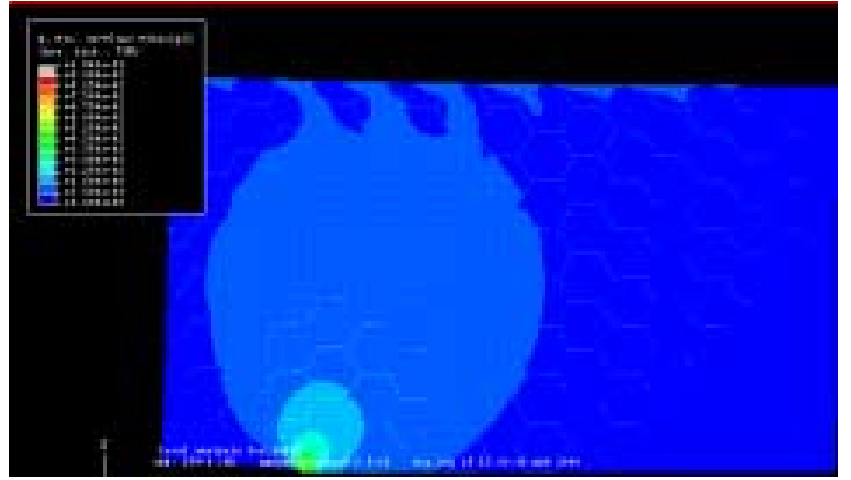

Principal strain distribution, crack growth, step1

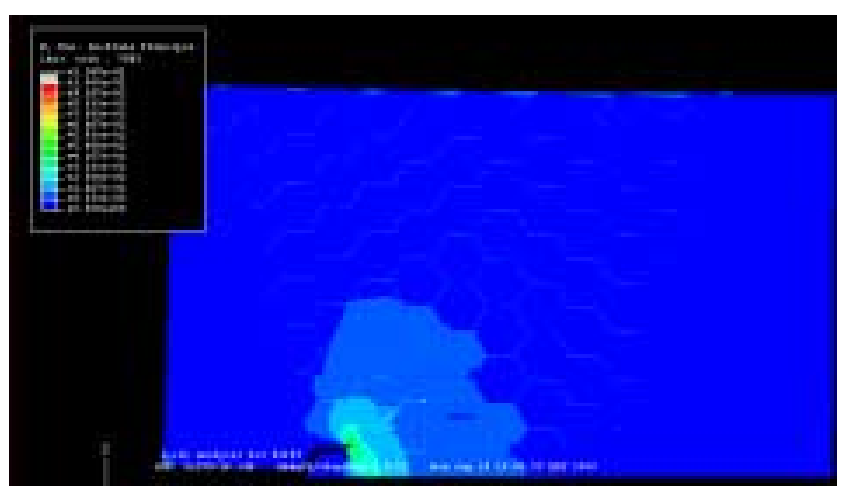

Principal strain distribution, crack growth, step 8

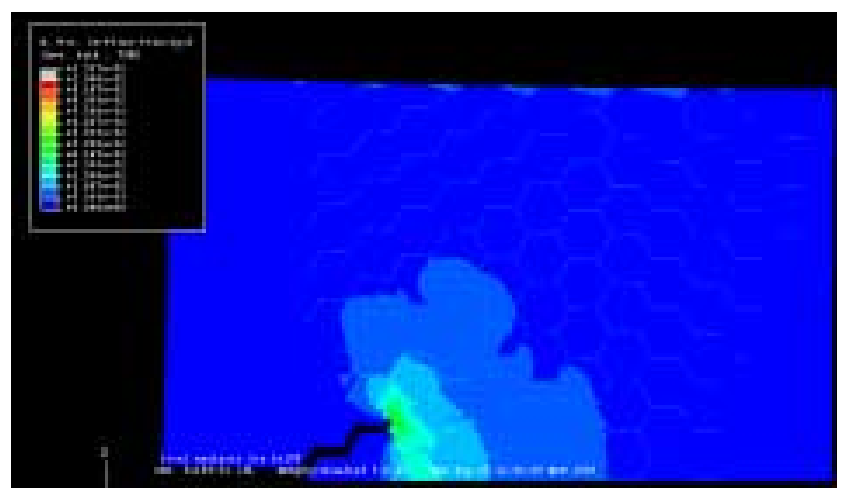

Principal strain distribution, crack growth, step 16

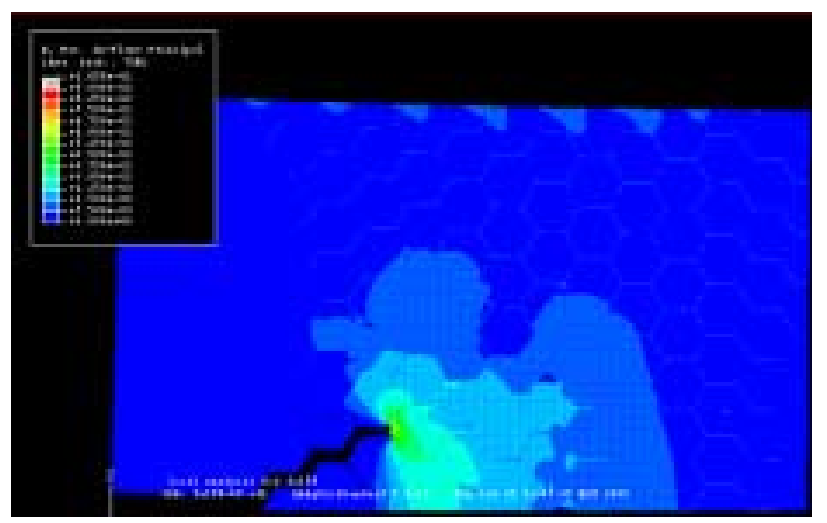

Principal strain distribution, crack growth, step 24 


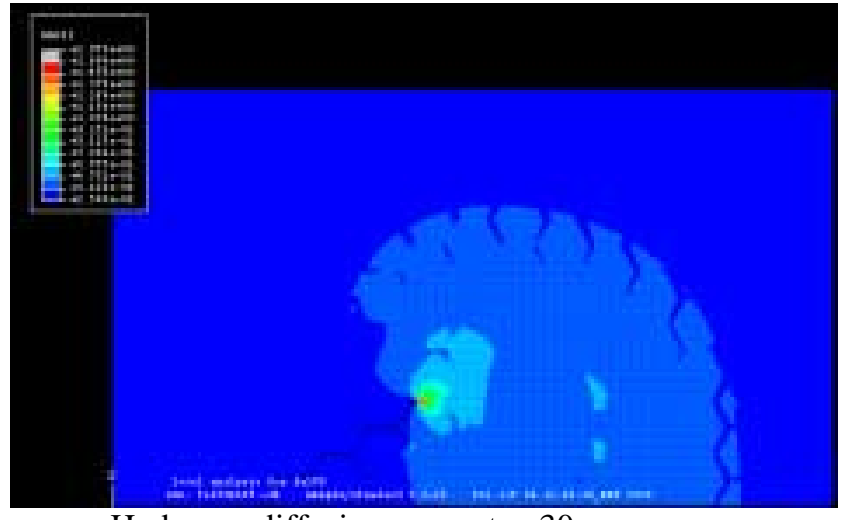

Hydrogen diffusion zone, step 30

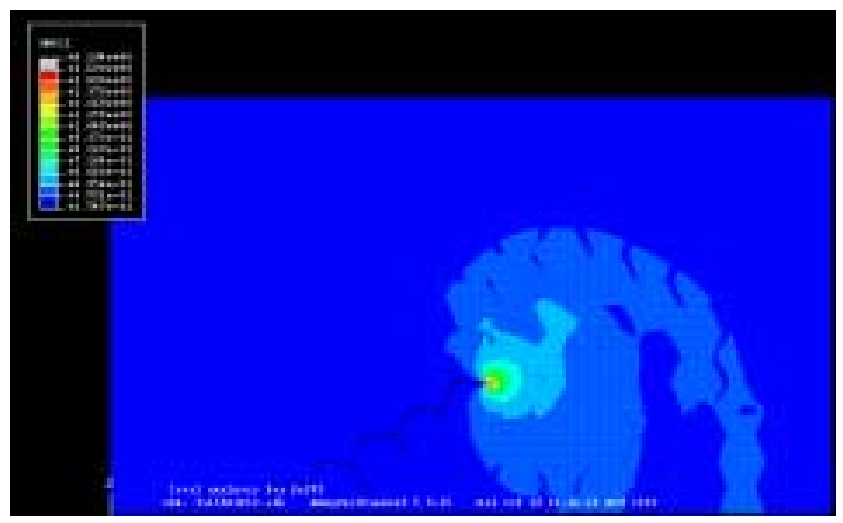

Hydrogen diffusion zone, step 37

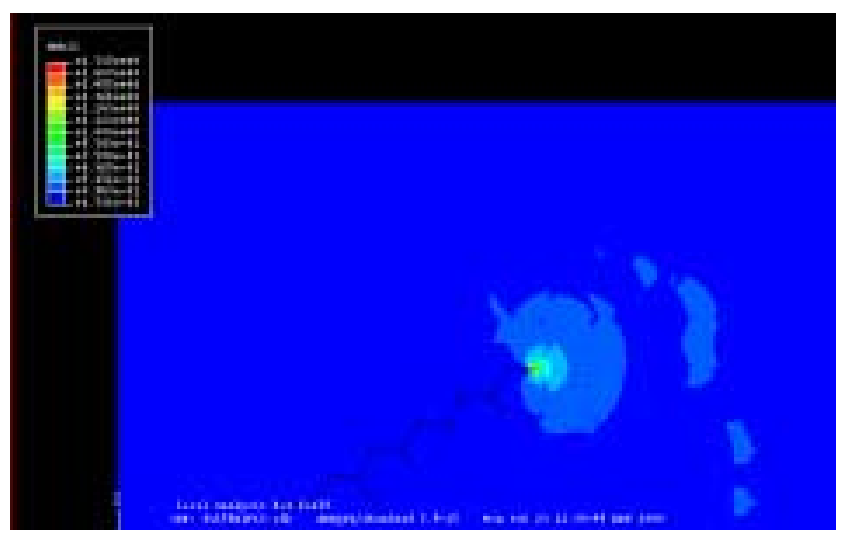

Hydrogen diffusion zone, step 40

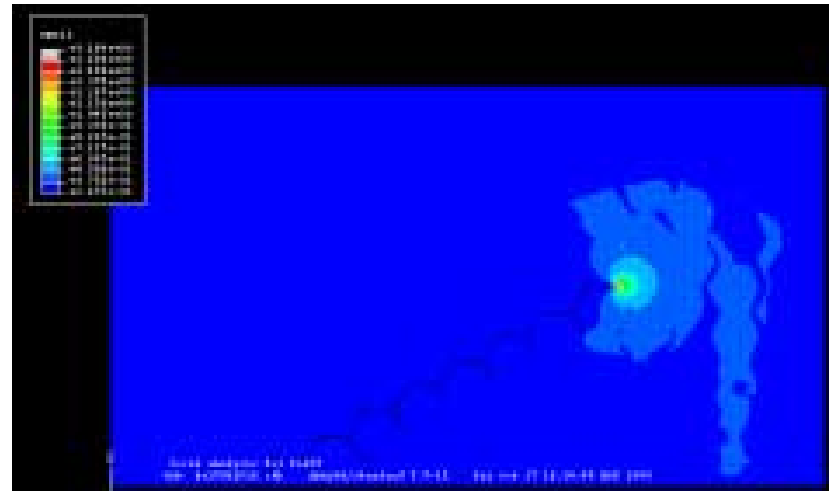

Hydrogen diffusion zone, step 48

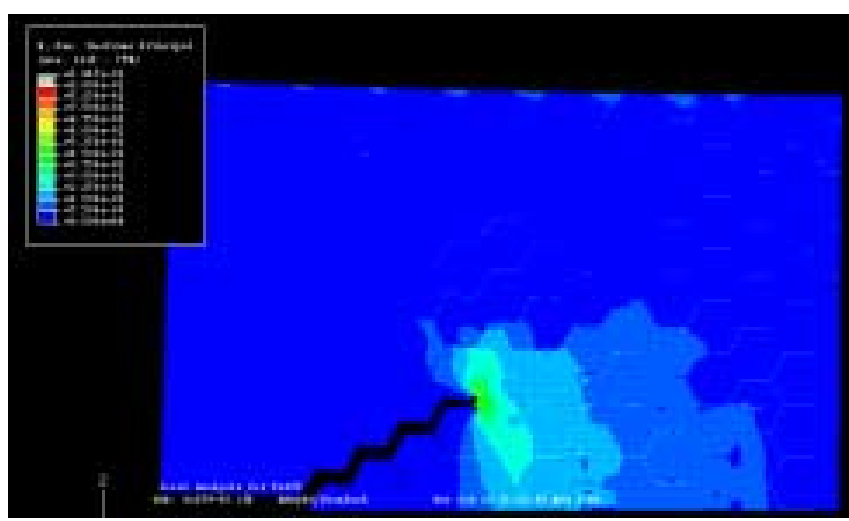

Principal strain distribution, crack growth, step 30

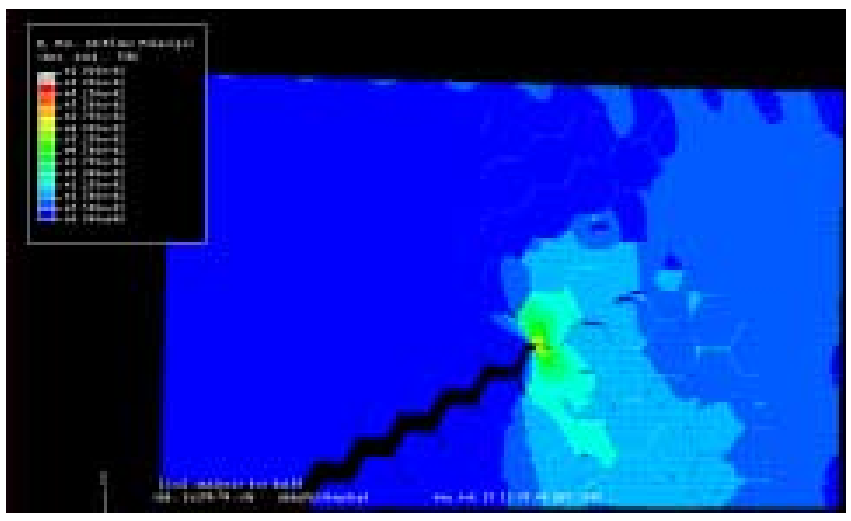

Principal strain distribution, crack growth, step 37

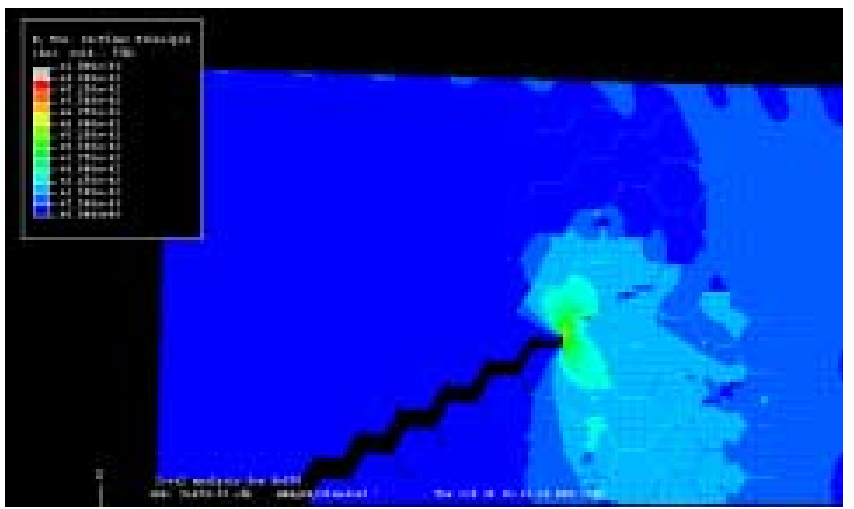

Principal strain distribution, crack growth, step 40

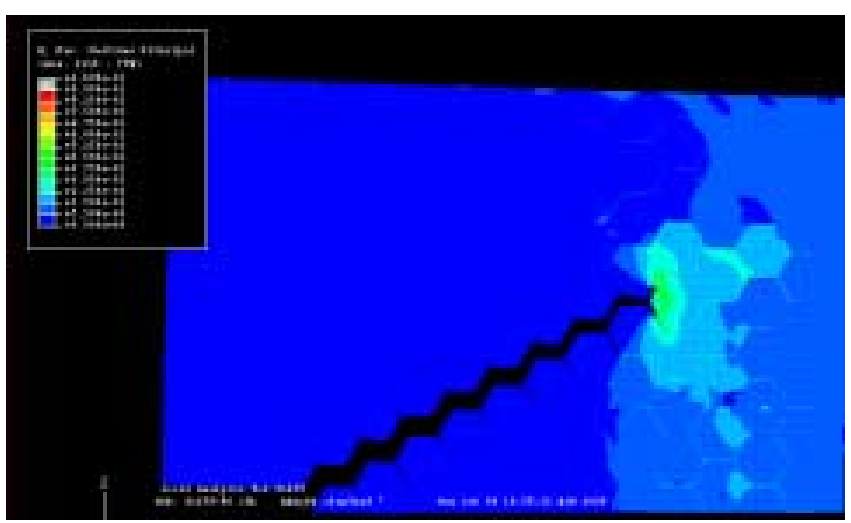

Principal strain distribution, crack growth, step 48 Fig. 5.11 Principal strain distribution for FA-189, $\mathrm{K}_{\mathrm{I}}=17.36 \mathrm{MPa} \sqrt{\mathrm{m}}$, Air, failure strain $6 \%$ 


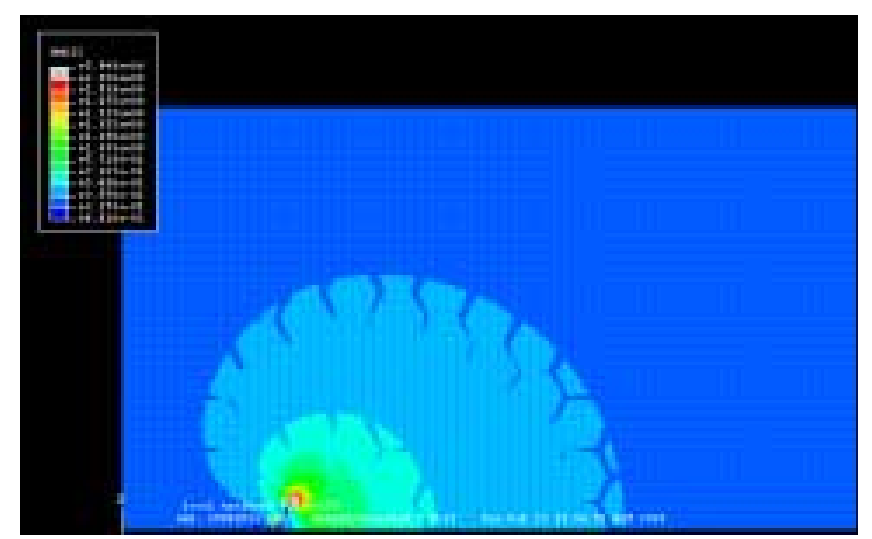

Hydrogen diffusion zone, step 2

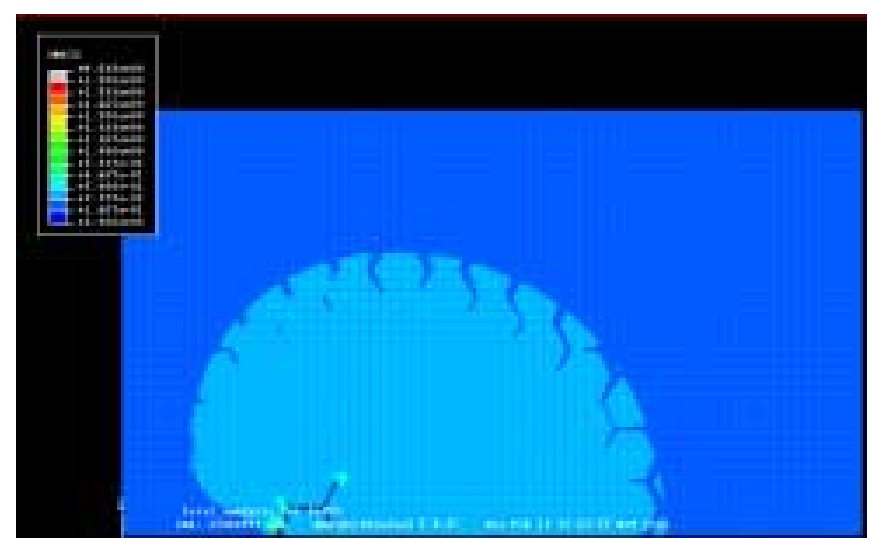

Hydrogen diffusion zone, step 4

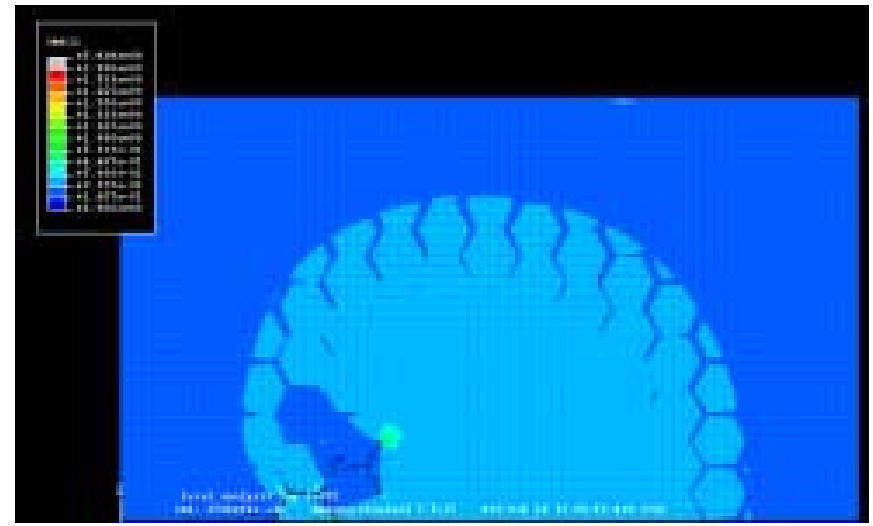

Hydrogen diffusion zone, step 6

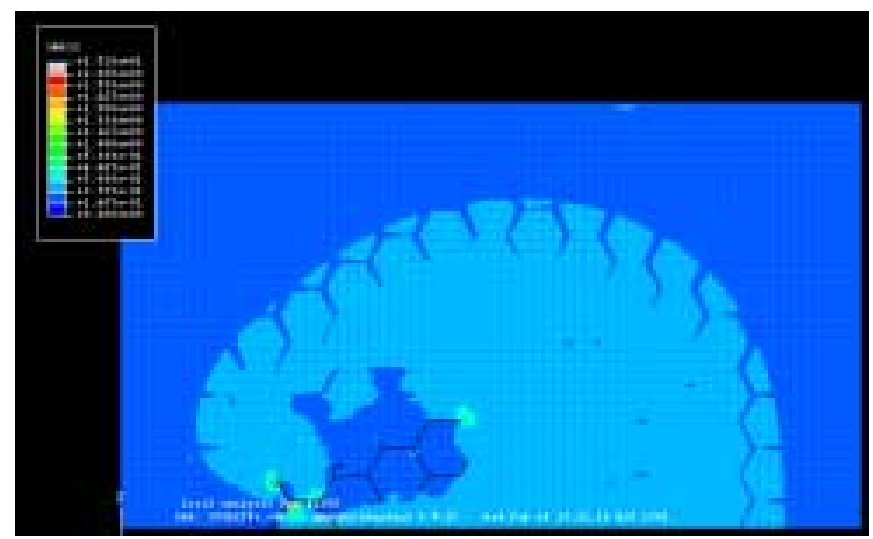

Hydrogen diffusion zone, step 8

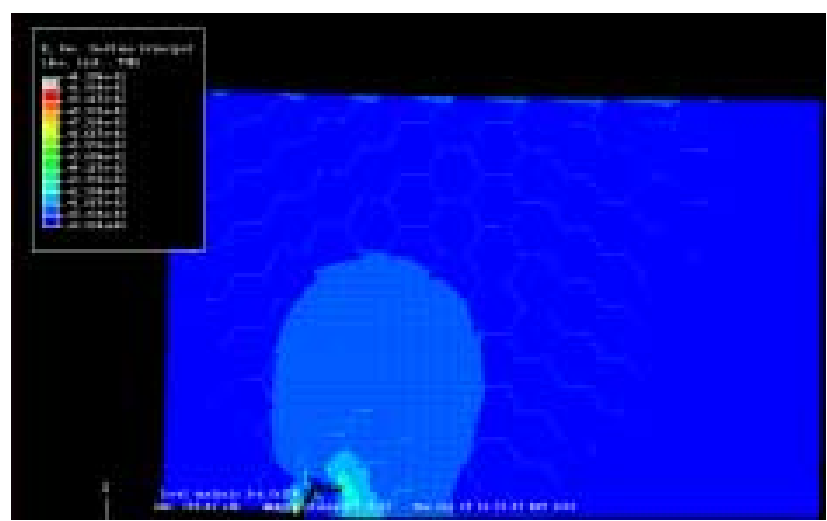

Principal strain distribution, crack growth, step 2

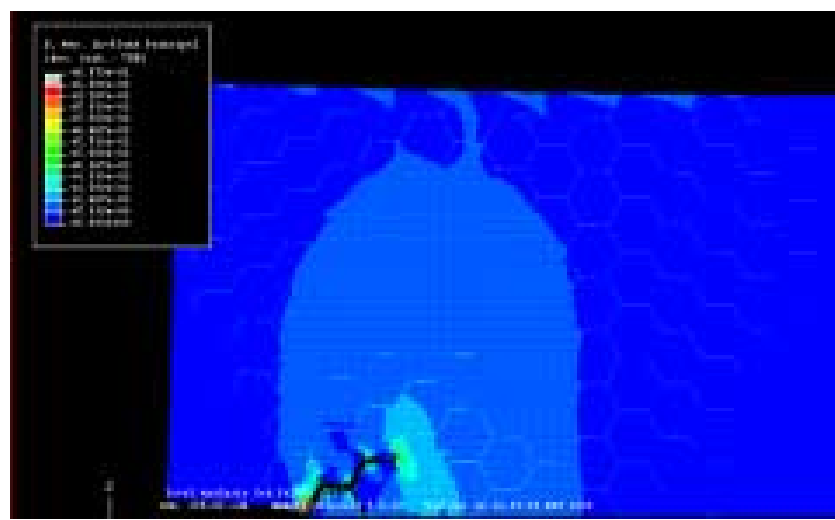

Principal strain distribution, crack growth, step 4

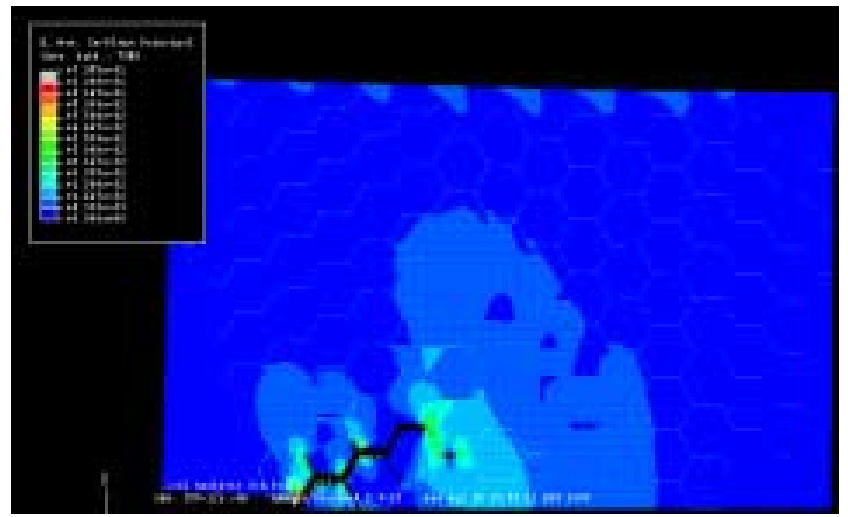

Principal strain distribution, crack growth, step 6

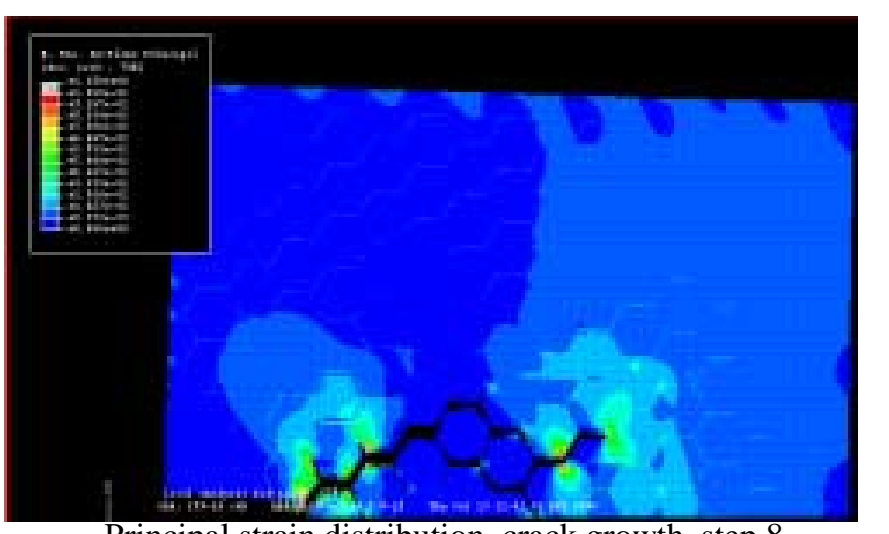

Principal strain distribution, crack growth, step 8

Fig. 5.12 Principal strain distribution for FA-189, $\mathrm{K}_{\mathrm{I}}=17.36 \mathrm{MPa} \sqrt{\mathrm{m}}$, Air, failure strain 4\% 


\section{CHAPTER 6}

\section{CONCLUSIONS AND RECOMMANDATIONS}

\subsection{Conclusions}

Comparative coupled stress and hydrogen diffusion analyses followed by an intergranular crack growth simulation of FA-186 and FA-189 iron aluminides under vacuum and air were carried out in this research. Comparative analyses between numerical modeling data and experimental data (fractographies and digital image processing of the experimental moiré images) were also conducted.

The computational modeling analysis presented is qualitative in nature. No attempt has been made to include the study of hydrogen transport kinetics such as incubation time period, kinetics of degradation, and the critical hydrogen concentration build-up before fracture. Summary conclusions are as follows:

1. With the same applied stress intensity factor in vacuum conditions, FA-189 showed a better resistance to fracture than FA-186 due to its micro-alloying addition $(0.5 \% \mathrm{Zr}$, $0.05 \% \mathrm{C}, 0.005 \% \mathrm{~B})$.

2. With the same applied stress intensity factor and with the same prescribed hydrogen concentration, FA-189 showed a larger hydrogen diffusion zone (with concentrations almost three times higher than those obtained for FA-186).

3. Small amount of hydrogen may be enough to cause significant embrittlement in iron aluminides, especially in FA-189.

4. Size of grain boundary may play a decisive role to the extrinsic environmental fracture behavior of iron aluminides. 
5. Our computational modeling analyses indicated that FA-189 is extrinsically more brittle than FA-186, but intrinsically its fracture resistance performance is better than that of FA-186.

6. Finally, good qualitative agreement between the modeling predictions and experimental results is observed.

\subsection{Recommendations}

(1) A time - dependent finite element simulation of the intergranular crack growth should be developed in order to include the influence of crack-growth rate on the fracture behavior of these two iron aluminides.

(2) A series of simulations could be carried out at different partial pressures of hydrogen gas with eventually predictions of threshold partial pressures at which the fracture initiates .

(3) Further investigation in order to introduce a phenomenological embrittlement model, in which the cohesive strength decreases with increasing hydrogen concentration, would be very useful. Our selection of degrading the material properties is arbitrary, and may underestimate the degree of embrittlement in a real situation.

(4) The model can be extended to encompass temperature-dependent response, diffusing transport of alloying species, and other phenomena as indicated by investigations of hydrogen - driven fracture in iron aluminides. 
(5) Developing a software which allows an automatically degrading of the material properties for the elements with high hydrogen concentrations and then releasing the nodes to simulate the intergranular crack growth would be very useful also.

(6) It would be interesting to carry-out comparative studies of the fracture behavior of these two alloys under cyclic loading conditions in air and vacuum and verify the assertions that FA-189 has lower fatigue crack growth rate than that of FA-186. 


\section{REFERENCES}

1. C.T.Liu and K.S.Kumar, Ordered Intermetallic Alloys, Part I: Nickel and Iron Aluminides. JOM, May 1993, p.38-44.

2. C.T.Liu et al. ISIJ Int., October 1991.

3. C.T.Liu, E.H.Lee, and C.G.McKamey. Scr. Metall., 23, (1989), p.875.

4. C.T.Liu, C.G.McKamey, and E.H.Lee. Scr. Metall., 24, (1990), p.385.

5. C.G.McKamey, E.H.Lee, High Temperature Ordered Intermetallic Alloys, $\mathrm{V}$ symposium, p.xix+1212,938-8, Boston, USA, 30 Nov - 3 Dec,1992.

6. C.T.Liu and C.G.McKamey, High Temperature Aluminides and Intermetallics, eds.S.H.Whan et al., (Warrendale,PA:TMS1990), p.133.

7. R. Balasubramanian, Journal of alloys and compounds, vol.253-254, no.1-2, p.148-51

8. C.T Liu, Intermetallic Compounds-Structure and Mechanical Properties, Proc. JIMIS-6 (Sendai, Japan: Japan Institute of Metals)1991, p.3-19.

9. C.T Liu, Ordered Intermetallics-Physical Metallurgy and Mechanical Behavior, eds.C.T.Liu,R.W. Cahn, and G.Sauthoff, p.321-334

10. B.S.-J.Kang,Q.Yao, Z.Li, C.T.Liu, Investigation on environmetal assisted fracture behavior of iron aluminides using moiré interferometry. Materials Science and Engineering A239-240 (1997), p.344-352.

11. C.T.Liu, Intermetallic Compounds-Structure and Mechanical Properties, Proc. JIMIS- 6, p.703-712.

12. M.Shea, A. Castagna, and N.S.Stoloff, High Temperature Ordered Intermetallic Alloys, IV ed. L.A.Johnson, et al.MRS Symp.Proc.,vol.213,1992, p.609

13. H.K.Birnbaum, Environment-induced Cracking of Metals, ed. R.G.Ganghoff and 
M.B.Ives, 1990, p.21-29.

14. S.P Lynch, Acta Metall., 369 (1988), p.2639.

15. D.B. Kasul and L.A.Heldt, Environmental Effects on Advanced Materials, TMSAIME, ed. R.H. Jones and R.E. Ricker, Warrendale, PA,1991, p.67

16. D. Zhang, D. She, G. Du, F.Zhu, and Hsiao,C.,Scripta Metall., vol. 27(1992), p.297301.

17. N.S.Stoloff and David J. Duquette, Moisture and Hydrogen-Induced Embrittlement of Iron Aluminides, Rensselaer Polytechnic Institute, 1992.

18. N.S.Stoloff, Hydrogen Effects on Material Behavior, Warrendale, PA:TMS,1990), p.483-497.

19. C.T.Liu and E.P.George, High Temperature Ordered Intermetallic Alloys, IV ed. L.A.Johnson, et al. MRS Symp.Proc.,vol.213,1992, p.527.

20. C.T.Liu and E.P George, Scripta Metall.,24(1990), p.1285.

21. W.C.Luu and J.K.Wu, Hydrogen transport and environmental embrittlement effects in iron aluminides. Journal of Materials Science 35(2000), p.4121-4127.

22. J.P Hirth, Hydrogen induced fracture. Chemistry and Physics of Fracture (eds. R.M. Latanisian and R.H.Jones), p.538-551.Martinus Nijhoff,Lancaster(1987).

23. H.K Birnbaum, Mechanisms of hydrogen-related fracture of metals. Environmentinduced Cracking of Metals (eds. R.P Gangloff and M.B.Ives), p.2130,NACE,Houston(1990).

24. R.A.Oriani, Environment-induced Cracking of Metals (eds. R.P Gangloff and M.B.Ives), p.439-448,NACE,Houston(1990). 
25. A.Turnbull, Modelling of Environment Assisted Cracking. Corrosion Science,vol.34,no.6, p.921-960 (1993).

26. C.D.Beachem, A new model for hydrogen-assisted cracking. Metall. Trans.3, p.437451(1972).

27. S.P.Lynch, Environmetally assisted cracking: Overview of evidence for an adsorption-induced localised slip process. Journal of Mater.Sci.21, p.692(1986).

28. H.P.Van Leuwen, The kinetics of hydrogen embrittlement: A quantitative diffusion model.Engineering Fracture Mechanics,6, p.141-161(1974).

29. D.J. Unger and E.C.Aifantis, Solutions of some diffusion equations related to stress corrosion cracking. Environmetal Degradation of Engineering Materials, p.131139(1977).

30. H.Kitagawa and Y.Kojima, Diffusion of hydrogen near an elasto-plastically deformed crack tip. Atomistics of Fracture (eds. R.M.Latanisian and J.R.Perkins), p.799-811.Plenum Press, New York(1983).

31. Scott X.Mao and M.Li, Mechanics and Thermodynamics on the Stress and Hydrogen Interaction in Crack Tip Stress Corrosion: Experiment and Theory. Journal of Mechanics and Physics of Solids 46, p.1125-1137, (1998).

32. P.Sofronis and R.M.McMeeking, Numerical Analysis of hydrogen transport near a blunting crack tip. Journal of Mechanics and Physics of Solids 37, p.317350,(1989).

33. J.Toribio, A.Valiente, R.Cortes, L.Caballero, Modelling hydrogen embrittlement in 316L austenitic stainless steel for the first wall of the Next European Torus. Fusion Eng. Des. 29, p.442-447. 
34. A.H.M. Krom, R.W.J. Koers, A.Bakker, Hydrogen Transport Near a Blunting Crack Tip. Journal of Mechanics and Physics of Solids 47, p.971-992,(1999).

35. ABAQUS/Standard User's Manual

36. Herbert H.Johnson, Hydrogen in Iron. The 1986 Campbell Memorial Lecture ASM International. Metall.Trans.A, vol.19A, Oct.1988, p.2371.

37. A. Troiano, Trans.ASM 52, p.54 (1960).

38. X.Chen, T.Foecke, M.Lii, Y.Katz, and W.W.Gerberich, The Role of Stress State on Hydrogen Cracking in Fe-Si Single crystals. Engineering Fracture Mechanics, vol.35, p.997-1017 (1990).

39. R.A.Oriani, Fundamental Aspects of Stress Corrosion Cracking, p.32, National Association of Corrosion Engineers, Houston, 1969.

40. H.W.Liu, Stress Corrosion Cracking and the Interaction Between Crack Tip Stress Field and Solute Atoms. J.Basic Eng., ASME, 1970,vol.92, p.633-638.

41. C.St.John and W.W.Gerberich, The Effect of Loading Mode on Hydrogen Embrittlement, Metall. Trans.,vol.4, february 1973, p.589-594.

42. J.C.M.Li, R.A.Oriani, and L.S. Darken, Z.Physik Chem.49, p.271 (1966).

43. J. Völkl and G.Alefeld, Hydrogen in Metals. Topics in Applied Physics, vol.28, p.321(edited by G.Alefeld and J.Volkl) (1978).

44. H.H. Johnson, Hydrogen in Metals, p.35 (edited by I.M.Bernstein and A.W.Thompson), ASM, Ohio (1974).

45. J.P.Hirth, Metall.Trans. 11A, p. 861

46. Smithells Metals Reference Book,1992.Ed.E.A.Brandis,G.B.Brooks, $7^{\text {th }}$ edn., Buttersworth, London 
47. N.S.Stoloff and C.T.Liu, Review - Environmental embrittlement of iron aluminides. Intermetallics 2 (1994), p.75- 87

48. Qizhou Yao, Master's Thesis, West Virginia University, Department of Mechanical Engineering, September 1996

49. Zhongrun Li, Master's Thesis, West Virginia University, Department of Mechanical Engineering, April 1998

50. C.G.McKamey, D.H.Pierce, Scripta Metall., vol.28,1993, p.1173 


\section{APPENDIX A}


FA-186, Air, $\mathrm{K}=36.9 \mathrm{MPa} \sqrt{\mathrm{m}}_{\mathrm{m}}$

$$
\mathrm{T}=0 \min
$$
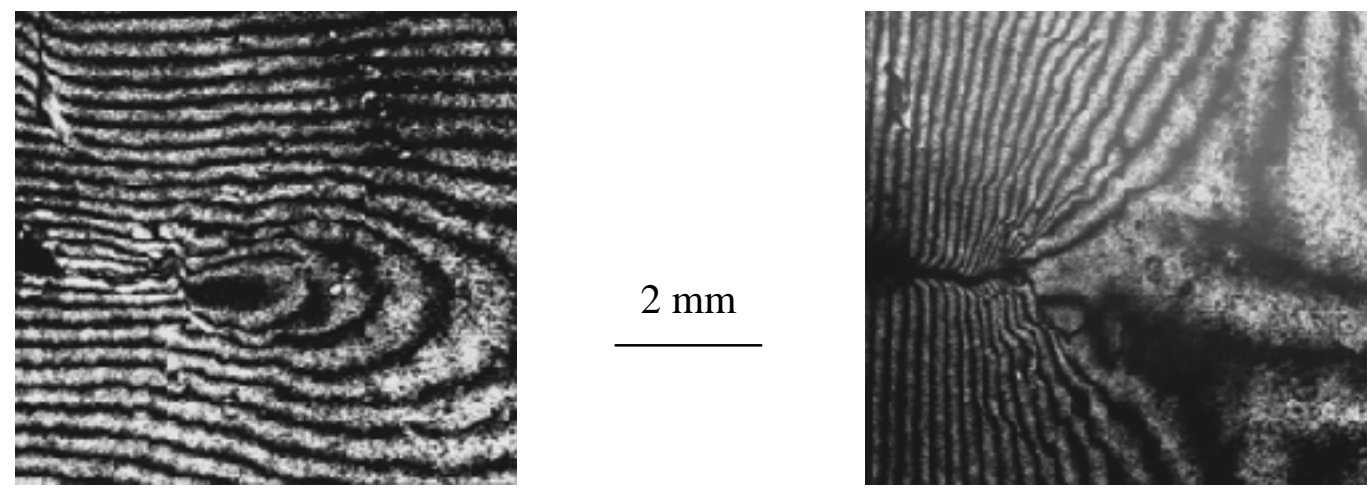

(The original moiré fringe pattern)
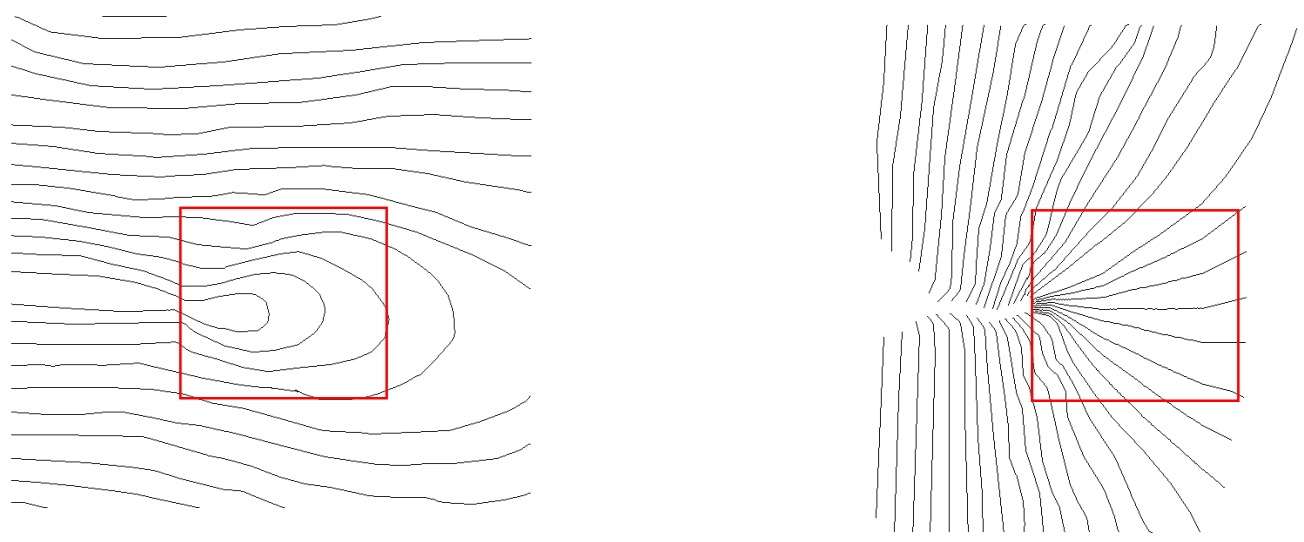

(after digital image processing)

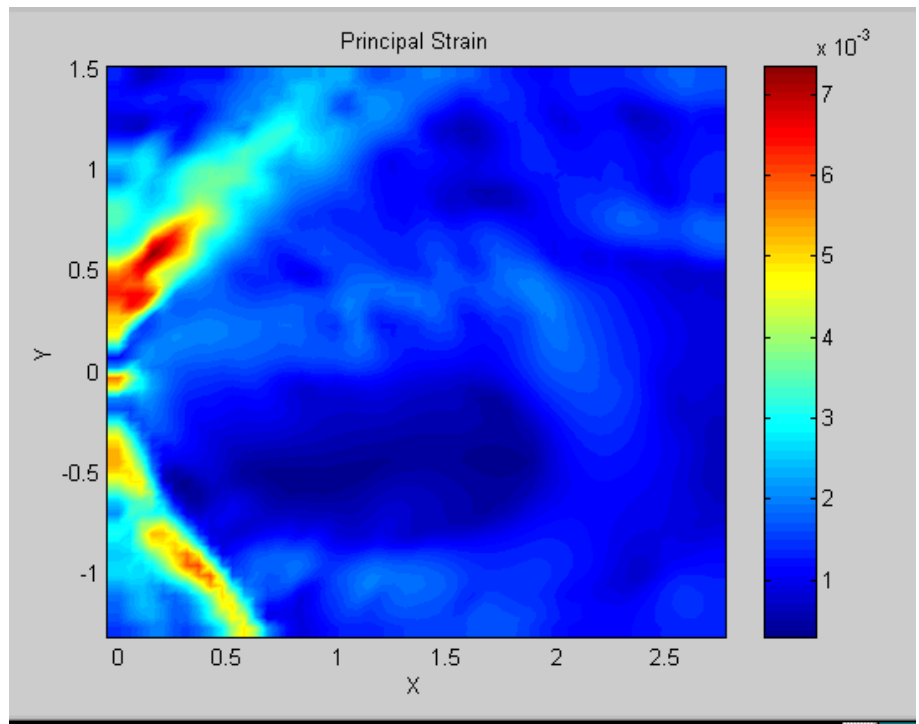

Maximum principal strain distribution after image processing 
FA-186, Air, K=36.9 MPa $\sqrt{m}_{\mathrm{m}}$

$\mathrm{T}=5 \mathrm{~min}$
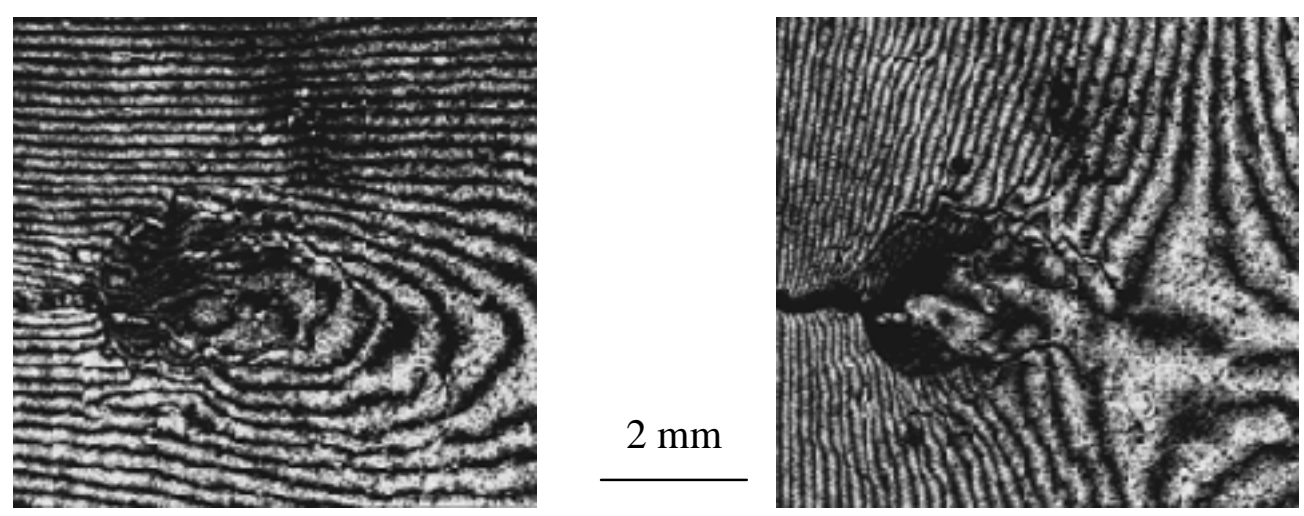

(The original moiré fringe pattern)
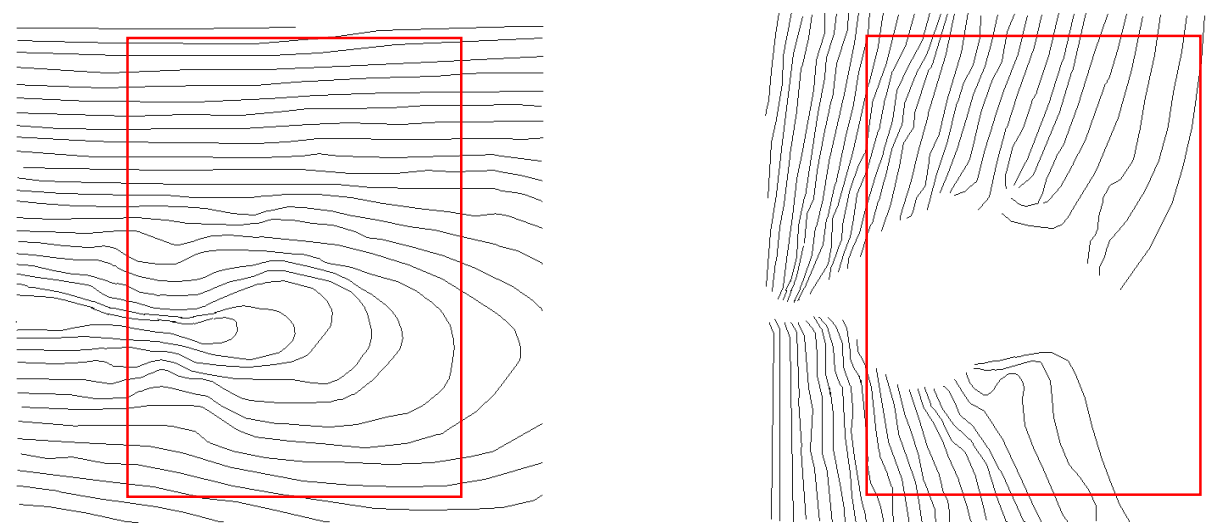

( after digital image processing)

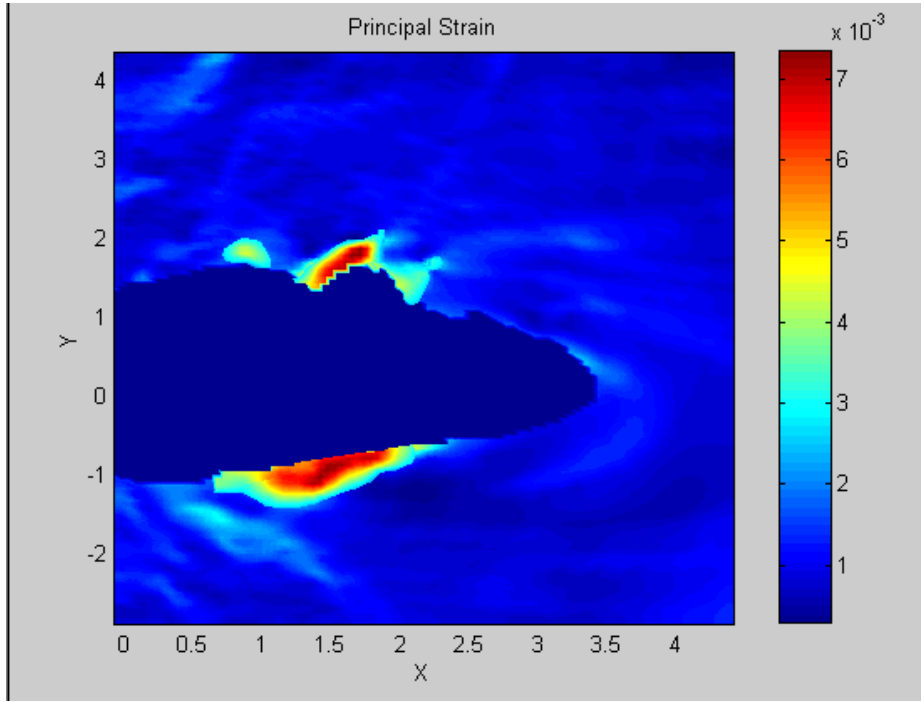

Maximum principal strain distribution after image processing 
FA-189, Air, K=17.36 MPa $\sqrt{m}$

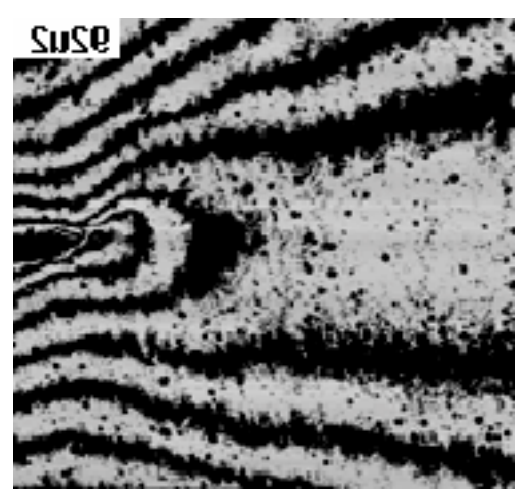

$$
\mathrm{T}=0 \mathrm{~min}
$$

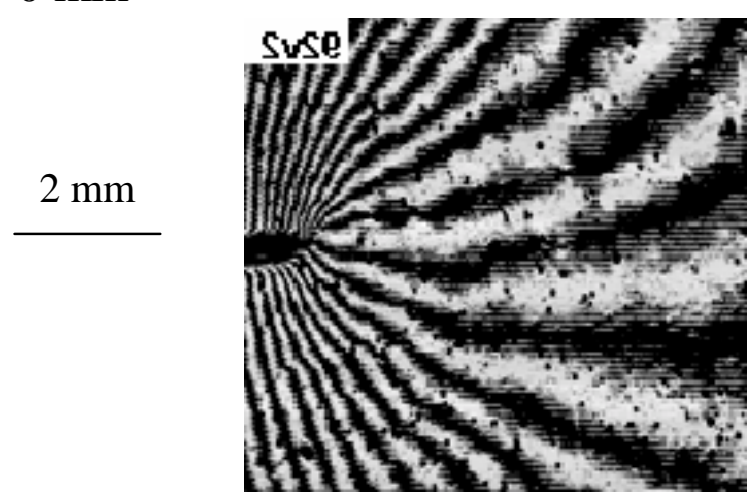

(original moiré fringe pattern)
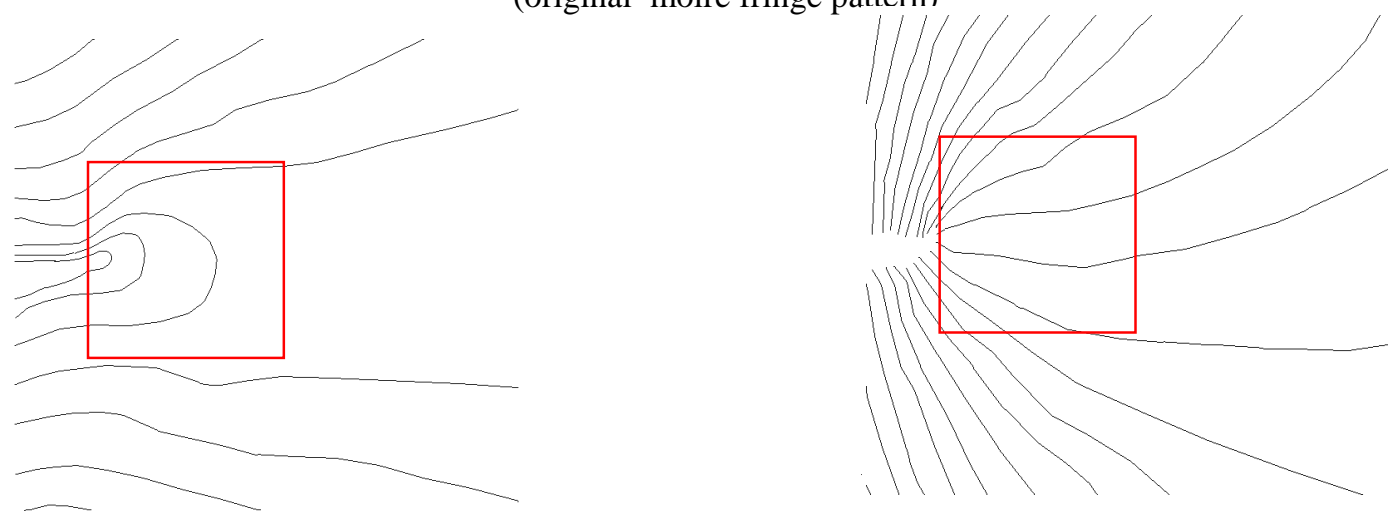

(after digital image processing)

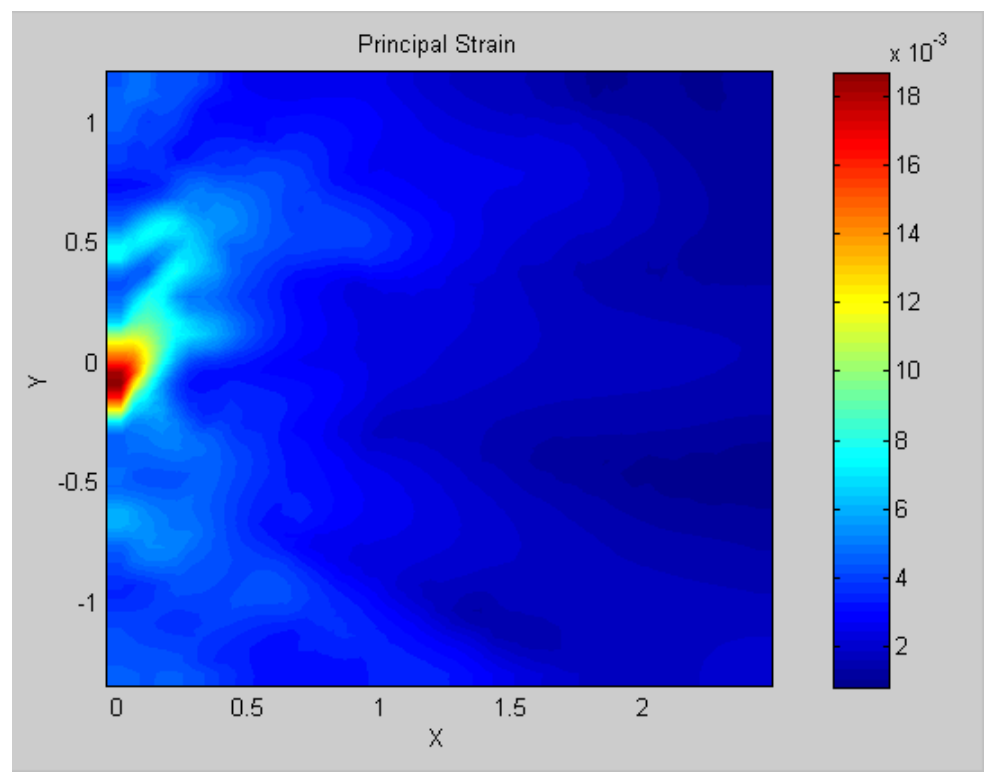

Maximum principal strain distribution after image processing 


$$
\mathrm{T}=2.5 \mathrm{~min}
$$
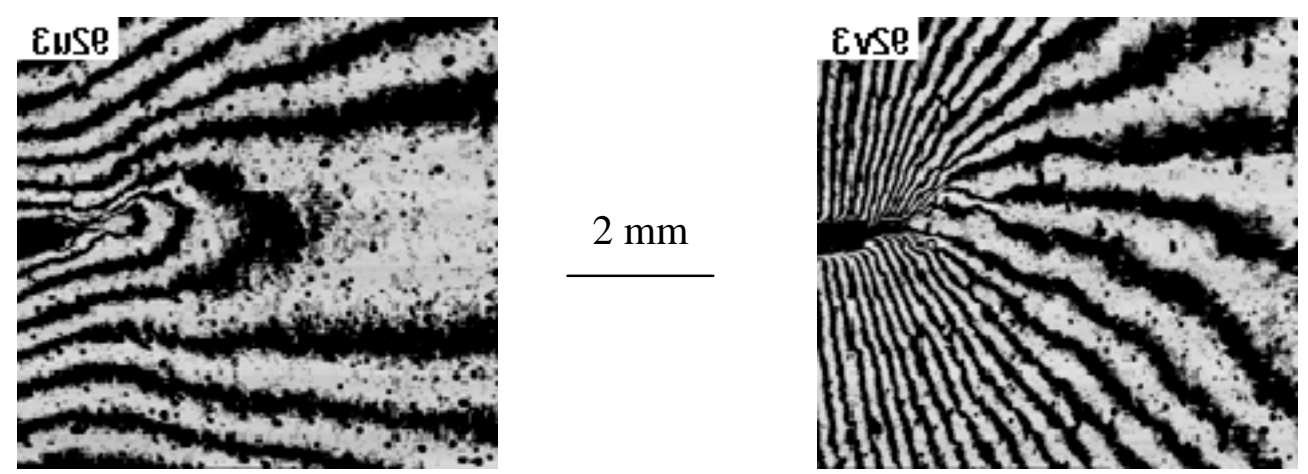

(original moiré fringe pattern)
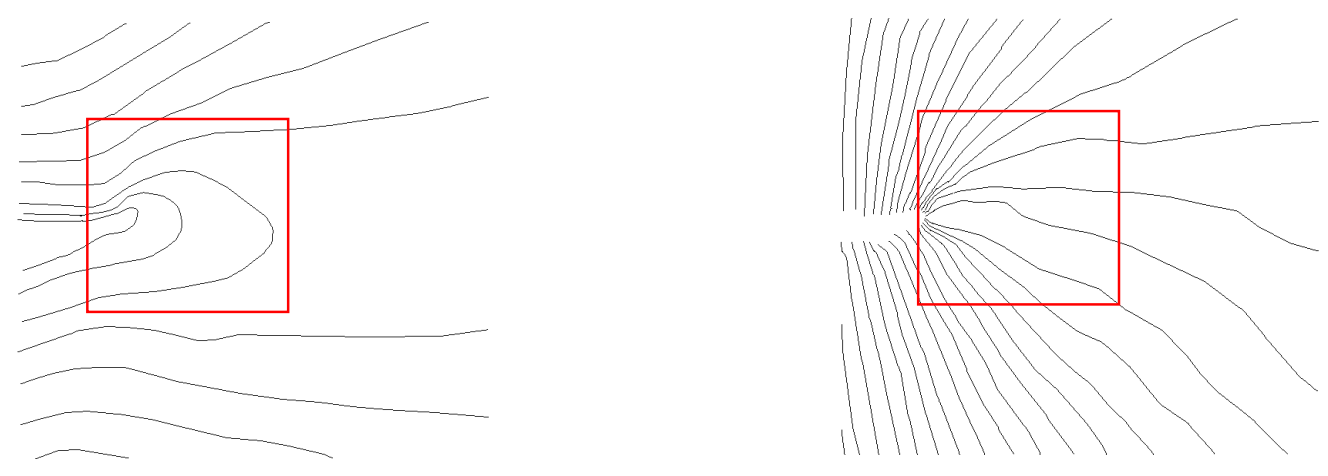

(after digital image processing)

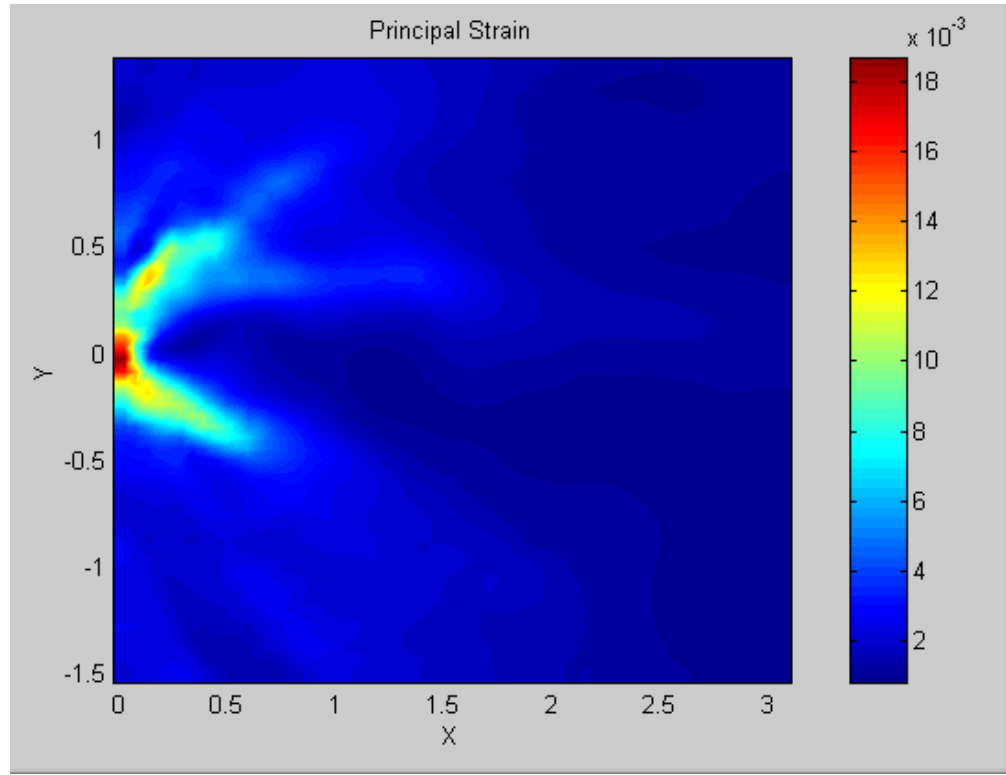

Maximum principal strain distribution after image processing 


\section{FA-189, Air, $\mathrm{K}=17.36 \mathrm{MPa} \sqrt{\mathrm{m}}_{\mathrm{m}}$}

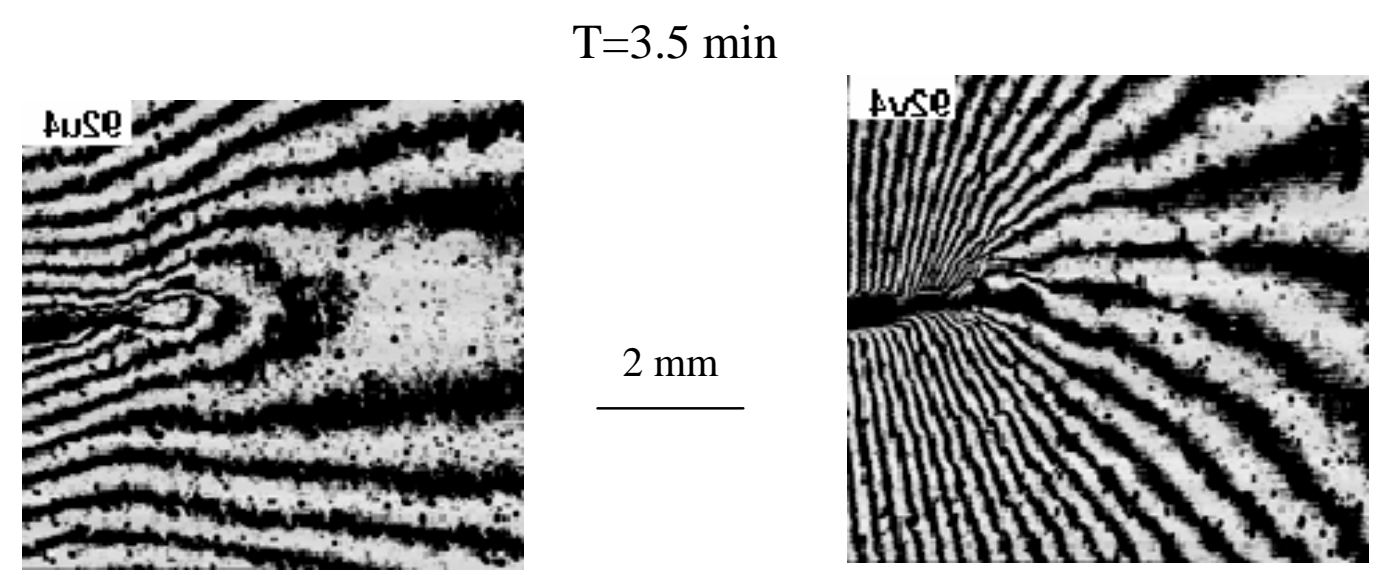

(original moiré fringe pattern)
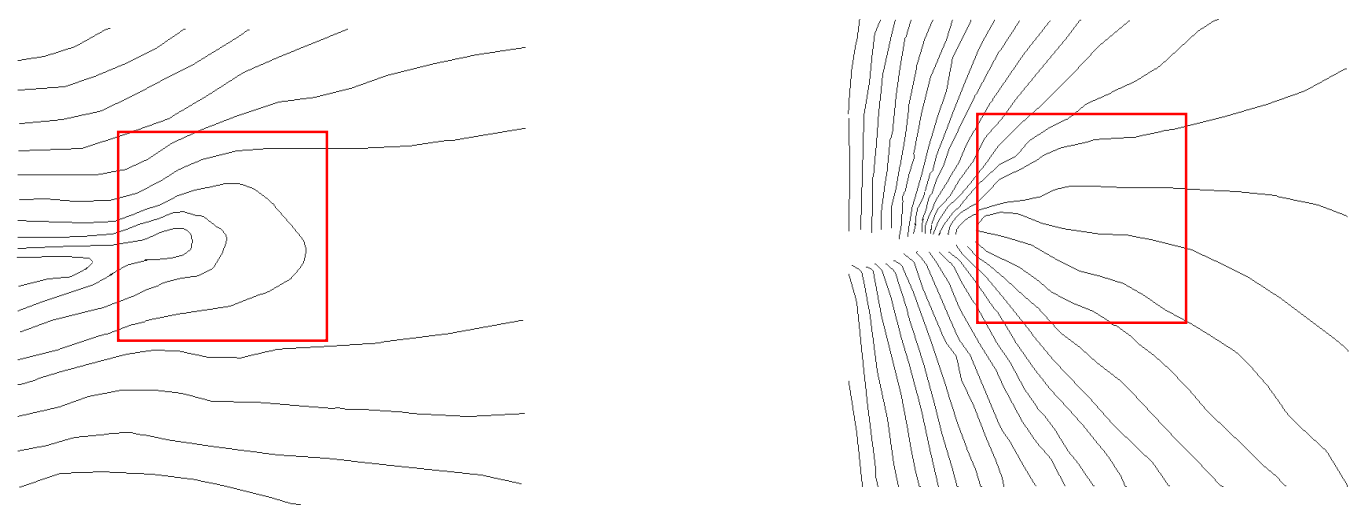

(after digital image processing)

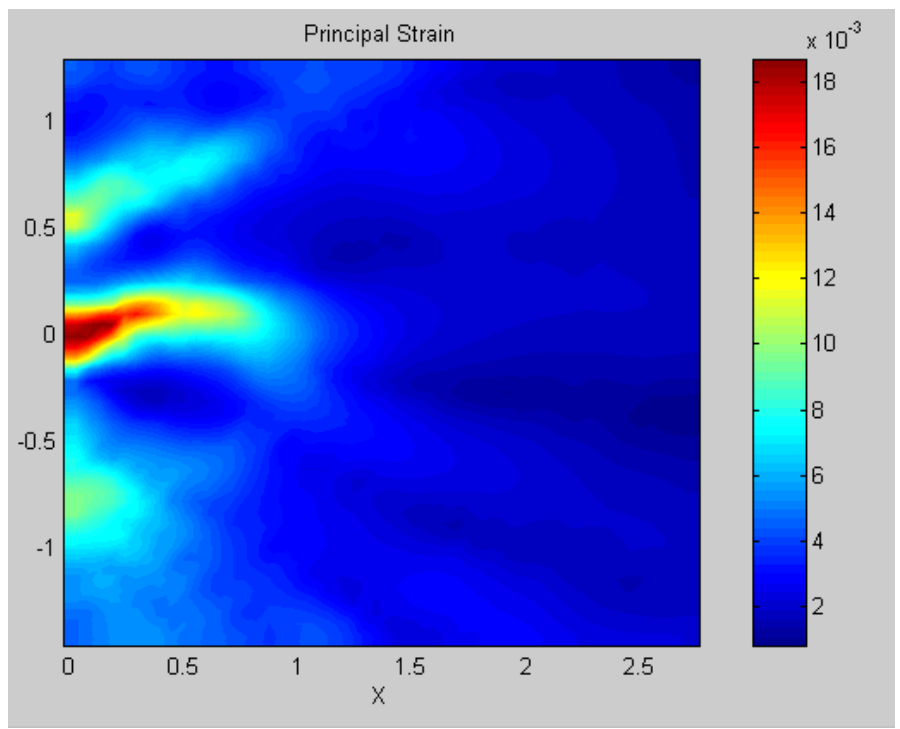

Maximum principal strain distribution after image processing 
FA-189, Air, K=17.36 MPa $\sqrt{m}$

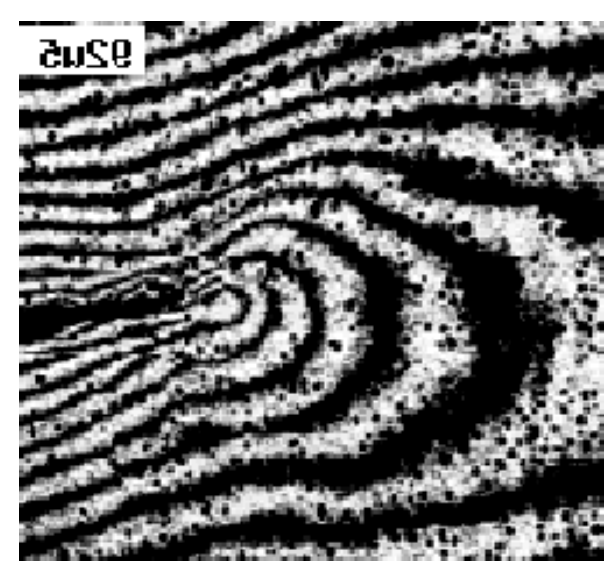

$\mathrm{T}=4.5 \mathrm{~min}$

$2 \mathrm{~mm}$

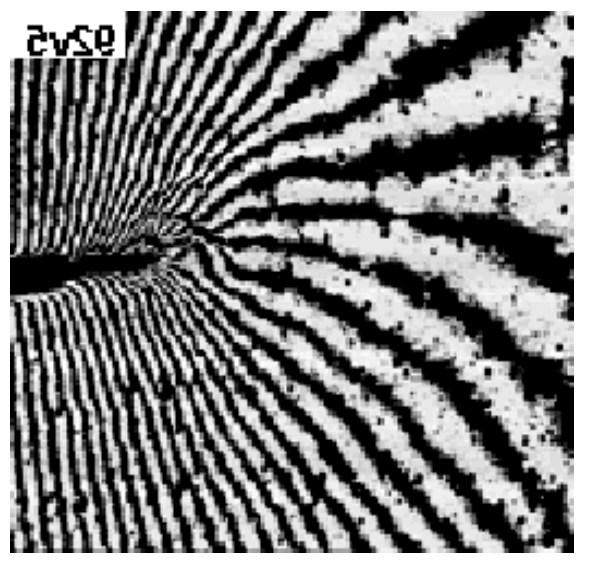

(original moiré fringe pattern)
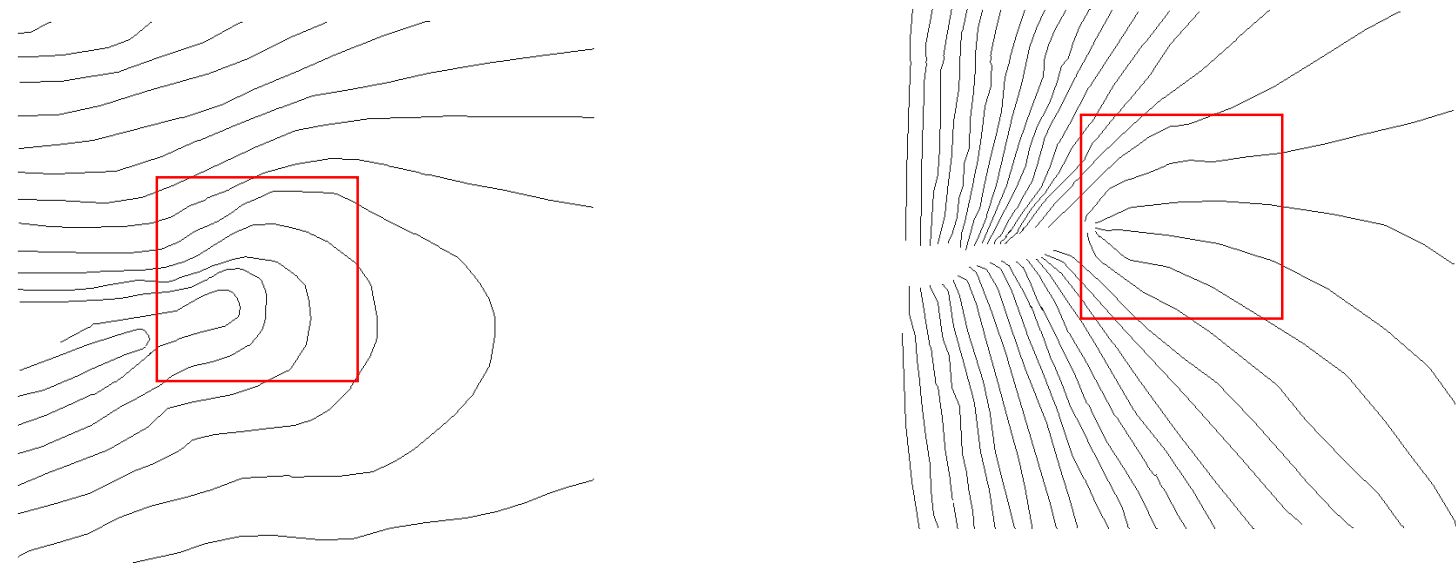

(after digital image processing)

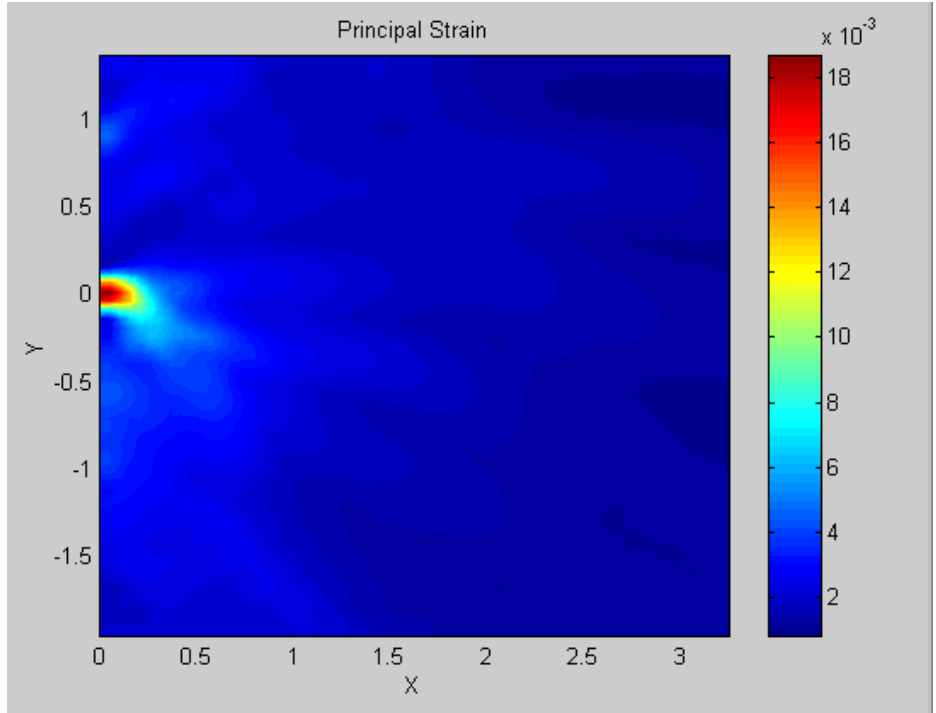

Maximum principal strain distribution after image processing 


\section{APPENDIX B}

Table 1 . Model validity check for initial stage, FA-189, $\mathrm{K}_{\mathrm{I}}=17.36 \mathrm{Mpa} \sqrt{\mathrm{m}}$

\begin{tabular}{|c|c|c|c|}
\hline \multirow[t]{2}{*}{ Boundary } & \multirow{2}{*}{$\begin{array}{c}\begin{array}{c}\text { Boundary node in the } \\
\text { global model }\end{array} \\
\begin{array}{c}\text { Corresponding boundary } \\
\text { node in submodel }\end{array}\end{array}$} & \multicolumn{2}{|c|}{ Nodal Displacements } \\
\hline & & U1 & $\mathrm{U} 2$ \\
\hline \multirow{12}{*}{ RIGHT BOUNDARY } & \multirow{2}{*}{$\begin{array}{c}409,410 \\
6499\end{array}$} & $5.28 \mathrm{E}-2,5.2 \mathrm{E}-2$ & 0,0 \\
\hline & & $5.24 \mathrm{E}-2$ & 0 \\
\hline & \multirow{2}{*}{$\begin{array}{c}393 \\
6517\end{array}$} & $5.2518 \mathrm{E}-2$ & $2.845 \mathrm{E}-4$ \\
\hline & & $5.247 \mathrm{E}-2$ & $2.69 \mathrm{E}-4$ \\
\hline & \multirow{2}{*}{$\begin{array}{c}376 \\
9405\end{array}$} & $5.2171 \mathrm{E}-2$ & $6.2434 \mathrm{E}-4$ \\
\hline & & $5.25 \mathrm{E}-2$ & $5.46 \mathrm{E}-4$ \\
\hline & \multirow{2}{*}{$\begin{array}{c}359 \\
15161\end{array}$} & $5.2839 \mathrm{E}-2$ & $8.7573 \mathrm{E}-4$ \\
\hline & & $5.27 \mathrm{E}-2$ & $8.1 \mathrm{E}-4$ \\
\hline & \multirow{2}{*}{$\begin{array}{c}308 \\
20891\end{array}$} & $5.3208 \mathrm{E}-2$ & $2.0312 \mathrm{E}-3$ \\
\hline & & $5.356 \mathrm{E}-2$ & $1.85 \mathrm{E}-3$ \\
\hline & \multirow{2}{*}{$\begin{array}{c}274 \\
17980\end{array}$} & $5.391 \mathrm{E}-2$ & $2.825 \mathrm{E}-3$ \\
\hline & & $5.41 \mathrm{E}-2$ & $2.41 \mathrm{E}-3$ \\
\hline \multirow{18}{*}{ TOP BOUNDARY } & \multirow{2}{*}{$\begin{array}{c}291 \\
17991\end{array}$} & $5.4168 \mathrm{E}-2$ & $2.2069 \mathrm{E}-3$ \\
\hline & & $5.3948 \mathrm{E}-2$ & $2.27 \mathrm{E}-3$ \\
\hline & \multirow{2}{*}{$\begin{array}{c}258 \\
18592\end{array}$} & $5.3734 \mathrm{E}-2$ & $3.0449 \mathrm{E}-3$ \\
\hline & & $5.387 \mathrm{E}-2$ & $2.83 \mathrm{E}-3$ \\
\hline & \multirow{2}{*}{$\begin{array}{c}954 \\
19166\end{array}$} & $5.415 \mathrm{E}-2$ & $3.137 \mathrm{E}-3$ \\
\hline & & $5.413 \mathrm{E}-2$ & $3.177 \mathrm{E}-3$ \\
\hline & \multirow{2}{*}{$\begin{array}{c}937 \\
18924\end{array}$} & $5.3498 \mathrm{E}-2$ & $3.6369 \mathrm{E}-3$ \\
\hline & & $5.38 \mathrm{E}-2$ & $3.69 \mathrm{E}-3$ \\
\hline & \multirow{2}{*}{$\begin{array}{c}886 \\
17240\end{array}$} & $5.4079 \mathrm{E}-2$ & $4.484 \mathrm{E}-3$ \\
\hline & & $5.389 \mathrm{E}-2$ & 4.407E-3 \\
\hline & \multirow{2}{*}{$\begin{array}{c}869 \\
17520\end{array}$} & $5.36 \mathrm{E}-2$ & $5.057 \mathrm{E}-3$ \\
\hline & & $5.371 \mathrm{E}-2$ & $5.09 \mathrm{E}-3$ \\
\hline & \multirow{2}{*}{$\begin{array}{c}818 \\
16870\end{array}$} & $5.4172 \mathrm{E}-2$ & $6.735 \mathrm{E}-3$ \\
\hline & & $5.4157 \mathrm{E}-2$ & $6.735 \mathrm{E}-3$ \\
\hline & \multirow{2}{*}{$\begin{array}{c}768 \\
16685\end{array}$} & $5.4178 \mathrm{E}-2$ & $8.2475 \mathrm{E}-3$ \\
\hline & & $5.4177 \mathrm{E}-2$ & $8.374 \mathrm{E}-3$ \\
\hline & \multirow{2}{*}{$\begin{array}{c}734 \\
16481\end{array}$} & $5.4102 \mathrm{E}-2$ & $9.933 \mathrm{E}-3$ \\
\hline & & $5.4058 \mathrm{E}-2$ & $1.02 \mathrm{E}-2$ \\
\hline \multirow{12}{*}{ LEFT BOUNDARY } & \multirow{2}{*}{$\begin{array}{c}718 \\
19467\end{array}$} & $5.3389 \mathrm{E}-2$ & $9.981 \mathrm{E}-3$ \\
\hline & & $5.31 \mathrm{E}-2$ & $9.73 \mathrm{E}-3$ \\
\hline & \multirow{2}{*}{$\begin{array}{c}702 \\
25138\end{array}$} & $5.2694 \mathrm{E}-2$ & $9.92 \mathrm{E}-3$ \\
\hline & & $5.2432 \mathrm{E}-2$ & $9.499 \mathrm{E}-3$ \\
\hline & \multirow{2}{*}{$\begin{array}{c}670 \\
22300\end{array}$} & $5.1389 \mathrm{E}-2$ & $9.486 \mathrm{E}-3$ \\
\hline & & $5.168 \mathrm{E}-2$ & $9.25 \mathrm{E}-3$ \\
\hline & \multirow{2}{*}{$\begin{array}{c}654 \\
10820\end{array}$} & $5.0789 \mathrm{E}-2$ & $9.121 \mathrm{E}-3$ \\
\hline & & $5.09 \mathrm{E}-2$ & $9.09 \mathrm{E}-3$ \\
\hline & & $5.0043 \mathrm{E}-2$ & $9.1074 \mathrm{E}-2$ \\
\hline & 13802 & $4.9998 \mathrm{E}-2$ & $8.984 \mathrm{E}-3$ \\
\hline & 111 & $4.6203 \mathrm{E}-2$ & $9.0792 \mathrm{E}-3$ \\
\hline & 5000 & $4.622 \mathrm{E}-2$ & $8.992 \mathrm{E}-3$ \\
\hline
\end{tabular}


Table 2. Model validity check for FA-189, $\mathrm{K}_{\mathrm{I}}=17.36 \mathrm{Mpa} \sqrt{\mathrm{m}}$, Vacuum, step 9

\begin{tabular}{|c|c|c|c|}
\hline \multirow[t]{2}{*}{ Boundary } & Boundary node in the & \multicolumn{2}{|c|}{ Nodal Displacements } \\
\hline & $\begin{array}{c}\text { Corresponding boundary } \\
\text { node in submodel }\end{array}$ & U1 & $\mathrm{U} 2$ \\
\hline \multirow{12}{*}{ RIGHT BOUNDARY } & \multirow{2}{*}{$\begin{array}{c}409,410 \\
6499\end{array}$} & $5.2446 \mathrm{E}-2,5.154 \mathrm{E}-2$ & 0,0 \\
\hline & & $5.195 \mathrm{E}-2$ & 0 \\
\hline & \multirow{2}{*}{$\begin{array}{c}393 \\
6517\end{array}$} & $5.207 \mathrm{E}-2$ & $3.105 \mathrm{E}-4$ \\
\hline & & $5.2 \mathrm{E}-2$ & $2.89 \mathrm{E}-4$ \\
\hline & \multirow{2}{*}{$\begin{array}{c}376 \\
9405\end{array}$} & $5.172 \mathrm{E}-2$ & $6.6233 \mathrm{E}-4$ \\
\hline & & $5.212 \mathrm{E}-2$ & $5.84 \mathrm{E}-4$ \\
\hline & \multirow{2}{*}{$\begin{array}{c}359 \\
15161\end{array}$} & $5.2442 \mathrm{E}-2$ & $9.577 \mathrm{E}-4$ \\
\hline & & $5.233 \mathrm{E}-2$ & $8.71 \mathrm{E}-4$ \\
\hline & \multirow{2}{*}{$\begin{array}{c}308 \\
20891\end{array}$} & $5.29 \mathrm{E}-2$ & $2.18 \mathrm{E}-3$ \\
\hline & & $5.32 \mathrm{E}-2$ & $2.0 \mathrm{E}-3$ \\
\hline & \multirow{2}{*}{$\begin{array}{c}274 \\
17980\end{array}$} & $5.368 \mathrm{E}-2$ & $3.0 \mathrm{E}-3$ \\
\hline & & $5.39 \mathrm{E}-2$ & $2.61 \mathrm{E}-3$ \\
\hline \multirow{18}{*}{ TOP BOUNDARY } & \multirow{2}{*}{$\begin{array}{c}291 \\
17991\end{array}$} & $5.3991 \mathrm{E}-2$ & $2.416 \mathrm{E}-3$ \\
\hline & & $5.368 \mathrm{E}-2$ & $2.403 \mathrm{E}-3$ \\
\hline & \multirow{2}{*}{$\begin{array}{c}258 \\
18592\end{array}$} & $5.351 \mathrm{E}-2$ & $3.032 \mathrm{E}-3$ \\
\hline & & $5.364 \mathrm{E}-2$ & $3.1 \mathrm{E}-3$ \\
\hline & \multirow{2}{*}{$\begin{array}{c}954 \\
19166\end{array}$} & $5.3978 \mathrm{E}-2$ & $3.52 \mathrm{E}-3$ \\
\hline & & $5.3953 \mathrm{E}-2$ & $3.55 \mathrm{E}-3$ \\
\hline & \multirow{2}{*}{$\begin{array}{c}937 \\
18924\end{array}$} & $5.3327 \mathrm{E}-2$ & $4.07 \mathrm{E}-3$ \\
\hline & & $5.36 \mathrm{E}-2$ & $4.15 \mathrm{E}-3$ \\
\hline & \multirow{2}{*}{$\begin{array}{c}886 \\
17240\end{array}$} & $5.396 \mathrm{E}-2$ & $5.155 \mathrm{E}-3$ \\
\hline & & $5.377 \mathrm{E}-2$ & $5.039 \mathrm{E}-3$ \\
\hline & \multirow{2}{*}{$\begin{array}{c}869 \\
17520\end{array}$} & $5.35 \mathrm{E}-2$ & $5.82 \mathrm{E}-3$ \\
\hline & & $5.36 \mathrm{E}-2$ & $5.86 \mathrm{E}-3$ \\
\hline & \multirow{2}{*}{$\begin{array}{c}818 \\
16870\end{array}$} & $5.402 \mathrm{E}-2$ & $7.79 \mathrm{E}-3$ \\
\hline & & $5.402 \mathrm{E}-2$ & $7.779 \mathrm{E}-3$ \\
\hline & \multirow{2}{*}{$\begin{array}{c}768 \\
16685\end{array}$} & $5.398 \mathrm{E}-2$ & $9.456 \mathrm{E}-3$ \\
\hline & & $5.398 \mathrm{E}-2$ & $9.58 \mathrm{E}-3$ \\
\hline & \multirow{2}{*}{$\begin{array}{c}734 \\
16481\end{array}$} & $5.384 \mathrm{E}-2$ & $1.12 \mathrm{E}-2$ \\
\hline & & $5.38 \mathrm{E}-2$ & $1.15 \mathrm{E}-2$ \\
\hline \multirow{12}{*}{ LEFT BOUNDARY } & \multirow{2}{*}{$\begin{array}{c}718 \\
19467\end{array}$} & $5.308 \mathrm{E}-2$ & $1.13 \mathrm{E}-2$ \\
\hline & & $5.28 \mathrm{E}-2$ & $1.117 \mathrm{E}-2$ \\
\hline & \multirow{2}{*}{$\begin{array}{c}702 \\
25138\end{array}$} & $5.234 \mathrm{E}-2$ & $1.13 \mathrm{E}-2$ \\
\hline & & $5.2 \mathrm{E}-2$ & $1.1 \mathrm{E}-2$ \\
\hline & \multirow{2}{*}{$\begin{array}{c}670 \\
22300\end{array}$} & $5.09 \mathrm{E}-2$ & $1.11 \mathrm{E}-2$ \\
\hline & & $5.12 \mathrm{E}-2$ & $1.08 \mathrm{E}-2$ \\
\hline & \multirow{2}{*}{$\begin{array}{c}654 \\
10820\end{array}$} & $5.032 \mathrm{E}-2$ & $1.08 \mathrm{E}-2$ \\
\hline & & $5.05 \mathrm{E}-2$ & $1.078 \mathrm{E}-2$ \\
\hline & \multirow{2}{*}{$\begin{array}{c}121 \\
13802\end{array}$} & $4.954 \mathrm{E}-2$ & $1.0876 \mathrm{E}-2$ \\
\hline & & $4.949 \mathrm{E}-2$ & $1.077 \mathrm{E}-2$ \\
\hline & 111 & $4.597 \mathrm{E}-2$ & $1.09 \mathrm{E}-2$ \\
\hline & 5000 & $4.6 \mathrm{E}-2$ & $1.08 \mathrm{E}-2$ \\
\hline
\end{tabular}


Table 3. Model validity check for FA-189, $\mathrm{K}_{\mathrm{I}}=17.36 \mathrm{Mpa} \sqrt{\mathrm{m}}$, Vacuum, step 23

\begin{tabular}{|c|c|c|c|}
\hline \multirow[t]{2}{*}{ Boundary } & \multirow{2}{*}{$\begin{array}{c}\text { Boundary node in the } \\
\text { global model }\end{array}$} & \multicolumn{2}{|c|}{ Nodal Displacements } \\
\hline & & U1 & $\mathrm{U} 2$ \\
\hline \multirow{12}{*}{ RIGHT BOUNDARY } & \multirow{2}{*}{$\begin{array}{c}409,410 \\
6499\end{array}$} & $5.14 \mathrm{E}-2,5.05 \mathrm{E}-2$ & 0,0 \\
\hline & & $5.09 \mathrm{E}-2$ & 0 \\
\hline & \multirow{2}{*}{$\begin{array}{c}393 \\
6517\end{array}$} & $5.096 \mathrm{E}-2$ & $3.122 \mathrm{E}-4$ \\
\hline & & $5.1 \mathrm{E}-2$ & $3.3 \mathrm{E}-4$ \\
\hline & \multirow{2}{*}{$\begin{array}{c}376 \\
9405\end{array}$} & $5.082 \mathrm{E}-2$ & $8.85 \mathrm{E}-4$ \\
\hline & & $5.11 \mathrm{E}-2$ & $7.72 \mathrm{E}-4$ \\
\hline & \multirow{2}{*}{$\begin{array}{c}359 \\
15161\end{array}$} & $5.147 \mathrm{E}-2$ & $1.04 \mathrm{E}-4$ \\
\hline & & $5.1407 \mathrm{E}-2$ & $1.033 \mathrm{E}-4$ \\
\hline & \multirow{2}{*}{$\begin{array}{c}308 \\
20891\end{array}$} & $5.239 \mathrm{E}-2$ & $2.74 \mathrm{E}-3$ \\
\hline & & $5.266 \mathrm{E}-2$ & $2.417 \mathrm{E}-3$ \\
\hline & \multirow{2}{*}{$\begin{array}{c}274 \\
17980\end{array}$} & $5.3331 \mathrm{E}-2$ & $3.750 \mathrm{E}-3$ \\
\hline & & $5.342 \mathrm{E}-2$ & $3.145 \mathrm{E}-3$ \\
\hline \multirow{18}{*}{ TOP BOUNDARY } & \multirow{2}{*}{$\begin{array}{c}291 \\
17991\end{array}$} & $5.33 \mathrm{E}-2$ & $3.189 \mathrm{E}-3$ \\
\hline & & $5.328 \mathrm{E}-2$ & $3.8 \mathrm{E}-3$ \\
\hline & \multirow{2}{*}{$\begin{array}{c}258 \\
18592\end{array}$} & $5.318 \mathrm{E}-2$ & $4.16 \mathrm{E}-3$ \\
\hline & & $5.325 \mathrm{E}-2$ & $3.89 \mathrm{E}-3$ \\
\hline & \multirow{2}{*}{$\begin{array}{c}954 \\
19166\end{array}$} & $5.362 \mathrm{E}-2$ & $4.56 \mathrm{E}-3$ \\
\hline & & $5.360 \mathrm{E}-2$ & $4.593 \mathrm{E}-3$ \\
\hline & \multirow{2}{*}{$\begin{array}{c}937 \\
18924\end{array}$} & $5.31 \mathrm{E}-2$ & $5.38 \mathrm{E}-3$ \\
\hline & & $5.33 \mathrm{E}-2$ & $5.48 \mathrm{E}-3$ \\
\hline & \multirow{2}{*}{$\begin{array}{c}886 \\
17240\end{array}$} & $5.37 \mathrm{E}-2$ & $6.962 \mathrm{E}-3$ \\
\hline & & $5.355 \mathrm{E}-2$ & $6.7899 \mathrm{E}-3$ \\
\hline & \multirow{2}{*}{$\begin{array}{c}869 \\
17520\end{array}$} & $5.328 \mathrm{E}-2$ & $7.94 \mathrm{E}-3$ \\
\hline & & $5.338 \mathrm{E}-2$ & $7.968 \mathrm{E}-3$ \\
\hline & \multirow{2}{*}{$\begin{array}{c}818 \\
16870\end{array}$} & $5.366 \mathrm{E}-2$ & $1.03 \mathrm{E}-2$ \\
\hline & & $5.365 \mathrm{E}-2$ & $1.027 \mathrm{E}-2$ \\
\hline & \multirow{2}{*}{$\begin{array}{c}768 \\
16685\end{array}$} & $5.349 \mathrm{E}-2$ & $1.211 \mathrm{E}-2$ \\
\hline & & $5.349 \mathrm{E}-2$ & $1.224 \mathrm{E}-2$ \\
\hline & \multirow{2}{*}{$\begin{array}{c}734 \\
16481\end{array}$} & $5.3277 \mathrm{E}-2$ & $1.39 \mathrm{E}-2$ \\
\hline & & $5.32 \mathrm{E}-2$ & $1.42 \mathrm{E}-2$ \\
\hline \multirow{12}{*}{ LEFT BOUNDARY } & \multirow{2}{*}{$\begin{array}{c}718 \\
19467\end{array}$} & $5.243 \mathrm{E}-2$ & $1.416 \mathrm{E}-2$ \\
\hline & & $5.21 \mathrm{E}-2$ & $1.406 \mathrm{E}-2$ \\
\hline & \multirow{2}{*}{$\begin{array}{c}702 \\
25138\end{array}$} & $5.161 \mathrm{E}-2$ & $1.429 \mathrm{E}-2$ \\
\hline & & $5.13 \mathrm{E}-2$ & $1.402 \mathrm{E}-2$ \\
\hline & \multirow{2}{*}{$\begin{array}{c}670 \\
22300\end{array}$} & $5.013 \mathrm{E}-2$ & $1.419 \mathrm{E}-2$ \\
\hline & & $5.04 \mathrm{E}-2$ & $1.40 \mathrm{E}-2$ \\
\hline & \multirow{2}{*}{$\begin{array}{c}654 \\
10820\end{array}$} & $4.9469 \mathrm{E}-2$ & $1.399 \mathrm{E}-2$ \\
\hline & & $4.96 \mathrm{E}-2$ & $1.4 \mathrm{E}-2$ \\
\hline & 121 & $4.859 \mathrm{E}-2$ & $1.418 \mathrm{E}-2$ \\
\hline & 13802 & $4.8587 \mathrm{E}-2$ & $1.404 \mathrm{E}-2$ \\
\hline & 111 & $4.548 \mathrm{E}-2$ & $1.425 \mathrm{E}-2$ \\
\hline & 5000 & $4.55 \mathrm{E}-2$ & $1.413 \mathrm{E}-2$ \\
\hline
\end{tabular}


Table 4. Model validity check for FA-189, $\mathrm{K}_{\mathrm{I}}=17.36 \mathrm{Mpa} \sqrt{\mathrm{m}}$, Vacuum, step 49

\begin{tabular}{|c|c|c|c|}
\hline \multirow[t]{2}{*}{ Boundary } & \multirow{2}{*}{$\begin{array}{c}\begin{array}{c}\text { Boundary node in the } \\
\text { global model }\end{array} \\
\begin{array}{c}\text { Corresponding boundary } \\
\text { node in submodel }\end{array}\end{array}$} & \multicolumn{2}{|c|}{ Nodal Displacements } \\
\hline & & $\mathrm{U} 1$ & $\mathrm{U} 2$ \\
\hline \multirow{12}{*}{ RIGHT BOUNDARY } & \multirow{2}{*}{$\begin{array}{c}409,410 \\
6499\end{array}$} & $5.028 \mathrm{E}-2,4.9 \mathrm{E}-2$ & 0,0 \\
\hline & & $5.96 \mathrm{E}-2$ & 0 \\
\hline & \multirow{2}{*}{$\begin{array}{c}393 \\
6517\end{array}$} & $4.98 \mathrm{E}-2$ & $5.98 \mathrm{E}-4$ \\
\hline & & $4.977 \mathrm{E}-2$ & $4.52 \mathrm{E}-4$ \\
\hline & \multirow{2}{*}{$\begin{array}{c}376 \\
9405\end{array}$} & $4.947 \mathrm{E}-2$ & $8.5 \mathrm{E}-4$ \\
\hline & & $4.99 \mathrm{E}-2$ & $8.57 \mathrm{E}-4$ \\
\hline & \multirow{2}{*}{$\begin{array}{c}359 \\
15161\end{array}$} & $5.068 \mathrm{E}-2$ & $1.68 \mathrm{E}-3$ \\
\hline & & $5.038 \mathrm{E}-2$ & $1.33 \mathrm{E}-3$ \\
\hline & \multirow{2}{*}{$\begin{array}{c}308 \\
20891\end{array}$} & $5.173 \mathrm{E}-2$ & $3.42 \mathrm{E}-3$ \\
\hline & & $5.208 \mathrm{E}-2$ & $3.165 \mathrm{E}-3$ \\
\hline & \multirow{2}{*}{$\begin{array}{c}274 \\
17980\end{array}$} & $5.2857 \mathrm{E}-2$ & $4.6885 \mathrm{E}-3$ \\
\hline & & $5.3 \mathrm{E}-2$ & $4.046 \mathrm{E}-3$ \\
\hline \multirow{18}{*}{ TOP BOUNDARY } & \multirow{2}{*}{$\begin{array}{c}291 \\
17991\end{array}$} & $5.302 \mathrm{E}-2$ & $3.961 \mathrm{E}-3$ \\
\hline & & $5.29 \mathrm{E}-2$ & $5.1 \mathrm{E}-3$ \\
\hline & \multirow{2}{*}{$\begin{array}{c}258 \\
18592\end{array}$} & $5.2796 \mathrm{E}-2$ & $5.3787 \mathrm{E}-3$ \\
\hline & & $5.291 \mathrm{E}-2$ & $5.119 \mathrm{E}-3$ \\
\hline & \multirow{2}{*}{$\begin{array}{c}954 \\
19166\end{array}$} & $5.343 \mathrm{E}-2$ & $6.45 \mathrm{E}-3$ \\
\hline & & $5.34 \mathrm{E}-2$ & $6.44 \mathrm{E}-3$ \\
\hline & \multirow{2}{*}{$\begin{array}{c}937 \\
18924\end{array}$} & $5.281 \mathrm{E}-2$ & $7.3797 \mathrm{E}-3$ \\
\hline & & $5.312 \mathrm{E}-2$ & $7.61 \mathrm{E}-3$ \\
\hline & \multirow{2}{*}{$\begin{array}{c}886 \\
17240\end{array}$} & $5.335 \mathrm{E}-2$ & $9.715 \mathrm{E}-3$ \\
\hline & & $5.321 \mathrm{E}-2$ & $9.387 \mathrm{E}-3$ \\
\hline & \multirow{2}{*}{$\begin{array}{c}869 \\
17520\end{array}$} & $5.287 \mathrm{E}-2$ & $1.07 \mathrm{E}-2$ \\
\hline & & $5.297 \mathrm{E}-2$ & $1.07 \mathrm{E}-2$ \\
\hline & \multirow{2}{*}{$\begin{array}{c}818 \\
16870\end{array}$} & $5.299 \mathrm{E}-2$ & $1.34 \mathrm{E}-2$ \\
\hline & & $5.3 \mathrm{E}-2$ & $1.335 \mathrm{E}-2$ \\
\hline & \multirow{2}{*}{$\begin{array}{c}768 \\
16685\end{array}$} & $5.274 \mathrm{E}-2$ & $1.52 \mathrm{E}-2$ \\
\hline & & $5.275 \mathrm{E}-2$ & $1.53 \mathrm{E}-2$ \\
\hline & \multirow{2}{*}{$\begin{array}{c}734 \\
16481\end{array}$} & $5.248 \mathrm{E}-2$ & $1.69 \mathrm{E}-2$ \\
\hline & & $5.244 \mathrm{E}-2$ & $1.71 \mathrm{E}-2$ \\
\hline \multirow{12}{*}{ LEFT BOUNDARY } & \multirow{2}{*}{$\begin{array}{c}718 \\
19467\end{array}$} & $5.1579 \mathrm{E}-2$ & $1.723 \mathrm{E}-2$ \\
\hline & & $5.126 \mathrm{E}-2$ & $1.711 \mathrm{E}-2$ \\
\hline & \multirow{2}{*}{$\begin{array}{c}702 \\
25138 \\
\end{array}$} & $5.072 \mathrm{E}-2$ & $1.73 \mathrm{E}-2$ \\
\hline & & $5.04 \mathrm{E}-2$ & $1.71 \mathrm{E}-2$ \\
\hline & \multirow{2}{*}{$\begin{array}{c}670 \\
22300\end{array}$} & $4.921 \mathrm{E}-2$ & $1.735 \mathrm{E}-2$ \\
\hline & & $4.9549 \mathrm{E}-2$ & $1.711 \mathrm{E}-2$ \\
\hline & \multirow{2}{*}{$\begin{array}{c}654 \\
10820\end{array}$} & $4.8564 \mathrm{E}-2$ & $1.719 \mathrm{E}-2$ \\
\hline & & $4.87 \mathrm{E}-2$ & $1.7 \mathrm{E}-2$ \\
\hline & 121 & $4.78 \mathrm{E}-2$ & $1.724 \mathrm{E}-2$ \\
\hline & 13802 & $4.77 \mathrm{E}-2$ & $1.716 \mathrm{E}-2$ \\
\hline & 111 & $4.499 \mathrm{E}-2$ & $1.727 \mathrm{E}-2$ \\
\hline & 5000 & $4.5 \mathrm{E}-2$ & $1.72 \mathrm{E}-2$ \\
\hline
\end{tabular}


Table 5. Model validity check for FA-189, $\mathrm{K}_{\mathrm{I}}=17.36 \mathrm{Mpa} \sqrt{\mathrm{m}}$, Air, step 7

\begin{tabular}{|c|c|c|c|}
\hline \multirow[t]{2}{*}{ Boundary } & \multirow{2}{*}{\begin{tabular}{|c|}
$\begin{array}{c}\text { Boundary node in the } \\
\text { global model }\end{array}$ \\
$\begin{array}{c}\text { Corresponding boundary } \\
\text { node in submodel }\end{array}$
\end{tabular}} & \multicolumn{2}{|c|}{ Nodal Displacements } \\
\hline & & U1 & $\mathrm{U} 2$ \\
\hline \multirow{12}{*}{ RIGHT BOUNDARY } & \multirow{2}{*}{$\begin{array}{c}409,410 \\
6499\end{array}$} & $5.243 \mathrm{E}-2,5.15 \mathrm{E}-2$ & 0,0 \\
\hline & & $5.19 \mathrm{E}-2$ & 0 \\
\hline & \multirow{2}{*}{$\begin{array}{c}393 \\
6517\end{array}$} & $5.206 \mathrm{E}-2$ & $3.128 \mathrm{E}-4$ \\
\hline & & $5.2 \mathrm{E}-2$ & $2.91 \mathrm{E}-4$ \\
\hline & \multirow{2}{*}{$\begin{array}{c}376 \\
9405\end{array}$} & $5.171 \mathrm{E}-2$ & $6.672 \mathrm{E}-4$ \\
\hline & & $5.2 \mathrm{E}-2$ & $5.88 \mathrm{E}-4$ \\
\hline & \multirow{2}{*}{$\begin{array}{c}359 \\
15161\end{array}$} & $5.24 \mathrm{E}-2$ & $9.642 \mathrm{E}-4$ \\
\hline & & $5.3 \mathrm{E}-2$ & $8.77 \mathrm{E}-4$ \\
\hline & \multirow{2}{*}{$\begin{array}{c}308 \\
20891\end{array}$} & $5.289 \mathrm{E}-2$ & $2.2 \mathrm{E}-3$ \\
\hline & & $5.32 \mathrm{E}-2$ & $2.01 \mathrm{E}-3$ \\
\hline & \multirow{2}{*}{$\begin{array}{c}274 \\
17980\end{array}$} & $5.3677 \mathrm{E}-2$ & $3.067 \mathrm{E}-3$ \\
\hline & & $5.39 \mathrm{E}-2$ & $2.625 \mathrm{E}-3$ \\
\hline \multirow{18}{*}{ TOP BOUNDARY } & \multirow{2}{*}{$\begin{array}{c}291 \\
17991\end{array}$} & $5.391 \mathrm{E}-2$ & $2.429 \mathrm{E}-3$ \\
\hline & & $5.367 \mathrm{E}-2$ & $2.41 \mathrm{E}-3$ \\
\hline & \multirow{2}{*}{$\begin{array}{c}258 \\
18592\end{array}$} & $5.3507 \mathrm{E}-2$ & $3.389 \mathrm{E}-3$ \\
\hline & & $5.36 \mathrm{E}-2$ & $3.12 \mathrm{E}-3$ \\
\hline & \multirow{2}{*}{$\begin{array}{c}954 \\
19166\end{array}$} & $5.3973 \mathrm{E}-2$ & $3.544 \mathrm{E}-3$ \\
\hline & & $5.394 \mathrm{E}-2$ & $3.580 \mathrm{E}-3$ \\
\hline & \multirow{2}{*}{$\begin{array}{c}937 \\
18924\end{array}$} & $5.332 \mathrm{E}-2$ & $4.102 \mathrm{E}-3$ \\
\hline & & $5.363 \mathrm{E}-2$ & $4.183 \mathrm{E}-3$ \\
\hline & \multirow{2}{*}{$\begin{array}{c}886 \\
17240\end{array}$} & $5.3955 \mathrm{E}-2$ & $5.19 \mathrm{E}-3$ \\
\hline & & $5.376 \mathrm{E}-2$ & $5.074 \mathrm{E}-3$ \\
\hline & \multirow{2}{*}{$\begin{array}{c}869 \\
17520\end{array}$} & $5.3499 \mathrm{E}-2$ & $5.867 \mathrm{E}-3$ \\
\hline & & $5.36 \mathrm{E}-2$ & $5.9 \mathrm{E}-3$ \\
\hline & \multirow{2}{*}{$\begin{array}{c}818 \\
16870\end{array}$} & $5.40 \mathrm{E}-2$ & $7.841 \mathrm{E}-3$ \\
\hline & & $5.4 \mathrm{E}-2$ & $7.825 \mathrm{E}-2$ \\
\hline & \multirow{2}{*}{$\begin{array}{c}768 \\
16685\end{array}$} & $5.396 \mathrm{E}-2$ & $9.5 \mathrm{E}-3$ \\
\hline & & $5.397 \mathrm{E}-2$ & $9.62 \mathrm{E}-3$ \\
\hline & \multirow{2}{*}{$\begin{array}{c}734 \\
16481\end{array}$} & $5.383 \mathrm{E}-2$ & $1.1268 \mathrm{E}-2$ \\
\hline & & $5.379 \mathrm{E}-2$ & $1.15 \mathrm{E}-2$ \\
\hline \multirow{12}{*}{ LEFT BOUNDARY } & \multirow{2}{*}{$\begin{array}{c}718 \\
19467\end{array}$} & $5.307 \mathrm{E}-2$ & $1.14 \mathrm{E}-2$ \\
\hline & & $5.278 \mathrm{E}-2$ & $1.122 \mathrm{E}-2$ \\
\hline & \multirow{2}{*}{$\begin{array}{c}702 \\
25138\end{array}$} & $5.2328 \mathrm{E}-2$ & $1.14 \mathrm{E}-2$ \\
\hline & & $5.2 \mathrm{E}-2$ & $1.1 \mathrm{E}-2$ \\
\hline & \multirow{2}{*}{$\begin{array}{c}670 \\
22300\end{array}$} & $5.094 \mathrm{E}-2$ & $1.11 \mathrm{E}-2$ \\
\hline & & $5.127 \mathrm{E}-2$ & $1.091 \mathrm{E}-2$ \\
\hline & \multirow{2}{*}{$\begin{array}{c}654 \\
10820\end{array}$} & $5.03 \mathrm{E}-2$ & $1.089 \mathrm{E}-2$ \\
\hline & & $5.05 \mathrm{E}-2$ & $1.0844 \mathrm{E}-2$ \\
\hline & 121 & $4.952 \mathrm{E}-2$ & $1.093 \mathrm{E}-2$ \\
\hline & 13802 & $4.947 \mathrm{E}-2$ & $1.08 \mathrm{E}-2$ \\
\hline & 111 & $4.595 \mathrm{E}-2$ & $1.097 \mathrm{E}-2$ \\
\hline & 5000 & $4.597 \mathrm{E}-2$ & $1.088 \mathrm{E}-2$ \\
\hline
\end{tabular}


Table 6. Model validity check for FA-189, $\mathrm{K}_{\mathrm{I}}=17.36 \mathrm{Mpa} \sqrt{\mathrm{m}}$, Air, step 23

\begin{tabular}{|c|c|c|c|}
\hline \multirow[t]{2}{*}{ Boundary } & Boundary node in the & \multicolumn{2}{|c|}{ Nodal Displacements } \\
\hline & $\begin{array}{l}\text { Corresponding boundary } \\
\text { node in submodel }\end{array}$ & U1 & $\mathrm{U} 2$ \\
\hline \multirow{12}{*}{ RIGHT BOUNDARY } & \multirow{2}{*}{$\begin{array}{c}409,410 \\
6499\end{array}$} & $5.17 \mathrm{E}-2,5.07 \mathrm{E}-2$ & 0,0 \\
\hline & & $5.119 \mathrm{E}-2$ & 0 \\
\hline & \multirow{2}{*}{$\begin{array}{c}393 \\
6517\end{array}$} & $5.133 \mathrm{E}-2$ & $3.969 \mathrm{E}-4$ \\
\hline & & $5.12 \mathrm{E}-2$ & $3.44 \mathrm{E}-4$ \\
\hline & \multirow{2}{*}{$\begin{array}{c}376 \\
9405\end{array}$} & $5.097 \mathrm{E}-2$ & 7.404E-4 \\
\hline & & $5.14 \mathrm{E}-2$ & $6.82 \mathrm{E}-4$ \\
\hline & \multirow{2}{*}{$\begin{array}{c}359 \\
15161\end{array}$} & $5.1809 \mathrm{E}-2$ & $1.19 \mathrm{E}-3$ \\
\hline & & $5.16 \mathrm{E}-2$ & $1.029 \mathrm{E}-3$ \\
\hline & \multirow{2}{*}{$\begin{array}{c}308 \\
20891\end{array}$} & $5.241 \mathrm{E}-2$ & $2.583 \mathrm{E}-3$ \\
\hline & & $5.2787 \mathrm{E}-2$ & $2.365 \mathrm{E}-3$ \\
\hline & \multirow{2}{*}{$\begin{array}{c}274 \\
17980\end{array}$} & $5.332 \mathrm{E}-2$ & $3.5877 \mathrm{E}-3$ \\
\hline & & $5.3522 \mathrm{E}-2$ & $3.0788 \mathrm{E}-3$ \\
\hline \multirow{18}{*}{ TOP BOUNDARY } & \multirow{2}{*}{$\begin{array}{c}291 \\
17991\end{array}$} & $5.353 \mathrm{E}-2$ & $2.910 \mathrm{E}-3$ \\
\hline & & $5.326 \mathrm{E}-2$ & $2.836 \mathrm{E}-3$ \\
\hline & \multirow{2}{*}{$\begin{array}{c}258 \\
18592\end{array}$} & $5.318 \mathrm{E}-2$ & $3.995 \mathrm{E}-3$ \\
\hline & & $5.331 \mathrm{E}-2$ & $3.755 \mathrm{E}-3$ \\
\hline & \multirow{2}{*}{$\begin{array}{c}954 \\
19166\end{array}$} & $5.3706 \mathrm{E}-2$ & $4.449 \mathrm{E}-3$ \\
\hline & & $5.3679 \mathrm{E}-2$ & $4.473 \mathrm{E}-3$ \\
\hline & \multirow{2}{*}{$\begin{array}{c}937 \\
18924\end{array}$} & $5.3076 \mathrm{E}-2$ & $5.128 \mathrm{E}-3$ \\
\hline & & $5.339 \mathrm{E}-2$ & $5.258 \mathrm{E}-3$ \\
\hline & \multirow{2}{*}{$\begin{array}{c}886 \\
17240\end{array}$} & $5.372 \mathrm{E}-2$ & $6.655 \mathrm{E}-3$ \\
\hline & & $5.3545 \mathrm{E}-2$ & $6.464 \mathrm{E}-3$ \\
\hline & \multirow{2}{*}{$\begin{array}{c}869 \\
17520\end{array}$} & $5.329 \mathrm{E}-2$ & $7.485 \mathrm{E}-3$ \\
\hline & & $5.3393 \mathrm{E}-2$ & $7.521 \mathrm{E}-3$ \\
\hline & \multirow{2}{*}{$\begin{array}{c}818 \\
16870\end{array}$} & $5.367 \mathrm{E}-2$ & $9.866 \mathrm{E}-3$ \\
\hline & & $5.367 \mathrm{E}-2$ & $9.827 \mathrm{E}-2$ \\
\hline & \multirow{2}{*}{$\begin{array}{c}768 \\
16685\end{array}$} & $5.3532 \mathrm{E}-2$ & $1.16 \mathrm{E}-2$ \\
\hline & & $5.3537 \mathrm{E}-2$ & $1.177 \mathrm{E}-2$ \\
\hline & \multirow{2}{*}{$\begin{array}{c}734 \\
16481\end{array}$} & $5.333 \mathrm{E}-2$ & $1.344 \mathrm{E}-2$ \\
\hline & & $5.329 \mathrm{E}-2$ & $1.37 \mathrm{E}-2$ \\
\hline \multirow{12}{*}{ LEFT BOUNDARY } & \multirow{2}{*}{$\begin{array}{c}718 \\
19467\end{array}$} & $5.2509 \mathrm{E}-2$ & $1.367 \mathrm{E}-2$ \\
\hline & & $5.22 \mathrm{E}-2$ & $1.352 \mathrm{E}-2$ \\
\hline & \multirow{2}{*}{$\begin{array}{c}702 \\
25138\end{array}$} & $5.171 \mathrm{E}-2$ & $1.378 \mathrm{E}-2$ \\
\hline & & $5.14 \mathrm{E}-2$ & $1.345 \mathrm{E}-2$ \\
\hline & \multirow{2}{*}{$\begin{array}{c}670 \\
22300\end{array}$} & $5.024 \mathrm{E}-2$ & $1.366 \mathrm{E}-2$ \\
\hline & & $5.057 \mathrm{E}-2$ & $1.34 \mathrm{E}-2$ \\
\hline & \multirow{2}{*}{$\begin{array}{c}654 \\
10820\end{array}$} & $4.9578 \mathrm{E}-2$ & $1.344 \mathrm{E}-2$ \\
\hline & & $4.976 \mathrm{E}-2$ & $1.3397 \mathrm{E}-2$ \\
\hline & \multirow{2}{*}{$\begin{array}{c}121 \\
13802\end{array}$} & $4.876 \mathrm{E}-2$ & $1.351 \mathrm{E}-2$ \\
\hline & & $4.873 \mathrm{E}-2$ & $1.342 \mathrm{E}-2$ \\
\hline & 111 & $4.553 \mathrm{E}-2$ & $1.356 \mathrm{E}-2$ \\
\hline & 5000 & $4.556 \mathrm{E}-2$ & $1.3479 \mathrm{E}-2$ \\
\hline
\end{tabular}


Table 7. Model validity check for FA-189, $\mathrm{K}_{\mathrm{l}}=17.36 \mathrm{Mpa} \sqrt{\mathrm{m}}$, Air, step 48

\begin{tabular}{|c|c|c|c|}
\hline \multirow[t]{2}{*}{ Boundary } & \multirow{2}{*}{$\begin{array}{c}\begin{array}{c}\text { Boundary node in the } \\
\text { global model }\end{array} \\
\begin{array}{c}\text { Corresponding boundary } \\
\text { node in submodel }\end{array} \\
\end{array}$} & \multicolumn{2}{|c|}{ Nodal Displacements } \\
\hline & & U1 & $\mathrm{U} 2$ \\
\hline \multirow{12}{*}{ RIGHT BOUNDARY } & \multirow{2}{*}{$\begin{array}{c}409,410 \\
6499\end{array}$} & $4.9151 \mathrm{E}-2,4.741 \mathrm{E}-2$ & 0,0 \\
\hline & & $4.82 \mathrm{E}-2$ & 0 \\
\hline & \multirow{2}{*}{$\begin{array}{c}393 \\
6517\end{array}$} & $4.86 \mathrm{E}-2$ & $1.066 \mathrm{E}-3$ \\
\hline & & $4.85 \mathrm{E}-2$ & $7.23 \mathrm{E}-4$ \\
\hline & \multirow{2}{*}{$\begin{array}{c}376 \\
9405\end{array}$} & $4.82 \mathrm{E}-2$ & $1.243 \mathrm{E}-3$ \\
\hline & & $4.88 \mathrm{E}-2$ & $1.298 \mathrm{E}-3$ \\
\hline & \multirow{2}{*}{$\begin{array}{c}359 \\
15161\end{array}$} & $5.004 \mathrm{E}-2$ & $2.67 \mathrm{E}-3$ \\
\hline & & $4.95 \mathrm{E}-2$ & $2.032 \mathrm{E}-3$ \\
\hline & \multirow{2}{*}{$\begin{array}{c}308 \\
20891\end{array}$} & $5.128 \mathrm{E}-2$ & $5.163 \mathrm{E}-3$ \\
\hline & & $5.22 \mathrm{E}-2$ & $4.638 \mathrm{E}-3$ \\
\hline & \multirow{2}{*}{$\begin{array}{c}274 \\
17980\end{array}$} & $5.248 \mathrm{E}-2$ & $6.52 \mathrm{E}-3$ \\
\hline & & $5.262 \mathrm{E}-2$ & $5.7 \mathrm{E}-3$ \\
\hline \multirow{18}{*}{ TOP BOUNDARY } & \multirow{2}{*}{$\begin{array}{c}291 \\
17991\end{array}$} & $5.267 \mathrm{E}-2$ & $5.809 \mathrm{E}-3$ \\
\hline & & $5.229 \mathrm{E}-2$ & $5.36 \mathrm{E}-3$ \\
\hline & \multirow{2}{*}{$\begin{array}{c}258 \\
18592\end{array}$} & $5.2408 \mathrm{E}-2$ & $7.63 \mathrm{E}-3$ \\
\hline & & $5.254 \mathrm{E}-2$ & $7.35 \mathrm{E}-3$ \\
\hline & \multirow{2}{*}{$\begin{array}{c}954 \\
19166\end{array}$} & $5.297 \mathrm{E}-2$ & $9.319 \mathrm{E}-3$ \\
\hline & & $5.295 \mathrm{E}-2$ & $9.226 \mathrm{E}-3$ \\
\hline & \multirow{2}{*}{$\begin{array}{c}937 \\
18924\end{array}$} & $5.225 \mathrm{E}-2$ & $1.041 \mathrm{E}-2$ \\
\hline & & $5.2568 \mathrm{E}-2$ & $1.068 \mathrm{E}-2$ \\
\hline & \multirow{2}{*}{$\begin{array}{c}886 \\
17240\end{array}$} & $5.261 \mathrm{E}-2$ & $1.307 \mathrm{E}-2$ \\
\hline & & $5.2499 \mathrm{E}-2$ & $1.269 \mathrm{E}-2$ \\
\hline & \multirow{2}{*}{$\begin{array}{c}869 \\
17520\end{array}$} & $5.204 \mathrm{E}-2$ & $1.408 \mathrm{E}-2$ \\
\hline & & $5.215 \mathrm{E}-2$ & $1.409 \mathrm{E}-2$ \\
\hline & \multirow{2}{*}{$\begin{array}{c}818 \\
16870\end{array}$} & $5.207 \mathrm{E}-2$ & $1.676 \mathrm{E}-2$ \\
\hline & & $5.21 \mathrm{E}-2$ & $1.668 \mathrm{E}-2$ \\
\hline & \multirow{2}{*}{$\begin{array}{c}768 \\
16685\end{array}$} & $5.18 \mathrm{E}-2$ & $1.855 \mathrm{E}-2$ \\
\hline & & $5.18 \mathrm{E}-2$ & $1.855 \mathrm{E}-2$ \\
\hline & \multirow{2}{*}{$\begin{array}{c}734 \\
16481 \\
\end{array}$} & $5.157 \mathrm{E}-2$ & $2.04 \mathrm{E}-2$ \\
\hline & & $5.15 \mathrm{E}-2$ & $2.0289 \mathrm{E}-2$ \\
\hline \multirow{12}{*}{ LEFT BOUNDARY } & \multirow{2}{*}{$\begin{array}{c}718 \\
19467\end{array}$} & $5.064 \mathrm{E}-2$ & $2.039 \mathrm{E}-2$ \\
\hline & & $5.03 \mathrm{E}-2$ & $2.028 \mathrm{E}-2$ \\
\hline & \multirow{2}{*}{$\begin{array}{c}702 \\
25138 \\
\end{array}$} & $4.9787 \mathrm{E}-2$ & $2.056 \mathrm{E}-2$ \\
\hline & & $4.948 \mathrm{E}-2$ & $2.03 \mathrm{E}-2$ \\
\hline & \multirow{2}{*}{$\begin{array}{c}670 \\
22300\end{array}$} & $4.83 \mathrm{E}-2$ & $2.0538 \mathrm{E}-2$ \\
\hline & & $4.86 \mathrm{E}-2$ & $2.031 \mathrm{E}-2$ \\
\hline & \multirow{2}{*}{$\begin{array}{c}654 \\
10820\end{array}$} & 4.767E-2 & $2.038 \mathrm{E}-2$ \\
\hline & & $4.783 \mathrm{E}-2$ & $2.033 \mathrm{E}-2$ \\
\hline & 121 & $4.693 \mathrm{E}-2$ & $2.042 \mathrm{E}-2$ \\
\hline & 13802 & $4.690 \mathrm{E}-2$ & $2.036 \mathrm{E}-2$ \\
\hline & 111 & $4.435 \mathrm{E}-2$ & $2.044 \mathrm{E}-2$ \\
\hline & 5000 & $4.438 \mathrm{E}-2$ & $2.038 \mathrm{E}-2$ \\
\hline
\end{tabular}


Table 8. Model validity check for initial stage, FA-186, $\mathrm{K}_{\mathrm{I}}=17.36 \mathrm{Mpa} \sqrt{\mathrm{m}}$

\begin{tabular}{|c|c|c|c|}
\hline \multirow[t]{2}{*}{ Boundary } & \multirow{2}{*}{$\begin{array}{c}\text { Boundary node in the } \\
\text { global model } \\
\begin{array}{c}\text { Corresponding boundary } \\
\text { node in submodel }\end{array}\end{array}$} & \multicolumn{2}{|c|}{ Nodal Displacements } \\
\hline & & U1 & $\mathrm{U} 2$ \\
\hline \multirow{12}{*}{ RIGHT BOUNDARY } & \multirow{2}{*}{$\begin{array}{c}406 \\
5759\end{array}$} & $5.343 \mathrm{E}-2$ & 0 \\
\hline & & $5.338 \mathrm{E}-2$ & 0 \\
\hline & \multirow{2}{*}{$\begin{array}{l}356 \\
7222\end{array}$} & $5.351 \mathrm{E}-2$ & $1.11 \mathrm{E}-3$ \\
\hline & & $5.372 \mathrm{E}-2$ & $1.163 \mathrm{E}-3$ \\
\hline & \multirow{2}{*}{$\begin{array}{c}339 \\
10115\end{array}$} & $5.447 \mathrm{E}-2$ & $1.379 \mathrm{E}-3$ \\
\hline & & $5.446 \mathrm{E}-2$ & $1.38 \mathrm{E}-3$ \\
\hline & \multirow{2}{*}{$\begin{array}{c}305 \\
8695\end{array}$} & $5.53 \mathrm{E}-2$ & $2.149 \mathrm{E}-3$ \\
\hline & & $5.5 \mathrm{E}-2$ & $2.08 \mathrm{E}-3$ \\
\hline & \multirow{2}{*}{$\begin{array}{c}288 \\
11543\end{array}$} & $5.505 \mathrm{E}-2$ & $2.837 \mathrm{E}-3$ \\
\hline & & $5.54 \mathrm{E}-2$ & $2.87 \mathrm{E}-3$ \\
\hline & \multirow{2}{*}{$\begin{array}{c}254 \\
13009\end{array}$} & $5.6 \mathrm{E}-2$ & $3.80 \mathrm{E}-3$ \\
\hline & & $5.606 \mathrm{E}-2$ & $3.75 \mathrm{E}-3$ \\
\hline \multirow{18}{*}{ TOP BOUNDARY } & \multirow{2}{*}{$\begin{array}{c}949 \\
13052\end{array}$} & $5.654 \mathrm{E}-2$ & $4.58 \mathrm{E}-3$ \\
\hline & & $5.688 \mathrm{E}-2$ & $4.275 \mathrm{E}-3$ \\
\hline & \multirow{2}{*}{$\begin{array}{c}932 \\
13314\end{array}$} & $5.741 \mathrm{E}-2$ & $4.566 \mathrm{E}-3$ \\
\hline & & $5.71 \mathrm{E}-2$ & $4.568 \mathrm{E}-3$ \\
\hline & \multirow{2}{*}{$\begin{array}{c}898 \\
13580\end{array}$} & $5.74 \mathrm{E}-2$ & $5.54 \mathrm{E}-3$ \\
\hline & & $5.70 \mathrm{E}-2$ & $5.42 \mathrm{E}-3$ \\
\hline & \multirow{2}{*}{$\begin{array}{c}881 \\
13472\end{array}$} & $5.68 \mathrm{E}-2$ & $6.36 \mathrm{E}-3$ \\
\hline & & $5.702 \mathrm{E}-2$ & $6.004 \mathrm{E}-3$ \\
\hline & \multirow{2}{*}{$\begin{array}{c}864 \\
12700\end{array}$} & $5.753 \mathrm{E}-2$ & $6.802 \mathrm{E}-3$ \\
\hline & & $5.728 \mathrm{E}-2$ & $7.15 \mathrm{E}-3$ \\
\hline & \multirow{2}{*}{$\begin{array}{c}830 \\
12944\end{array}$} & $5.767 \mathrm{E}-2$ & $8.43 \mathrm{E}-3$ \\
\hline & & $5.73 \mathrm{E}-2$ & $8.044 \mathrm{E}-3$ \\
\hline & \multirow{2}{*}{$\begin{array}{c}813 \\
12524\end{array}$} & $5.723 \mathrm{E}-2$ & $9.53 \mathrm{E}-3$ \\
\hline & & $5.736 \mathrm{E}-2$ & $9.75 \mathrm{E}-3$ \\
\hline & \multirow{2}{*}{$\begin{array}{c}780 \\
12398\end{array}$} & $5.78 \mathrm{E}-2$ & $1.044 \mathrm{E}-2$ \\
\hline & & $5.76 \mathrm{E}-2$ & $1.086 \mathrm{E}-2$ \\
\hline & \multirow{2}{*}{$\begin{array}{c}746 \\
12276\end{array}$} & $5.783 \mathrm{E}-2$ & $1.277 \mathrm{E}-2$ \\
\hline & & $5.754 \mathrm{E}-2$ & $1.22 \mathrm{E}-2$ \\
\hline \multirow{12}{*}{ LEFT BOUNDARY } & \multirow{2}{*}{$\begin{array}{c}749 \\
12288\end{array}$} & $5.517 \mathrm{E}-2$ & $1.0579 \mathrm{E}-3$ \\
\hline & & $5.68 \mathrm{E}-2$ & $1.16 \mathrm{E}-3$ \\
\hline & \multirow{2}{*}{$\begin{array}{c}734 \\
7937\end{array}$} & $5.41 \mathrm{E}-2$ & $9.934 \mathrm{E}-3$ \\
\hline & & $5.436 \mathrm{E}-2$ & $1.004 \mathrm{E}-2$ \\
\hline & \multirow{2}{*}{$\begin{array}{c}719 \\
9429\end{array}$} & $5.253 \mathrm{E}-2$ & $9.205 \mathrm{E}-3$ \\
\hline & & $5.288 \mathrm{E}-2$ & $9.217 \mathrm{E}-3$ \\
\hline & \multirow{2}{*}{$\begin{array}{c}671 \\
6511\end{array}$} & $5.073 \mathrm{E}-2$ & $8.59 \mathrm{E}-3$ \\
\hline & & $5.102 \mathrm{E}-2$ & $8.5 \mathrm{E}-3$ \\
\hline & & $5.0118 \mathrm{E}-2$ & $8.189 \mathrm{E}-2$ \\
\hline & 5018 & $5.011 \mathrm{E}-2$ & $8.345 \mathrm{E}-3$ \\
\hline & 89 & $4.6195 \mathrm{E}-2$ & $8.06 \mathrm{E}-3$ \\
\hline & 5000 & $4.622 \mathrm{E}-2$ & $8.301 \mathrm{E}-3$ \\
\hline
\end{tabular}


Table 9. Model validity check for FA-186, Vacuum, last step, $\mathrm{K}_{\mathrm{I}}=17.36 \mathrm{Mpa}{ }_{\mathrm{m}}$

\begin{tabular}{|c|c|c|c|}
\hline \multirow[t]{2}{*}{ Boundary } & \multirow{2}{*}{$\begin{array}{c}\begin{array}{c}\text { Boundary node in the } \\
\text { global model }\end{array} \\
\begin{array}{c}\text { Corresponding boundary } \\
\text { node in submodel }\end{array}\end{array}$} & \multicolumn{2}{|c|}{ Nodal Displacements } \\
\hline & & U1 & $\mathrm{U} 2$ \\
\hline \multirow{12}{*}{ RIGHT BOUNDARY } & \multirow{2}{*}{$\begin{array}{c}406 \\
5759\end{array}$} & $5.03 \mathrm{E}-2$ & 0 \\
\hline & & $5.028 \mathrm{E}-2$ & 0 \\
\hline & \multirow{2}{*}{$\begin{array}{l}356 \\
7222\end{array}$} & $5.076 \mathrm{E}-2$ & $1.72 \mathrm{E}-3$ \\
\hline & & $5.108 \mathrm{E}-2$ & $1.89 \mathrm{E}-3$ \\
\hline & \multirow{2}{*}{$\begin{array}{c}339 \\
10115\end{array}$} & $5.227 \mathrm{E}-2$ & $2.574 \mathrm{E}-3$ \\
\hline & & $5.227 \mathrm{E}-2$ & $2.575 \mathrm{E}-3$ \\
\hline & \multirow{2}{*}{$\begin{array}{c}305 \\
8695\end{array}$} & $5.37 \mathrm{E}-2$ & $3.937 \mathrm{E}-3$ \\
\hline & & $5.323 \mathrm{E}-2$ & $3.7 \mathrm{E}-3$ \\
\hline & \multirow{2}{*}{$\begin{array}{c}288 \\
11543\end{array}$} & $5.363 \mathrm{E}-2$ & $4.757 \mathrm{E}-3$ \\
\hline & & $5.416 \mathrm{E}-2$ & $4.9 \mathrm{E}-3$ \\
\hline & \multirow{2}{*}{$\begin{array}{c}254 \\
13009\end{array}$} & $5.502 \mathrm{E}-2$ & $6.21 \mathrm{E}-3$ \\
\hline & & $5.508 \mathrm{E}-2$ & $6.16 \mathrm{E}-3$ \\
\hline \multirow{18}{*}{ TOP BOUNDARY } & \multirow{2}{*}{$\begin{array}{c}949 \\
13052\end{array}$} & $5.583 \mathrm{E}-2$ & $7.321 \mathrm{E}-3$ \\
\hline & & $5.61 \mathrm{E}-2$ & $7.167 \mathrm{E}-3$ \\
\hline & \multirow{2}{*}{$\begin{array}{c}932 \\
13314\end{array}$} & $5.682 \mathrm{E}-2$ & $8.065 \mathrm{E}-3$ \\
\hline & & $5.64 \mathrm{E}-2$ & $7.9368 \mathrm{E}-3$ \\
\hline & \multirow{2}{*}{$\begin{array}{c}898 \\
13580\end{array}$} & $5.693 \mathrm{E}-2$ & $1.037 \mathrm{E}-2$ \\
\hline & & $5.65 \mathrm{E}-2$ & $9.68 \mathrm{E}-3$ \\
\hline & \multirow{2}{*}{$\begin{array}{c}881 \\
13472\end{array}$} & $5.634 \mathrm{E}-2$ & $1.14 \mathrm{E}-2$ \\
\hline & & $5.65 \mathrm{E}-2$ & $1.08 \mathrm{E}-2$ \\
\hline & \multirow{2}{*}{$\begin{array}{c}864 \\
12700\end{array}$} & $5.7 \mathrm{E}-2$ & $1.24 \mathrm{E}-2$ \\
\hline & & $5.67 \mathrm{E}-2$ & $1.30 \mathrm{E}-2$ \\
\hline & \multirow{2}{*}{$\begin{array}{c}830 \\
12944\end{array}$} & $5.69 \mathrm{E}-2$ & $1.509 \mathrm{E}-2$ \\
\hline & & $5.66 \mathrm{E}-2$ & $1.447 \mathrm{E}-2$ \\
\hline & \multirow{2}{*}{$\begin{array}{c}813 \\
12524\end{array}$} & $5.64 \mathrm{E}-2$ & $1.65 \mathrm{E}-2$ \\
\hline & & $5.647 \mathrm{E}-2$ & $1.69 \mathrm{E}-2$ \\
\hline & \multirow{2}{*}{$\begin{array}{c}780 \\
12398\end{array}$} & $5.67 \mathrm{E}-2$ & $1.78 \mathrm{E}-2$ \\
\hline & & $5.65 \mathrm{E}-2$ & $1.83 \mathrm{E}-2$ \\
\hline & \multirow{2}{*}{$\begin{array}{c}746 \\
12276\end{array}$} & $5.65 \mathrm{E}-2$ & $2.05 \mathrm{E}-2$ \\
\hline & & $5.63 \mathrm{E}-2$ & $1.98 \mathrm{E}-2$ \\
\hline \multirow{12}{*}{ LEFT BOUNDARY } & \multirow{2}{*}{$\begin{array}{c}749 \\
12288\end{array}$} & $5.33 \mathrm{E}-2$ & $1.932 \mathrm{E}-2$ \\
\hline & & $5.54 \mathrm{E}-2$ & $1.96 \mathrm{E}-2$ \\
\hline & \multirow{2}{*}{$\begin{array}{c}734 \\
7937 \\
\end{array}$} & $5.18 \mathrm{E}-2$ & $1.94 \mathrm{E}-2$ \\
\hline & & $5.22 \mathrm{E}-2$ & $1.934 \mathrm{E}-2$ \\
\hline & \multirow{2}{*}{$\begin{array}{c}719 \\
9429\end{array}$} & $4.988 \mathrm{E}-2$ & $1.93 \mathrm{E}-2$ \\
\hline & & $5.02 \mathrm{E}-2$ & $1.934 \mathrm{E}-2$ \\
\hline & \multirow{2}{*}{$\begin{array}{c}671 \\
6511 \\
\end{array}$} & $4.775 \mathrm{E}-2$ & $1.944 \mathrm{E}-2$ \\
\hline & & $4.8 \mathrm{E}-2$ & $1.937 \mathrm{E}-2$ \\
\hline & & $4.718 \mathrm{E}-2$ & $1.928 \mathrm{E}-2$ \\
\hline & 5018 & $4.715 \mathrm{E}-2$ & $1.931 \mathrm{E}-2$ \\
\hline & 89 & $4.456 \mathrm{E}-2$ & $1.929 \mathrm{E}-2$ \\
\hline & 5000 & $4.4569 \mathrm{E}-2$ & $1.940 \mathrm{E}-2$ \\
\hline
\end{tabular}


Table 10. Model validity check for FA-186, Air, step $15, \mathrm{~K}_{\mathrm{I}}=17.36 \mathrm{Mpa} \sqrt{\mathrm{m}}$

\begin{tabular}{|c|c|c|c|}
\hline \multirow[t]{2}{*}{ Boundary } & \multirow{2}{*}{$\begin{array}{c}\text { Boundary node in the } \\
\text { global model }\end{array}$} & \multicolumn{2}{|c|}{ Nodal Displacements } \\
\hline & & U1 & $\mathrm{U} 2$ \\
\hline \multirow{12}{*}{ RIGHT BOUNDARY } & \multirow{2}{*}{$\begin{array}{c}406 \\
5759\end{array}$} & $5.16 \mathrm{E}-2$ & 0 \\
\hline & & $5.156 \mathrm{E}-2$ & 0 \\
\hline & \multirow{2}{*}{$\begin{array}{l}356 \\
7222\end{array}$} & $5.19 \mathrm{E}-2$ & $1.776 \mathrm{E}-3$ \\
\hline & & $5.212 \mathrm{E}-2$ & $1.83 \mathrm{E}-3$ \\
\hline & \multirow{2}{*}{$\begin{array}{c}339 \\
10115\end{array}$} & $5.29 \mathrm{E}-2$ & $3.035 \mathrm{E}-3$ \\
\hline & & $5.293 \mathrm{E}-2$ & $2.81 \mathrm{E}-3$ \\
\hline & \multirow{2}{*}{$\begin{array}{c}305 \\
8695\end{array}$} & $5.41 \mathrm{E}-2$ & $3.286 \mathrm{E}-3$ \\
\hline & & $5.37 \mathrm{E}-2$ & $3.20 \mathrm{E}-3$ \\
\hline & \multirow{2}{*}{$\begin{array}{c}288 \\
11543\end{array}$} & $5.406 \mathrm{E}-2$ & $4.34 \mathrm{E}-3$ \\
\hline & & $5.45 \mathrm{E}-2$ & $4.4 \mathrm{E}-3$ \\
\hline & \multirow{2}{*}{$\begin{array}{c}254 \\
13009\end{array}$} & $5.53 \mathrm{E}-2$ & $5.65 \mathrm{E}-3$ \\
\hline & & $5.532 \mathrm{E}-2$ & $5.58 \mathrm{E}-3$ \\
\hline \multirow{18}{*}{ TOP BOUNDARY } & \multirow{2}{*}{$\begin{array}{c}949 \\
13052\end{array}$} & $5.6 \mathrm{E}-2$ & $6.85 \mathrm{E}-3$ \\
\hline & & $5.62 \mathrm{E}-2$ & $6.34 \mathrm{E}-3$ \\
\hline & \multirow{2}{*}{$\begin{array}{c}932 \\
13314\end{array}$} & $5.68 \mathrm{E}-2$ & $6.99 \mathrm{E}-3$ \\
\hline & & $5.65 \mathrm{E}-2$ & $6.96 \mathrm{E}-3$ \\
\hline & \multirow{2}{*}{$\begin{array}{c}898 \\
13580\end{array}$} & $5.69 \mathrm{E}-2$ & $8.63 \mathrm{E}-3$ \\
\hline & & $5.65 \mathrm{E}-2$ & $8.40 \mathrm{E}-3$ \\
\hline & \multirow{2}{*}{$\begin{array}{c}881 \\
13472\end{array}$} & $5.63 \mathrm{E}-2$ & $9.92 \mathrm{E}-3$ \\
\hline & & $5.65 \mathrm{E}-2$ & $9.40 \mathrm{E}-3$ \\
\hline & \multirow{2}{*}{$\begin{array}{c}864 \\
12700\end{array}$} & $5.7 \mathrm{E}-2$ & $1.065 \mathrm{E}-2$ \\
\hline & & $5.677 \mathrm{E}-2$ & $1.121 \mathrm{E}-2$ \\
\hline & \multirow{2}{*}{$\begin{array}{c}830 \\
12944\end{array}$} & $5.71 \mathrm{E}-2$ & $1.3 \mathrm{E}-2$ \\
\hline & & $5.677 \mathrm{E}-2$ & $1.25 \mathrm{E}-2$ \\
\hline & \multirow{2}{*}{$\begin{array}{c}813 \\
12524\end{array}$} & $5.65 \mathrm{E}-2$ & $1.46 \mathrm{E}-2$ \\
\hline & & $5.664 \mathrm{E}-2$ & $1.483 \mathrm{E}-2$ \\
\hline & \multirow{2}{*}{$\begin{array}{c}780 \\
12398\end{array}$} & $5.7 \mathrm{E}-2$ & $1.565 \mathrm{E}-2$ \\
\hline & & $5.678 \mathrm{E}-2$ & $1.62 \mathrm{E}-2$ \\
\hline & \multirow{2}{*}{$\begin{array}{c}746 \\
12276\end{array}$} & $5.68 \mathrm{E}-2$ & $1.83 \mathrm{E}-2$ \\
\hline & & $5.66 \mathrm{E}-2$ & $1.77 \mathrm{E}-2$ \\
\hline \multirow{12}{*}{ LEFT BOUNDARY } & \multirow{2}{*}{$\begin{array}{c}749 \\
12288\end{array}$} & $5.385 \mathrm{E}-2$ & $1.69 \mathrm{E}-2$ \\
\hline & & $5.57 \mathrm{E}-2$ & $1.74 \mathrm{E}-2$ \\
\hline & \multirow{2}{*}{$\begin{array}{c}734 \\
7937\end{array}$} & $5.25 \mathrm{E}-2$ & $1.675 \mathrm{E}-3$ \\
\hline & & $5.285 \mathrm{E}-2$ & $1.676 \mathrm{E}-2$ \\
\hline & \multirow{2}{*}{$\begin{array}{c}719 \\
9429\end{array}$} & $5.053 \mathrm{E}-2$ & $1.672 \mathrm{E}-2$ \\
\hline & & $5.0988 \mathrm{E}-2$ & $1.658 \mathrm{E}-2$ \\
\hline & \multirow{2}{*}{$\begin{array}{c}671 \\
6511 \\
\end{array}$} & $4.83 \mathrm{E}-2$ & $1.675 \mathrm{E}-2$ \\
\hline & & $4.87 \mathrm{E}-2$ & $1.656 \mathrm{E}-2$ \\
\hline & 99 & $4.771 \mathrm{E}-2$ & $1.656 \mathrm{E}-2$ \\
\hline & 5018 & $4.771 \mathrm{E}-2$ & $1.66 \mathrm{E}-2$ \\
\hline & 89 & $4.468 \mathrm{E}-2$ & $1.661 \mathrm{E}-2$ \\
\hline & 5000 & $4.47 \mathrm{E}-2$ & $1.666 \mathrm{E}-2$ \\
\hline
\end{tabular}


Table 11. Model validity check for FA-186, air, last step, $\mathrm{K}_{\mathrm{I}}=17.36 \mathrm{Mpa} \sqrt{\mathrm{m}}$

\begin{tabular}{|c|c|c|c|}
\hline \multirow[t]{2}{*}{ Boundary } & Boundary node in the & \multicolumn{2}{|c|}{ Nodal Displacements } \\
\hline & $\begin{array}{c}\text { Corresponding boundary } \\
\text { node in submodel }\end{array}$ & U1 & $\mathrm{U} 2$ \\
\hline \multirow{12}{*}{ RIGHT BOUNDARY } & \multirow{2}{*}{$\begin{array}{c}406 \\
5759\end{array}$} & $5.0244 \mathrm{E}-2$ & 0 \\
\hline & & $5.0243 \mathrm{E}-2$ & 0 \\
\hline & \multirow{2}{*}{$\begin{array}{l}356 \\
7222\end{array}$} & $5.073 \mathrm{E}-2$ & $1.968 \mathrm{E}-3$ \\
\hline & & $5.106 \mathrm{E}-2$ & $2.14 \mathrm{E}-3$ \\
\hline & \multirow{2}{*}{$\begin{array}{c}339 \\
10115\end{array}$} & $5.226 \mathrm{E}-2$ & $2.871 \mathrm{E}-3$ \\
\hline & & $5.225 \mathrm{E}-2$ & $2.873 \mathrm{E}-3$ \\
\hline & \multirow{2}{*}{$\begin{array}{c}305 \\
8695\end{array}$} & $5.37 \mathrm{E}-2$ & $4.35 \mathrm{E}-3$ \\
\hline & & $5.31 \mathrm{E}-2$ & $4.1 \mathrm{E}-3$ \\
\hline & \multirow{2}{*}{$\begin{array}{c}288 \\
11543\end{array}$} & $5.35 \mathrm{E}-2$ & $5.24 \mathrm{E}-3$ \\
\hline & & $5.404 \mathrm{E}-2$ & $5.402 \mathrm{E}-3$ \\
\hline & \multirow{2}{*}{$\begin{array}{c}254 \\
13009\end{array}$} & $5.488 \mathrm{E}-2$ & $6.79 \mathrm{E}-3$ \\
\hline & & $5.49 \mathrm{E}-2$ & $6.73 \mathrm{E}-3$ \\
\hline \multirow{18}{*}{ TOP BOUNDARY } & \multirow{2}{*}{$\begin{array}{c}949 \\
13052\end{array}$} & $5.565 \mathrm{E}-2$ & $8.28 \mathrm{E}-3$ \\
\hline & & $5.602 \mathrm{E}-2$ & $7.808 \mathrm{E}-3$ \\
\hline & \multirow{2}{*}{$\begin{array}{c}932 \\
13314\end{array}$} & $5.67 \mathrm{E}-2$ & $8.28 \mathrm{E}-3$ \\
\hline & & $5.633 \mathrm{E}-2$ & $8.643 \mathrm{E}-3$ \\
\hline & \multirow{2}{*}{$\begin{array}{c}898 \\
13580\end{array}$} & $5.676 \mathrm{E}-2$ & $1.087 \mathrm{E}-2$ \\
\hline & & $5.63 \mathrm{E}-2$ & $1.047 \mathrm{E}-2$ \\
\hline & \multirow{2}{*}{$\begin{array}{c}881 \\
13472\end{array}$} & $5.61 \mathrm{E}-2$ & $1.225 \mathrm{E}-2$ \\
\hline & & $5.633 \mathrm{E}-2$ & $1.17 \mathrm{E}-2$ \\
\hline & \multirow{2}{*}{$\begin{array}{c}864 \\
12700\end{array}$} & $5.67 \mathrm{E}-2$ & $1.33 \mathrm{E}-2$ \\
\hline & & $5.64 \mathrm{E}-2$ & $1.39 \mathrm{E}-2$ \\
\hline & \multirow{2}{*}{$\begin{array}{c}830 \\
12944\end{array}$} & $5.67 \mathrm{E}-2$ & $1.6 \mathrm{E}-2$ \\
\hline & & $5.637 \mathrm{E}-2$ & $1.537 \mathrm{E}-2$ \\
\hline & \multirow{2}{*}{$\begin{array}{c}813 \\
12524\end{array}$} & $5.611 \mathrm{E}-2$ & $1.75 \mathrm{E}-2$ \\
\hline & & $5.618 \mathrm{E}-2$ & $1.78 \mathrm{E}-2$ \\
\hline & \multirow{2}{*}{$\begin{array}{c}780 \\
12398\end{array}$} & $5.65 \mathrm{E}-2$ & $1.879 \mathrm{E}-2$ \\
\hline & & $5.623 \mathrm{E}-2$ & $1.93 \mathrm{E}-2$ \\
\hline & \multirow{2}{*}{$\begin{array}{c}746 \\
12276\end{array}$} & $5.624 \mathrm{E}-2$ & $2.15 \mathrm{E}-2$ \\
\hline & & $5.60 \mathrm{E}-2$ & $2.08 \mathrm{E}-2$ \\
\hline \multirow{12}{*}{ LEFT BOUNDARY } & \multirow{2}{*}{$\begin{array}{c}749 \\
12288\end{array}$} & $5.306 \mathrm{E}-2$ & $2.03 \mathrm{E}-2$ \\
\hline & & $5.508 \mathrm{E}-2$ & $2.06 \mathrm{E}-2$ \\
\hline & \multirow{2}{*}{$\begin{array}{c}734 \\
7937\end{array}$} & $5.155 \mathrm{E}-2$ & $2.047 \mathrm{E}-2$ \\
\hline & & $5.193 \mathrm{E}-2$ & $2.033 \mathrm{E}-2$ \\
\hline & \multirow{2}{*}{$\begin{array}{c}719 \\
9429\end{array}$} & $4.956 \mathrm{E}-2$ & $2.038 \mathrm{E}-2$ \\
\hline & & $4.998 \mathrm{E}-2$ & $2.031 \mathrm{E}-2$ \\
\hline & \multirow{2}{*}{$\begin{array}{c}671 \\
6511\end{array}$} & $4.74 \mathrm{E}-2$ & $2.044 \mathrm{E}-2$ \\
\hline & & $4.77 \mathrm{E}-2$ & $2.037 \mathrm{E}-2$ \\
\hline & \multirow{2}{*}{$\begin{array}{c}99 \\
5018\end{array}$} & $4.68 \mathrm{E}-2$ & $2.028 \mathrm{E}-2$ \\
\hline & & $4.68 \mathrm{E}-2$ & $2.039 \mathrm{E}-2$ \\
\hline & 89 & $4.416 \mathrm{E}-2$ & $2.029 \mathrm{E}-2$ \\
\hline & 5000 & $4.421 \mathrm{E}-2$ & $2.04 \mathrm{E}-2$ \\
\hline
\end{tabular}

